\title{
FATIGUE CRACK PROPAGATION IN RAIL STEELS
}

\author{
C.E. Feddersen \\ R.D. Buchheit \\ D. Broek \\ BATTELLE COLUMBUS LABORATORIES \\ 505 King Avenue \\ Columbus $\mathrm{OH} \quad 43201$

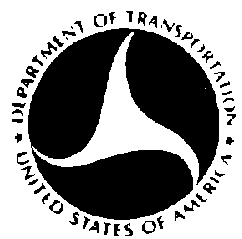 \\ JUNE 1977 \\ INTERIM REPORT
}

\author{
DOCUMENT IS AVAILABLE TO THE U.S. PUBLIC \\ THAOUGH THE NATIONAL TECHNICAL \\ INFORMATION SERVICE, SPRINGFIELD, \\ VIRGINIA 22161 \\ Prepared for \\ U.S. DEPARTMENT OF TRANSPORTATION \\ FEDERAL RAILROAD ADMINISTRATION \\ Research and Development \\ Washington DC 20590
}




\section{NOT ICE}

This document is disseminated under the sponsorship of the Department of Transportation in the interest of information exchange. The United States Government assumes no liability for its contents or use thereof.

\section{NOTICE}

The United States Government does not endorse products or manufacturers. Trade or manufacturers' names appear herein solely because they are considered essential to the object of this report. 


\section{GENERAL DISCLAIMER}

This document may have problems that one or more of the following disclaimer statements refer to:

- This document has been reproduced from the best copy furnished by the sponsoring agency. It is being released in the interest of making available as much information as possible.

- This document may contain data which exceeds the sheet parameters. It was furnished in this condition by the sponsoring agency and is the best copy available.

- This document may contain tone-on-tone or color graphs, charts and/or pictures which have been reproduced in black and white.

- The document is paginated as submitted by the original source.

- Portions of this document are not fully legible due to the historical nature of some of the material. However, it is the best reproduction available from the original submission. 

Technical Report Documentation Page

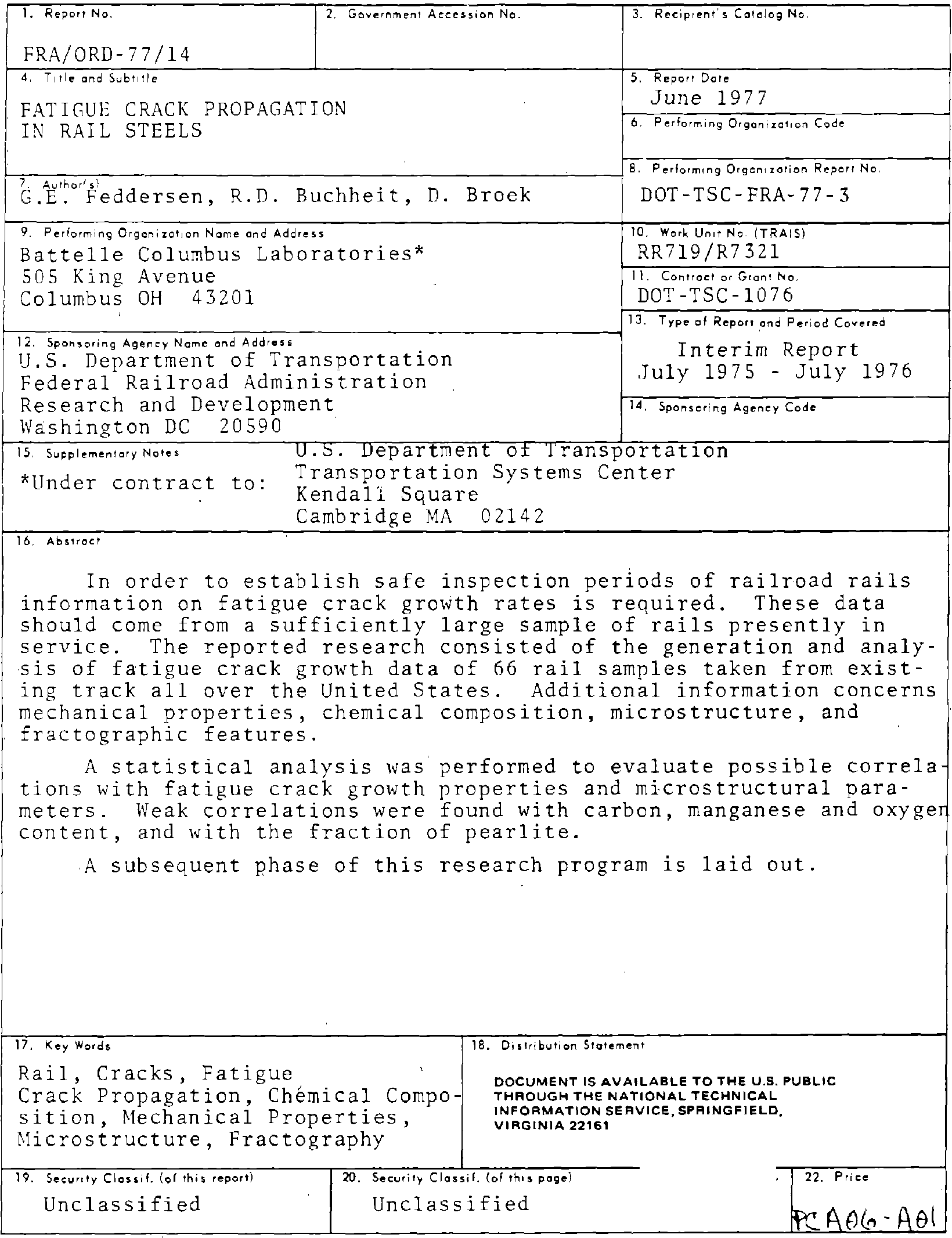

Form DOT F $1700.7(8-72)$

Reproduction of completed poge outhorized 


\section{PREFACE}

This report presents the results of the first phase of a program on Rail Material Failure Characterization. It has been prepared by Battelle's Columbus Laboratories (BCL) under Contract DOT-TSC-1076 for the Transportation Systems Center (TSC) of the Department of Transportation. The work was conducted under the technical direction of Mr. Roger Steele of TSC.

The results of this phase of the program are the basis for the lay out of the second phase. The objective of the second phase is the development of a computational rail failure model. This model, in conjunction with the results of ongoing studies on Engineering Stress Analysis of Rails and on Wheel-RailLoads when incorporated into a reliability analyses will enable establishment of safe inspection schedules.

The cooperation of the American Association of Railroads (AAR) and the various railroads (Boston \& Maine Railroad Company, Chessie System, Denver and Rio Grande Western Railroad Company, Penn Central Railroad Company, Southern Pacific Transportation Company, and Union Pacific Railroad Company) in acquiring rail samples is gratefully acknowledged. The cooperation and assistance of Mr. Roger Steele of TSC, Mr. Omar Deel and Mr. David Utah of BCL were of great value to the program.

\section{Preceding page blank}




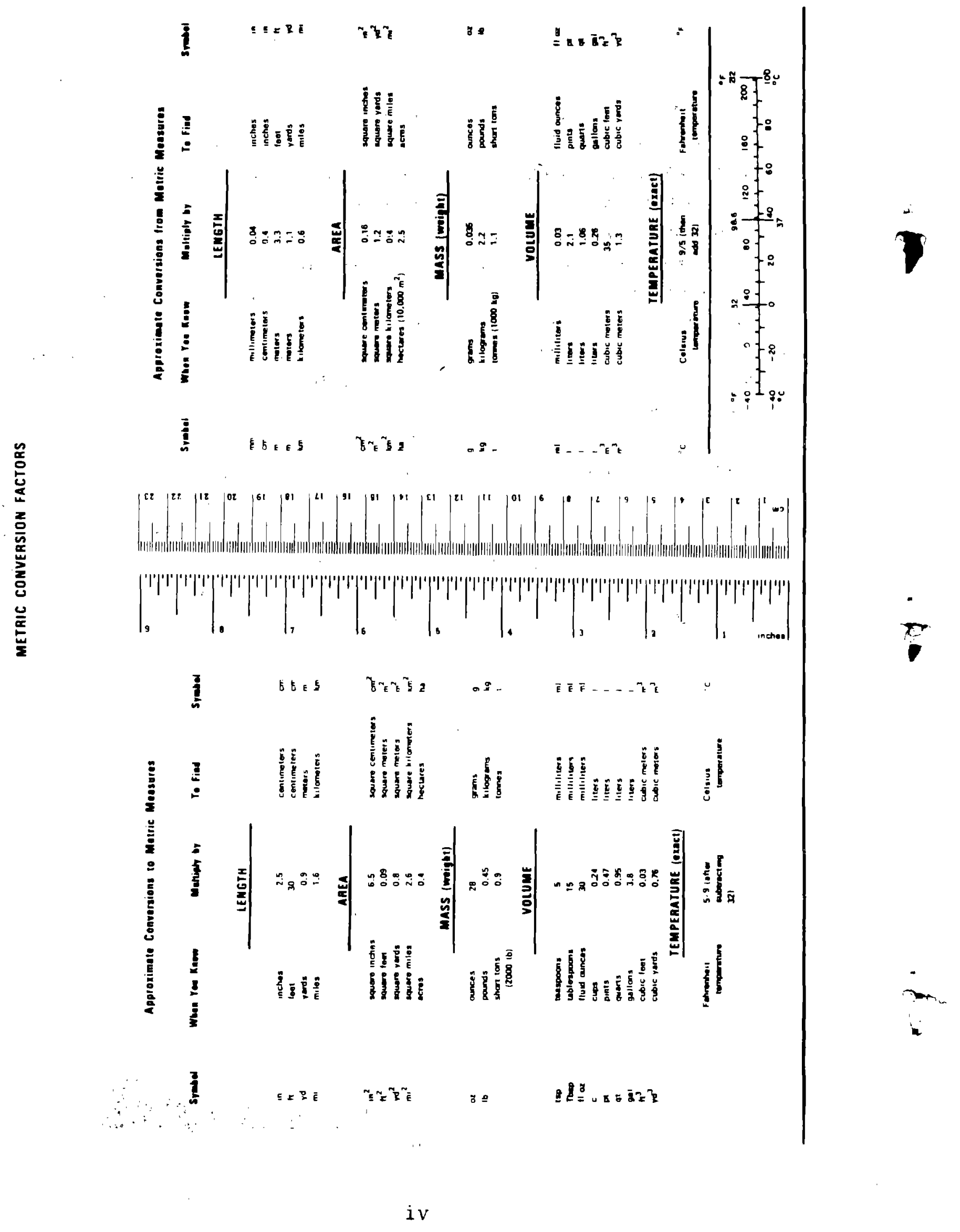


TABLE OF CONTENTS

Section

$\underline{\text { Page }}$

1. INTRODUCTION................................

2. RAIL MATERIALS: SAMPLE SOURCE AND DESCRIPTION............. 2

3. METALLOGRAPHIC CHARACTERIZATIONS ................... 2

3.1 Chemical Analyses........................... 2

3.2 Macrostructures........................... 7

3.3 Microstructures.......................... 18

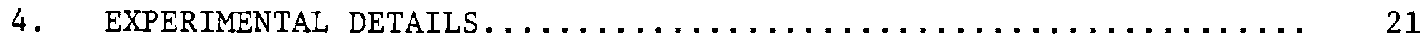

4.1 Specimens............................. 21

4.2 Testing Procedures.......................... 21

5. TEST RESULTS............................. 26

6. DATA ANALYSIS ............................... 26

6.1 Analysis of Rate Data.......................... 34

6.2 Synthesis of Crack-Growth Data.................... 41

Synthesis Results..................... 42

6.3 Correlation of Rate Data with Other Properties......... 42

6.3 .1 General Approach..................... 42

6.3.2 Automatic Interaction Detector (AID) Analysis...... 43

6.3 .3 Process of Analysis.................... 46

6.3 .4 Results of Analysis.................... 46

6.3 .5 Correlation Analysis.................... 48

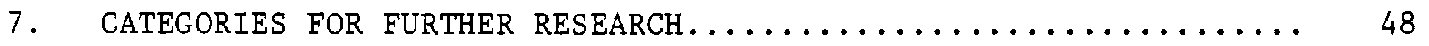

7.1 Selection of Categories...................... 48

7.2 Microstructural Analysis of Three Categories........... 51

7.2 .1 Rail Samples Used..................... 51

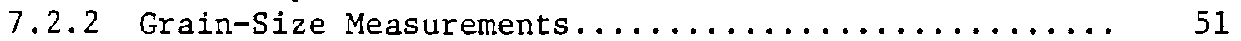

7.2 .3 Pearlite Interlamellar Spacing................ 52

7.2 .4 Other Microstructural Parameters.............. 53

7.3 Fractography.............................. 55

7.4 Projected Experiments for Phase II................. 69

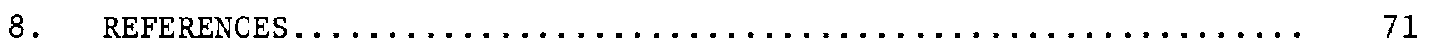

APPENDIX A BASELINE CRACK-GROWTH DATA.................... A-1

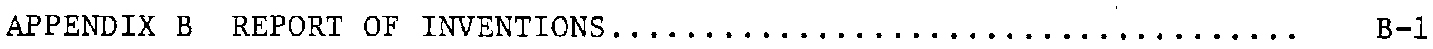




\section{LIST OF FIGURES}

$\underline{\text { Page }}$

Figure 1. Typical Coarse-Textured Macrostructure of

Ra1ls - Sample 027................. 8

Figure 2. Typical Fine-Textured Macrostructure of

Rails - Sample 019................... . 9

Figure 3. Macrostructure of Rail Sample 058 . . . . . . . . . 10

Figure 4. Macrostructure of a Heat-Treated Running

Surface - Rail Sample 059 ............. . 11

Figure 5. Macrostructure of a Repaired Running Surface -

Rail Sample 002 ................ 12

Figure 6. Macrostructure of Rail Sample 001 . . . . . . . . . . 13

Figure 7. Macrostructure of Rail Sample 061. . . . . . . . . . . 14

Figure 8. Macrostructure of Rail Sample 062 . . . . . . . . . . 15

Figure 9. Macrostructure of Rail Sample 063 ............ 16

Figure 10. Macrostructure of Rail Sample 003 . . . . . . . . . . 17

Figure 11. Pearlitic Microstructure Typical of the

Majority of Rails - Sample 051L . . . . . . . . . 19

Figure 12. Ferrite Network in a Matrix of Pearlite - Sample 004. . 19

Figure 13. Heat-Treated Pearlitic Microstructure of

Rail Sample 058L. . . . . . . . . . . . 20

Figure 14. Internal Crack in Rail Sample 00IL. . . . . . . . . . 20

Figure 15. Orientation of Specimens. . . . . . . . . . . . . 22

Figure 16. Compact Tension Fatigue Crack Growth Specimen . . . . 23

Figure 17. Compact Tension Specimens Before and After Testing. . . 24

Figure 18. Compact Tension Specimen in Fatigue Machine . . . . . . 25

Figure 19. Typical Fatigue Crack Propagation Curves. . . . . . . . . 33

Figure 20. Variability of Fatigue Crack Propagation

Rate Behavior... . . . . . . . . . . 36 
Figure 21. Sample Graphical Output from Program AID. . . . . . . 45

Figure 22. Variation of Life With Leading Predictors . . . . . 47

Figure 23. Typical Scanning Electron Microscope

Views of Pearlite In Rail Samples........... 54

Figure 24. Fatigue Test Fracture Surfaces. . . . . . . . . . 56

Figure 25. Fracture Surface of Sample 004 at the Notch Tip . . . . 60

Figure 26. Fracture Surface of Sample 002 at the Notch Tip . . . 61

Figure 27. Fracture Surface of Sample 030 at the Notch Tip . . . . 62

Figure 28. Fracture Surface of Sample 006 at the Notch Tip . . . . 63

Figure 29. Fracture Surface of Sample 001 at the Notch Tip . . . . 64

Figure 30. Fracture Surface of Sample 024 at the Notch Tip . . . . 65

Figure 31. Fracture Surface of Sample 0020.17 Inch
from the Notch Tip. ............. . . 66

Figure 32. Fracture Surface of Sample 0240.56 Inch

from the Notch Tip. . . . . . . . . . . 67

Figure 33. Examples of Fracture Surface Striations . . . . . . . 67

Figure 34. Cross-Hatched Line Pattern - Sample 024,

1.21 Inches from Notch Tip. . . . . . . . . 68

Figure 35. Cleavage Fracture - Sample 024, 1.21

Inches from Notch Tip........... . 68

\section{LIST OF TABLES}

$\underline{\text { Page }}$

Table 1. Rail Materials Inventory............... 3

Table 2. Results of Chemical Analyses of

Rail Samples 001 through 066 ........... 5

Table 3. Rail Samples Not Within Chemical Requirements. . . . . 6 
Table 4. Tension Test Results for 66 Rail Samples . . . . . . . 27

Table 5. Charpy Impact Test Results for Category 1 Rai1s...... 30

Table 6. Charpy Impact Test Results for Category 2 Rails (Medium Growth Rate) . . . . . . . . . . . 31

Table 7. Charpy Impact Test Results for Category 3 Rails (Low Growth Rate). . . . . . . . . . . . 32

Table 8. Sample of Computer Printout of Basic Data Along With First Stage of Rate Analysis. . . . . . . . 37

Table 9. Sumary of Crack Behavior Parameters for Baseline Rail Material Specimens. . . . . . . . 38

Table 10, Results of Crack-Growth Synthesis. . . . . . . . . . . . 42

Table 11. The Three Categories for Phase II. . . . . . . . . 50

Table 12. Prior Austenite Grain-Size Measurements. . . . . . . . 52

Table 13. Pearlite Interlamellar Spacing . . . . . . . . . . . 53

Table 14. Locations of Fractographic Studies . . . . . . . . . . 55

Table 15. General Fracture-Surface Characteristics . . .. . . . . 57

Table 16. Samples Selected for Additional Testing. . . . . . . . 70

Table 17. Experiments in Phase III . . . . . . . . . . . . 70 


\section{EXPLANATORY NOTE}

This report conveys preliminary information on the crack growth behavior of a sample of rail steels ( 66 rails) taken from the population currently in use in the United States. Ultimately, this information will be used to predict the flaw growth behavior of actual rails in service under various loading and support conditions. A more comprehensive treatment of the subject, with additional test data, will be available later in 1977. This interim report is being issued at this time to provide other Investigators working in the field with the results which have been generated thus far. 
1

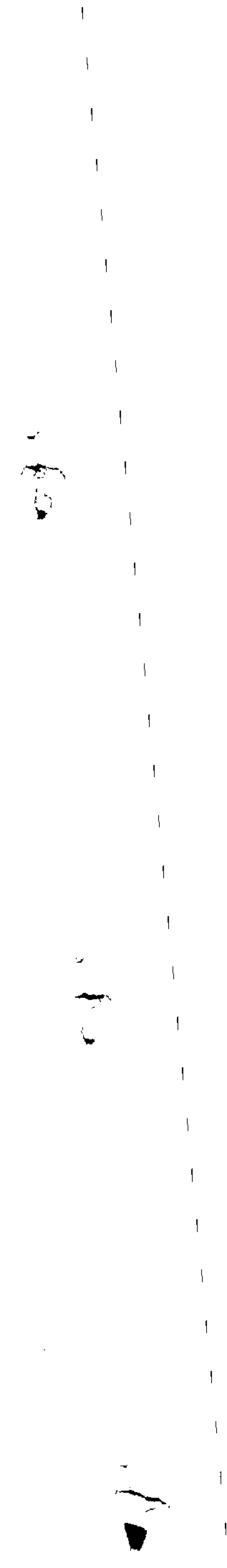




\section{INTRODUCTION}

Fatigue cracks in railroad rails can be the cause of rail failures and subsequent derallments. Prevention of these failures relies on timely detection of fatigue cracks when they are still small and not likely to cause failures. In order to establish safe inspection periods, data are required on the available time for crack detection, i.e., the time it takes for a small detectable crack to grow to a critical size that can cause rail failure. Therefore, the rate of fatiguecrack propagation has to be known.

One portion of the Federal Railroad Administration's (FRA) Track Performance Improvement Program is the development of a predictive rail failure model that enables a determination of optimal inspection periods through a calculation of fatigue-crack-propagation behavior. The research reported here concerns the first phase of a program to develop this rail failure model.

In order to predict fatigue-crack growth and failures under a service load environment, fatigue-crack-rate data are required. These data should come from a sufficiently large sample of rails presently in service to properly evaluate the statistical variability of fatigue-crack-growth properties. The first phase of this program consisted of the generation and analysis of fatigue-crack-growth data of 66 ratl samples of various age, make, and weight. The samples were taken from existing track from all sections of the United States.

This report presents the crack-growth data for the 66 rail samples. Also presented are chemical compositions, mechanical properties, and some data on microstructure and fractographic features. A statistical analysis was performed to evaluate possible correlation between one or more of these parameters and the resistance to fatigue-crack propagation.

On the basis of the present results, the 66 samples were divided into three broad categories of rate behavior. Further characterization of the three categories will be conducted; i.e., the effect of parameters such as stress ratio, temperature, and microstructural orientation be experimentally evaluated. The behavior under variable amplitude loading also will be investigated. Subsequently, the computational failure model will be developed after which the results will be reported. 


\section{RAIL MATERIALS: SAMPLE SOURCE AND DESCRIPTION}

At the outset of this program; an effort was made to assemble a representagive sampling of rail materials which are presently, and will continue to be, in service on U. S. railroads. Variations of rail size, rail producer, and year of production were the primary selection criteria. Eleven of the major railroad organizations were contacted for contributions of rail samples. Directly or indirectly samples were received from the following organizations:

- Association of American Railroads

- Boston and Maine Railroad Company

- Chessie System.

- Denver and Rio Grande Western Railroad Company

- Penn Central Railroad Company

- Southern Pacific Transportation Company

- Transportation Systems Center

- Union Pacific Railroad Company.

A total of 66 material samples were received representing sizes from $851 \mathrm{~b} / \mathrm{yd}$ to $140 \mathrm{lb} / \mathrm{yd}$, produced over a period from 1911 to 1975 in both U. S. and Japanese mills. The samples were given identification numbers from 001 to 066 . Basic information on the samples is presented in Table 1 .

\section{METALLOGRAPHIC CHARACTERIZATIONS}

\subsection{CHEMICAL ANALYSES}

Specifications for the chemical composition of rail steels vary slightly with the rail size (expressed as the weight per yard of rail). The ASTM Standard Specification for Carbon-Steel Rails, ASTM Designation: Al-68a, states the following chemical requirements:

\begin{tabular}{|c|c|c|c|c|}
\hline \multirow{2}{*}{$\begin{array}{l}\text { Element, } \\
\text { percent }\end{array}$} & \multicolumn{4}{|c|}{ Nominal Weight, lb/yd } \\
\hline & $61-80$ & $81-90$ & $91-120$ & 121 and Over \\
\hline Carbon & $0.55-0.68$ & $0.64-0.77$ & $0.67-0.80$ & $0.69-0.82$ \\
\hline Manganese & $0.60-0.90$ & $0.60-0.90$ & $0.70-1.00$ & $0.70-1.00$ \\
\hline Phosphorus, max & 0.04 & 0.04 & 0.04 & 0.04 \\
\hline Silicon & $0.10-0.23$ & $0.10-0.23$ & $0.10-0.23$ & $0.10-0.23$ \\
\hline
\end{tabular}


TABLE 1. RAIL MATERIALS INVENTORY

\begin{tabular}{|c|c|c|c|c|c|c|c|c|c|c|c|}
\hline $\begin{array}{c}\text { BCL } \\
\text { Sequence } \\
\text { Number }\end{array}$ & $\begin{array}{l}\text { Rucespte } \\
\text { Duse }\end{array}$ & Sourte & $\begin{array}{l}\text { Source } \\
\text { Number }\end{array}$ & $\begin{array}{l}\text { Wt. or } \\
\text { Soction } \\
\text { Number }\end{array}$ & Type & $\begin{array}{l}\text { Controlled } \\
\text { Cool }\end{array}$ & $\begin{array}{l}\text { Mali } \\
\text { Brand }\end{array}$ & $\begin{array}{l}\text { Year } \\
\text { Rolled }\end{array}$ & $\begin{array}{l}\text { Month } \\
\text { Rolled }\end{array}$ & $\begin{array}{l}\text { Semple } \\
\text { Lenget }\end{array}$ & Romarkg \\
\hline $\begin{array}{l}001 \\
002 \\
003 \\
204 \\
005 \\
006 \\
007 \\
008 \\
009 \\
010\end{array}$ & $10 / 10 / 75$ & $\begin{array}{r}\mathrm{TSC} \\
\end{array}$ & $\begin{array}{l}418 \\
521 \\
399 \\
100 \\
398 \\
\text { VD-1 } \\
40-2 \\
315 \\
442 \\
339\end{array}$ & $\begin{array}{r}130 \\
85 \\
130 \\
85 \\
130 \\
115 \\
115 \\
85 \\
130 \\
85\end{array}$ & $\begin{array}{l}\mathrm{RE} \\
\mathrm{RE}\end{array}$ & & esco & $\begin{array}{l}1929 \\
1911 \\
1929 \\
1920 \\
1929 \\
1994 \\
1974 \\
1924 \\
1999 \\
1919\end{array}$ & $\begin{array}{l}11 \\
11 \\
9\end{array}$ & $\begin{array}{l}34-7 / 8 \\
34-i / 8 \\
37-1 / 8 \\
36 \\
35-3 / 8 \\
35-1 / 2 \\
36-1 / 8 \\
35-5 / 8 \\
36-1 / 8 \\
36-1 / 4\end{array}$ & 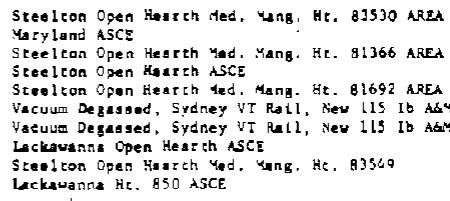 \\
\hline $\begin{array}{l}011 \\
012 \\
013 \\
014 \\
015 \\
016 \\
017 \\
018 \\
019 . \\
020 \\
021 \\
022 \\
023 \\
024 \\
025 \\
026 \\
027 \\
028 \\
029 \\
030 \\
031 \\
032 \\
033 \\
034\end{array}$ & $10 / 14 / 75$ & $\begin{array}{r}M R \\
1\end{array}$ & 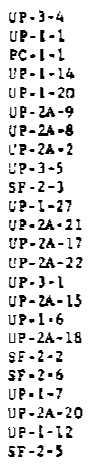 & $\begin{array}{l}1330 \\
1330 \\
1270 \mathrm{M} \\
1330 \\
1330 \\
133 \\
133 \\
1330 \\
1330 \\
119 \\
1330 \\
1330 \\
133 \\
1330 \\
1330 \\
1330 \\
133 \\
1330 \\
119 \\
119 \\
133 \\
13331 \\
133 \\
1190\end{array}$ & $\begin{array}{l}\mathrm{RE} \\
\mathrm{RE} \\
\mathrm{RE} \\
\mathrm{RE} \\
\mathrm{RE} \\
\mathrm{RE} \\
\mathrm{RE} \\
\mathrm{RE}\end{array}$ & $\begin{array}{l}\text { Yes } \\
\text { Yes } \\
\text { Yes } \\
\text { Yes } \\
\text { Yes } \\
\text { Yos } \\
\text { Yes } \\
\text { Yes } \\
\text { Yes } \\
\text { Yes } \\
\text { Yes } \\
\text { Yos } \\
\text { Yes } \\
\text { Yes } \\
\text { Yos }\end{array}$ & 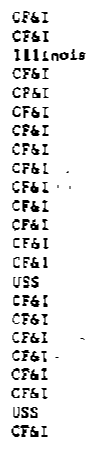 & $\begin{array}{l}1965 \\
1955 \\
1954 \\
1955 \\
1949 \\
1957 \\
1957 \\
1953 \\
1965 \\
1957 \\
1953 \\
1956 \\
1957 \\
1956 \\
1956 \\
1957 \\
1956 \\
1953 \\
1958 \\
1959 \\
1936 \\
1953 \\
1953 \\
1957\end{array}$ & $\begin{array}{r}11 \\
12 \\
1 \\
11 \\
2 \\
5 \\
\vdots \\
4 \\
11 \\
11 \\
11 \\
3 \\
1 \\
1 \\
7 \\
1 \\
12 \\
31 \\
11 \\
11 \\
12 \\
3 \\
11 \\
1\end{array}$ & $\begin{array}{l}63-1 / 2 \\
47-1 / 2 \\
60-1 / 2 \\
48 \\
47-1 / 2 \\
50-1 / 2 \\
48 \\
40 \\
60-3 / 4 \\
47-1 / 4 \\
42-1 / 4 \\
51-1 / 2 \\
52-1 / 2 \\
51-1 / 2 \\
46-3 / 4 \\
49-3 / 4 \\
46 \\
50 \\
39-3 / 4 \\
48-1 / 4 \\
36-3 / 4 \\
47-3 / 4 \\
46-1 / 2 \\
46-3 / 4\end{array}$ & . $\quad$. \\
\hline 035 & $12 / 4 / 75$ & $\begin{array}{l}\text { Denver o } \\
\text { Rio Crande }\end{array}$ & 163 & 1150 & $\mathrm{RE}$ & Yes & CFGI & 2935 & 5 & $35-3 / 6$ & Heat 대 9232 DS DePoer tDO S, Defece No. i6s \\
\hline $\begin{array}{l}036 \\
037 \\
038 \\
039 \\
040\end{array}$ & & 1 & $\begin{array}{l}143 \\
601 \\
158 \\
215 \\
699\end{array}$ & $\begin{array}{l}112 \\
1155 \\
1121 \\
90 \\
100\end{array}$ & $\mathrm{RE}$ & Yeg & $\begin{array}{l}\text { CFbI } \\
\text { CFGI } \\
\text { CPSII } \\
\text { GPsI } \\
\text { CFGI }\end{array}$ & $\begin{array}{l}1939 \\
1963 \\
1930 \\
1924 \\
1928\end{array}$ & $\begin{array}{r}2 \\
12 \\
9 \\
4 \\
3\end{array}$ & $\begin{array}{l}34-3 / 4 \\
60-1 / 4 \\
37-3 / 4 \\
36-1 / 4 \\
36\end{array}$ & 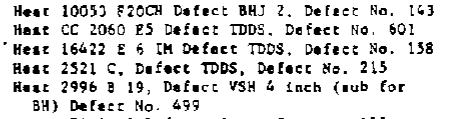 \\
\hline $\begin{array}{l}041 \\
042 \\
043 \\
044 \\
045 \\
046\end{array}$ & & 1 & $\begin{array}{r}155 \\
496 \\
179 \\
24 \\
199\end{array}$ & $\begin{array}{l}1150 \\
100 \\
90 \\
110 \\
110 \\
136\end{array}$ & $\begin{array}{l}\mathrm{RE} \\
\mathrm{RE} \\
\mathrm{RE} \\
\mathrm{RE}\end{array}$ & Yes & $\begin{array}{l}\text { CFSI } \\
\text { CFSI } \\
\text { CFS1 } \\
\text { GSLI } \\
\text { CFSI } \\
\text { CFSI }\end{array}$ & $\begin{array}{l}1953 \\
1928 \\
1921 \\
1936 \\
1930 \\
1968\end{array}$ & $\begin{array}{l}3 \\
3 \\
3 \\
3 \\
2 \\
2\end{array}$ & $\begin{array}{l}36-1 / 6 \\
36- \\
36-1 / 4 \\
36-1 / 4 \\
35-1 / 2 \\
36\end{array}$ & 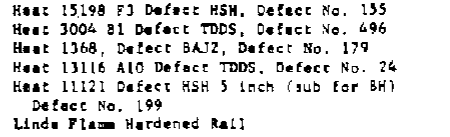 \\
\hline $\begin{array}{l}047 \\
048 \\
049 \\
050 \\
051 \\
032 \\
033 \\
094 \\
095 \\
056 \\
057 \\
058 \\
099 \\
060 \\
061 \\
062 \\
063 \\
064 \\
065 \\
066\end{array}$ & $\cdot$ & chorste & & $\begin{array}{l}130 \\
122 \\
115 \\
132 \\
130 \\
100 \\
140 \\
131 \\
131 \\
132 \\
140 \\
140 \\
133 \\
124 \\
124 \\
124 \\
124 \\
124 \\
124 \\
124\end{array}$ & $\begin{array}{c}R E \\
C B \\
R E \\
R E \\
R R \\
R R A B \\
R E \\
R R \\
R R \\
R E \\
R E \\
R E \\
R E\end{array}$ & $\begin{array}{l}\text { Yos } \\
\text { Yas } \\
\text { Yes }\end{array}$ & $\begin{array}{l}\text { Sech. } \\
\text { Beth. } \\
\text { USS } \\
\text { USS } \\
\text { Inlend } \\
\text { USS } \\
\text { USS } \\
\text { USS } \\
\text { Bach. } \\
\text { Becth. } \\
\text { Bech. } \\
\text { Bech. } \\
\text { USS } \\
\text { Bech. } \\
\text { Bech. } \\
\text { Bech. } \\
\text { Bech. } \\
\text { Nippon } \\
\text { N1ppon } \\
\text { Sippon. }\end{array}$ & $\begin{array}{l}1965 \\
1950 \\
1948 \\
1931 \\
1916 \\
1956 \\
1933 \\
1947 \\
1949 \\
1953 \\
1974 \\
1967 \\
1975 \\
1975 \\
1975 \\
1975 \\
1975 \\
19975 \\
1975\end{array}$ & $\begin{array}{r}11 \\
11 \\
12 \\
12 \\
7 \\
7 \\
7\end{array}$ & $\begin{array}{l}36 \\
36 \\
36 \\
36 \\
36 \\
36 \\
36 \\
36 \\
36 \\
36 \\
36 \\
36 \\
36 \\
36 \\
36 \\
36 \\
36 \\
36 \\
36 \\
36\end{array}$ & 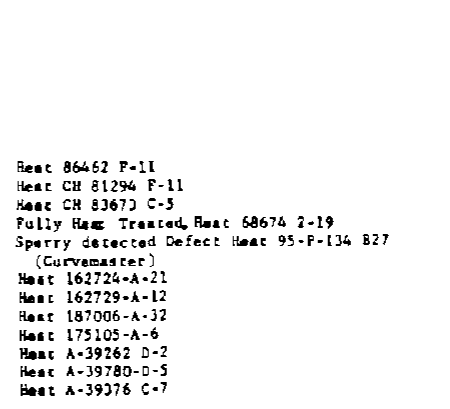 \\
\hline
\end{tabular}


No specification for the sulfur content is given by the ASTM Standard, but it states "that thoroughly deoxidized steel will be furnished and that, in every stage of manufacture, strict adherence to the standards of best practice of the individual mill will be observed". On this basis, it is reasonable to assume that the sulfur content of rail steels should be controlled by the mill to a maximum of about 0.050 weight percent.

Chemical analyses of each of the 66 rail samples were made for total carbon, manganese, silicon, and sulfur in percent by weight, and for hydrogen and oxygen in parts per million (ppm). The results of the analyses are presented in Table 2. Duplicate and, in some instances, triplicate analyses were made for hydrogen and oxygen and these are shown individually in the table.

Four rail steels, Samples 001,003, 005, and 009, were designated by the suppliers as medium manganese steels. The manganese contents of three of these steels (Samples 001, 005, and 009) were within a range, 1.36 to 1.48 percent, normally associated with medium manganese steels. However, the manganese content of Sample $003,0.76$ weight percent, was within the standard chemical requirements for its rail size. A fourth rail steel, Sample 038, contained a manganese content of 1.48 weight percent, which means that it is a medium manganese steel also. Since the chemical requirements for the medium manganese steels were not available for rall steels, an assessment of these values in the total range of compositional variation cannot be made.

An analysis of the composition data presented in Table 2 indicates that the compositions of several rail samples, excluding the medium manganese steels, do not meet the chemical requirements contained in the ASTM Standard and the assumed maximum sulfur content. Table 3 lists the samples which do not meet the requirements and the manner in which they deviate from the requirements.

With the exception of Sample 053, the hydrogen content determined in each of the 66 rails was between 0.2 and 1.1 ppm. The hydrogen content of Sample 053 was reported to be 6.1 and $6.5 \mathrm{ppm}$ in two determinations. The concentration of hydrogen in all other rails was characteristic of residual levels of hydrogen concentrations present in steels. Since hydrogen will effuse from steel at ambient temperatures over a period of time, it would be expected that rails of early vintage that may have had high hydrogen contents when placed into service would now contain only residual amounts.

The oxygen contents of the 66 rails were generally well below 100 ppm. The only exceptions were rail samples 004 and 045 which contained averages of 538 and $333 \mathrm{ppm}$ of oxygen, respectively. These oxygen contents are considerably higher than normal for silicon deoxidized rail steels. 
TABLE 2. RESULTS OF CHEMICAL ANALYSES OF RAIL SAMPLES 001 THROUGH 066

\begin{tabular}{|c|c|c|c|c|c|c|c|}
\hline \multirow{2}{*}{$\begin{array}{c}\text { Rail } \\
\text { Sample }\end{array}$} & \multirow{2}{*}{$\begin{array}{l}\text { S1ze, } \\
1 \mathrm{~b} / \mathrm{yd}\end{array}$} & \multicolumn{4}{|c|}{$\begin{array}{c}\text { Elemental Content, } \\
\text { weight percent }\end{array}$} & \multirow{2}{*}{$\begin{array}{c}\text { Hydrogen, } \\
\text { Ppm }\end{array}$} & \multirow{2}{*}{$\begin{array}{c}\text { Oxygen, } \\
\text { ppm }\end{array}$} \\
\hline & & C & $\mathrm{Mn}$ & Si & $\mathrm{S}$ & & \\
\hline 001 & 130 & 0.63 & 1.48 & 0.21 & 0.022 & $0.8,1.0$ & 100,96 \\
\hline 002 & 85 & 0.74 & 0.61 & 0.07 & 0.154 & $0.8,0.9$ & 46,48 \\
\hline 003 & 130 & 0.77 & 0.76 & 0.20 & 0.036 & $0.4,0.5$ & 71,69 \\
\hline 004 & 85 & 0.67 & 0.62 & 0.30 & 0.052 & $0.7,0.5$ & $519,435,659$ \\
\hline 005 & 130 & 0.63 & 1.36 & 0.21 & 0.033 & $0.6,0.8$ & 52,54 \\
\hline 006 & 115 & 0.72 & 0.97 & 0.10 & 0.028 & $0.4,0.4$ & 23,25 \\
\hline 007 & 115 & 0.73 & 0.93 & 0.18 & 0.037 & $0.4,0.3$ & 24,26 \\
\hline 008 & 85 & 0.66 & 0.94 & 0.20 & 0.029 & $0.8,0.8$ & 57,61 \\
\hline 009 & 130 & 0.61 & 1.46 & 0.29 & 0.039 & $0.7,0.7$ & 56,59 \\
\hline 010 & 85 & 0.63 & 0.74 & 0.14 & 0.028 & $1.1,0.9$ & $132, \quad 138$ \\
\hline 011 & 133 & 0.73 & 0.81 & 0.19 & 0.028 & $0.4,0.4$ & $57,51,56$ \\
\hline 012 & 133 & 0.79 & 0.84 & 0.18 & 0.029 & $0.8,0.7$ & 54,58 \\
\hline 013 & 127 & 0.74 & 0.89 & 0.24 & 0.028 & $0.8,1.0$ & 51,47 \\
\hline 014 & 133 & 0.78 & 0.74 & 0.17 & 0.014 & $0.8,0.8$ & 86,84 \\
\hline 015 & 133 & 0.76 & 0.82 & 0.19 & 0.033 & $0.6,0.6$ & 54,54 \\
\hline 016 & 133 & 0.81 & 0.93 & 0.17 & 0.044 & $0.6,0.8$ & 39,43 \\
\hline 017 & 133 & 0.79 & 0.85 & 0.26 & 0.048 & $0.9,1.0$ & 44,43 \\
\hline 018 & 133 & 0.75 & 0.89 & 0.17 & 0.046 & $0.7,0.6$ & 45,43 \\
\hline 019 & 133 & 0.74 & 0.88 & 0.21 & 0.038 & $0.4,0.4$ & $38, \quad 36$ \\
\hline 020 & 119 & 0.75 & 0.83 & 0.15 & 0.033 & $0.8,0.7$ & 34,32 \\
\hline 021 & 133 & 0.79 & 0.90 & 0.21 & 0.024 & $0.7,0.6$ & 41,45 \\
\hline 022 & 133 & 0.78 & 0.87 & 0.20 & 0.028 & $0.4,0.5$ & 46,47 \\
\hline 023 & 133 & 0.79 & 0.92 & 0.21 & 0.040 & $0.6,0.7$ & $39,35,46$ \\
\hline 024 & 133 & 0.81 & 0.83 & 0.12 & 0.030 & $1.0,0.7$ & 26,28 \\
\hline 025 & 133 & 0.80 & 0.91 & 0.23 & 0.016 & $0.7,0.7$ & 29,27 \\
\hline 026 & 133 & 0.78 & 0.94 & 0.17 & 0.050 & $0.5, \quad 0.5$ & 47,46 \\
\hline 027 & 133 & 0.78 & 0.87 & 0.23 & 0.022 & $0.7,0.6$ & 45,45 \\
\hline 028 & 133 & 0.71 & 0.90 & 0.17 & 0.022 & $0.7,1.0$ & $79,53,69$ \\
\hline 029 & 119 & 0.72 & 0.89 & 0.19 & 0.046 & $0.5,0.6$ & 45,43 \\
\hline 030 & 119 & 0.80 & 0.90 & 0.16 & 0.028 & $0.5,0.7$ & 52,54 \\
\hline 031 & 133 & 0.79 & 0.76 & 0.15 & 0.022 & $0.5,0.4$ & 53,49 \\
\hline 032 & 133 & 0.80 & 0.94 & 0.18 & 0.035 & $0.5,0.5$ & 63,61 \\
\hline 033 & 133 & 0.78 & 0.92 & 0.23 & 0.025 & $0.6,0.5$ & 37,35 \\
\hline 034 & 119 & 0.77 & 1.04 & 0.17 & 0.023 & $0.5,0.7$ & 38,38 \\
\hline 035 & 115 & 0.76 & 0.80 & 0.23 & 0.028 & $0.5,0.4$ & $27, \quad 27$ \\
\hline 036 & 112 & 0.75 & 0.81 & 0.18 & 0.016 & $0.4,0.5$ & 57,54 \\
\hline 037 & 115 & 0.72 & 0.93 & 0.25 & 0.017 & $0.4,0.5$ & $86,67,61$ \\
\hline 038 & 112 & 0.57 & 1.48 & 0.16 & 0.029 & $0.3,0.3$ & 78,82 \\
\hline 039 & 90 & 0.71 & 0.81 & 0.17 & 0.028 & $0.3,0.3$ & $81,107,168$ \\
\hline 040 & 100 & 0.58 & 0.64 & 0.08 & 0.030 & $0.4,0.4$ & 39,34 \\
\hline 041 & 115 & 0.77 & 0.81 & 0.21 & 0.043 & $0.4,0.3$ & 91,93 \\
\hline 042 & 100 & 0.63 & 0.71 & 0.08 & 0.026 & $0.3,0.4$ & $49,36,64$ \\
\hline 043 & 90 & 0.75 & 0.81 & 0.15 & 0.032 & $0.6,0.4$ & 84,85 \\
\hline
\end{tabular}


TABLE 2. (Continued)

\begin{tabular}{|c|c|c|c|c|c|c|c|}
\hline \multirow{2}{*}{$\begin{array}{l}\text { Rail } \\
\text { Sample }\end{array}$} & \multirow{2}{*}{$\begin{array}{l}\text { Size, } \\
1 \mathrm{~b} / \mathrm{yd}\end{array}$} & \multicolumn{4}{|c|}{$\begin{array}{c}\text { Elemental Content, } \\
\text { weight percent }\end{array}$} & \multirow{2}{*}{$\begin{array}{c}\text { Hydrogen, } \\
\text { ppm }\end{array}$} & \multirow{2}{*}{$\begin{array}{c}\text { Oxygen, } \\
\text { Ppm }\end{array}$} \\
\hline & & $\mathrm{C}$ & $\mathrm{Mn}$ & $\mathrm{Si}$ & $S$ & & \\
\hline 044 & 110 & 0.78 & 0.88 & 0.20 & 0.016 & $0.3,0.3$ & $84 \quad 86$ \\
\hline 045 & 110 & 0.65 & 0.65 & 0.21 & 0.027 & $0.6,0.5$ & $342,286,372$ \\
\hline 046 & 133 & 0.78 & 0.90 & 0.20 & 0.027 & $0.2,0.3$ & 49,48 \\
\hline 047 & 130 & 0.76 & 0.46 & 0.11 & 0.044 & $1.1,0.7$ & 43,41 \\
\hline 048 & 122 & 0.79 & 0.95 & 0.17 & 0.022 & $0.7,0.6$ & 58,61 \\
\hline 049 & 115 & 0.80 & 0.89 & 0.11 & 0.040 & $0.9,1.1$ & 48,50 \\
\hline 050 & 133 & 0.75 & 0.91 & 0.20 & 0.036 & $0.5,0.6$ & 56,56 \\
\hline 051 & 130 & 0.84 & 0.72 & 0.19 & 0.016 & $0.6,0.5$ & 47,51 \\
\hline 052 & 100 & 0.72 & 0.90 & 0.19 & 0.021 & $0.4,0.4$ & 52,54 \\
\hline 053 & 140 & 0.85 & 0.91 & 0.18 & 0.032 & $6.1,6.5$ & 44,44 \\
\hline 054 & 131 & 0.78 & 0.76 & 0.20 & 0.021 & $1.0,0.6$ & 36,32 \\
\hline 055 & 131 & 0.78 & 0.90 & 0.17 & 0.028 & $0.8,0.8$ & 33,35 \\
\hline 056 & 132 & 0.80 & 0.90 & 0.19 & 0.039 & $0.7,0.7$ & 44,46 \\
\hline 057 & 140 & 0.77 & 0.94 & 0.16 & 0.028 & $0.7,0.9$ & $58,46,50$ \\
\hline 058 & 140 & 0.83 & 0.84 & 0.18 & 0.048 & $0.4,0.5$ & 47,44 \\
\hline 059 & 133 & 0.83 & 0.98 & 0.14 & 0.024 & $0.4,0.3$ & $22, \quad 25$ \\
\hline 060 & 124 & 0.80 & 0.90 & 0.12 & 0.013 & $0.5,0.4$ & $56,36,47$ \\
\hline 061 & 124 & 0.80 & 0.91 & 0.12 & 0.015 & $0.4,0.7$ & 46,46 \\
\hline 062 & 124 & 0.79 & 0.84 & 0.08 & 0.017 & $0.3,0.6$ & $45,51,48$ \\
\hline 063 & 124 & 0.79 & 0.86 & 0.12 & 0.033 & $0.3,0.3$ & $49,59,64$ \\
\hline 064 & 124 & 0.76 & 0.85 & 0.18 & 0.018 & $0.6,0.6$ & $43,49,54$ \\
\hline 065 & 124 & 0.82 & 0.90 & 0.17 & 0.016 & $0.3,0.3$ & 41,42 \\
\hline 066 & 124 & 0.75 & 0.90 & 0.18 & 0.019 & $0.4,0.7$ & 37,36 \\
\hline
\end{tabular}

TABLE 3. RAIL SAMPLES NOT WITHIN CHEMICAL REQUIREMENTS

\begin{tabular}{|c|c|c|c|c|c|c|c|}
\hline $\begin{array}{c}\text { Rail } \\
\text { Sample }\end{array}$ & $\begin{array}{c}\mathrm{High} \\
\mathrm{C}\end{array}$ & $\begin{array}{c}\text { Low } \\
\text { C }\end{array}$ & $\begin{array}{c}\text { High } \\
\text { Mn }\end{array}$ & $\begin{array}{l}\text { Low } \\
\mathrm{Mn}\end{array}$ & $\begin{array}{c}\mathrm{High} \\
\mathrm{Si}\end{array}$ & $\begin{array}{l}\text { Low } \\
\mathrm{Si}\end{array}$ & $\begin{array}{c}\text { High } \\
\mathrm{S}\end{array}$ \\
\hline 002 & & & & $\mathrm{x}$ & & $\mathrm{x}$ & $\mathrm{X}$ \\
\hline 004 & & & & & $x$ & & $\mathrm{x}$ \\
\hline 008 & & $\mathrm{x}$ & & & & & \\
\hline 010 & & $x$ & & & & & \\
\hline 013 & & & & & $x$ & & \\
\hline 017 & & & & & $\mathrm{X}$ & & \\
\hline 034 & & & $\mathrm{X}$ & & & & \\
\hline 037 & & & & & $\mathrm{X}$ & & \\
\hline 040 & & $x$ & & $\mathrm{x}$ & & $x$ & \\
\hline 042 & & $\mathrm{X}$ & & & & $x$ & \\
\hline 045 & & $x$ & & $\mathrm{X}$ & & & \\
\hline 047 & & & & $\mathrm{X}$ & & & \\
\hline 051 & $\mathrm{X}$ & & & & & & \\
\hline 053 & $x$ & & & & & & \\
\hline 058 & $\mathrm{X}$ & & & & & & \\
\hline 059 & $x$ & & & - & & & \\
\hline 062 & & & & & & $\mathrm{x}$ & \\
\hline
\end{tabular}




\subsection{MACROSTRUCTURES}

Most of the 66 rail samples exhibited uniform macrostructures throughout their full cross sections. The principle variances in the macrostructures among the rail samples were differences in fineness or coarseness. These differences may be related to the prior austenite grain size and/or the pearlite colony size. Typical macrostructures observed are exemplified by the photomacrographs in Figures 1 and 2, Samples 027 and 019 , respectively. Figure 1 shows a typical coarse-textured macrostructure which was observed in 19 rail samples (Samples 007, 012, 014 through 018, 020 through 024, 027 through 032, and 042). Figure 2 shows a fine-textured macrostructure which was observed in the remaining 47 rail samples, except for Sample 058. Sample 058 had a macrostructure which exhibited very little of a structural pattern as shown in Figure 3 .

The macrostructures of Samples 046 and 059 showed that the running surfaces apparently had been heat treated. The heat-treated surface of Sample 059 is evident in Figure 4. The surface heat treatment suggested that these two samples were from the ends of rails that were end-hardened, a process commonly used to reduce wheel batter at the rail joint.

The macrostructure of Sample 002 showed that its running surface apparently had been repaired by the mechanical removal of surface damage and subsequent deposition of weld metal. The repair weld in this sample is evident in Figure 5.

The macrostructure of Sample 001 showed evidence of a high inclusion content and internal fissuring, both conditions being located primarily in the web section and at the bottom of the head section. These conditions can be seen in Figure 6.

Cracks were observed in the macrostructures of Samples 061, 062, and 063. The cracks in these three rails were located centrally in the web below the rail head. All three cracks extended through the entire thickness ( 1 inch) of the transverse cross sections. The cracks are believed to be the remains of shrinkage porosity formed in the steels during solidification of the original ingots. The cracks are visible in the photomacrographs of Samples 061, 062, and 063 shown in Figures 7, 8, and 9, respectively. Sample 062 exhibited decarburization around the crack as indicated by the white zone in Figure 8 .

Some chemical segregation in the central zone of the web rail section

was indicated by the macrostructures of Samples 003, 025, 040,060,061, 062, and 063. An example of this condition is shown by the photomacrograph of Sample 003 in Figure 10. Similar conditions of chemical segregation exist in Figures 7,8 , and 9 . 


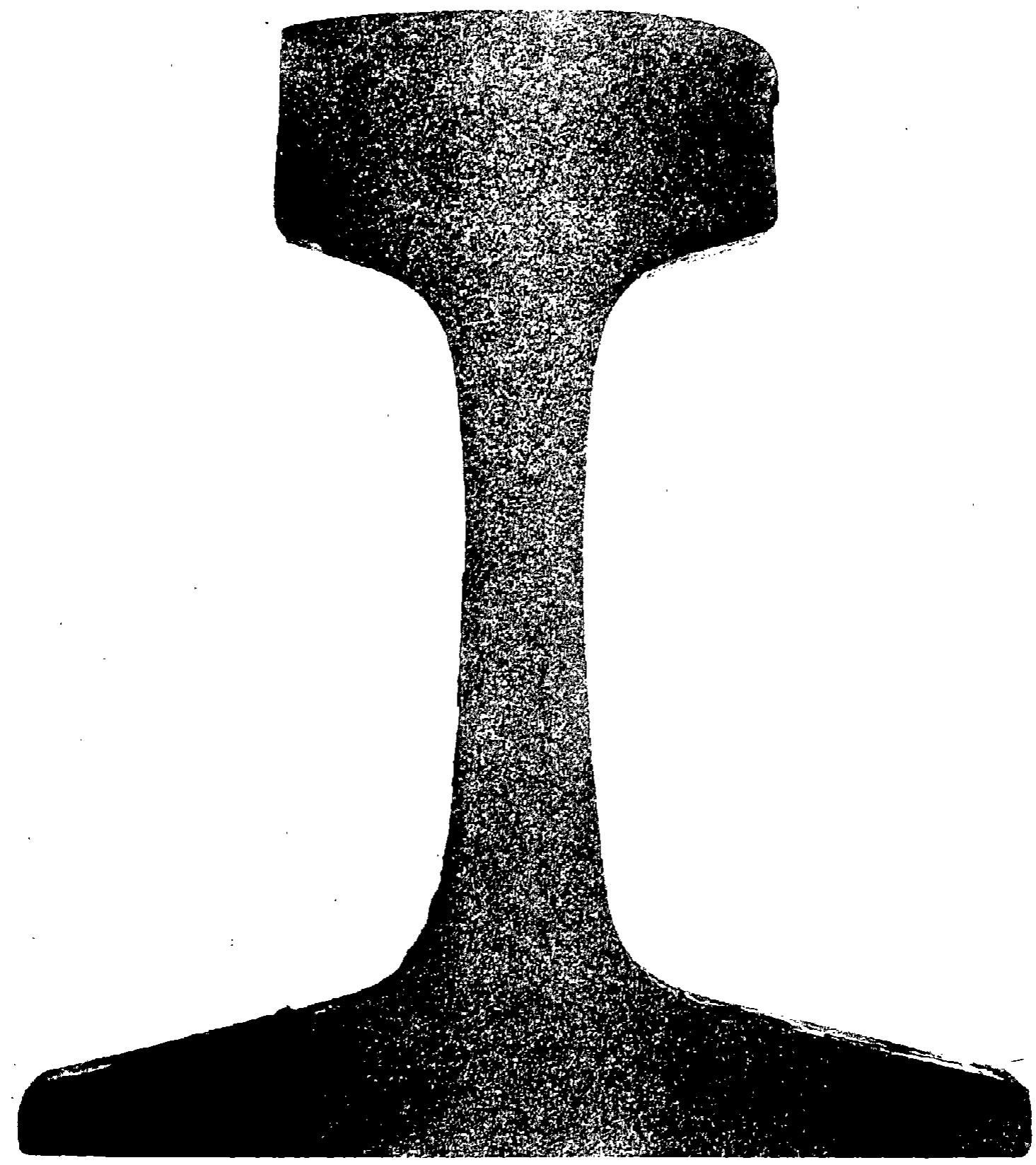

IX

FIGURE 1. TYPICAL COARSE-TEXTURED MACROSTRUCTURE OF RAILS - SAMPLE 027 


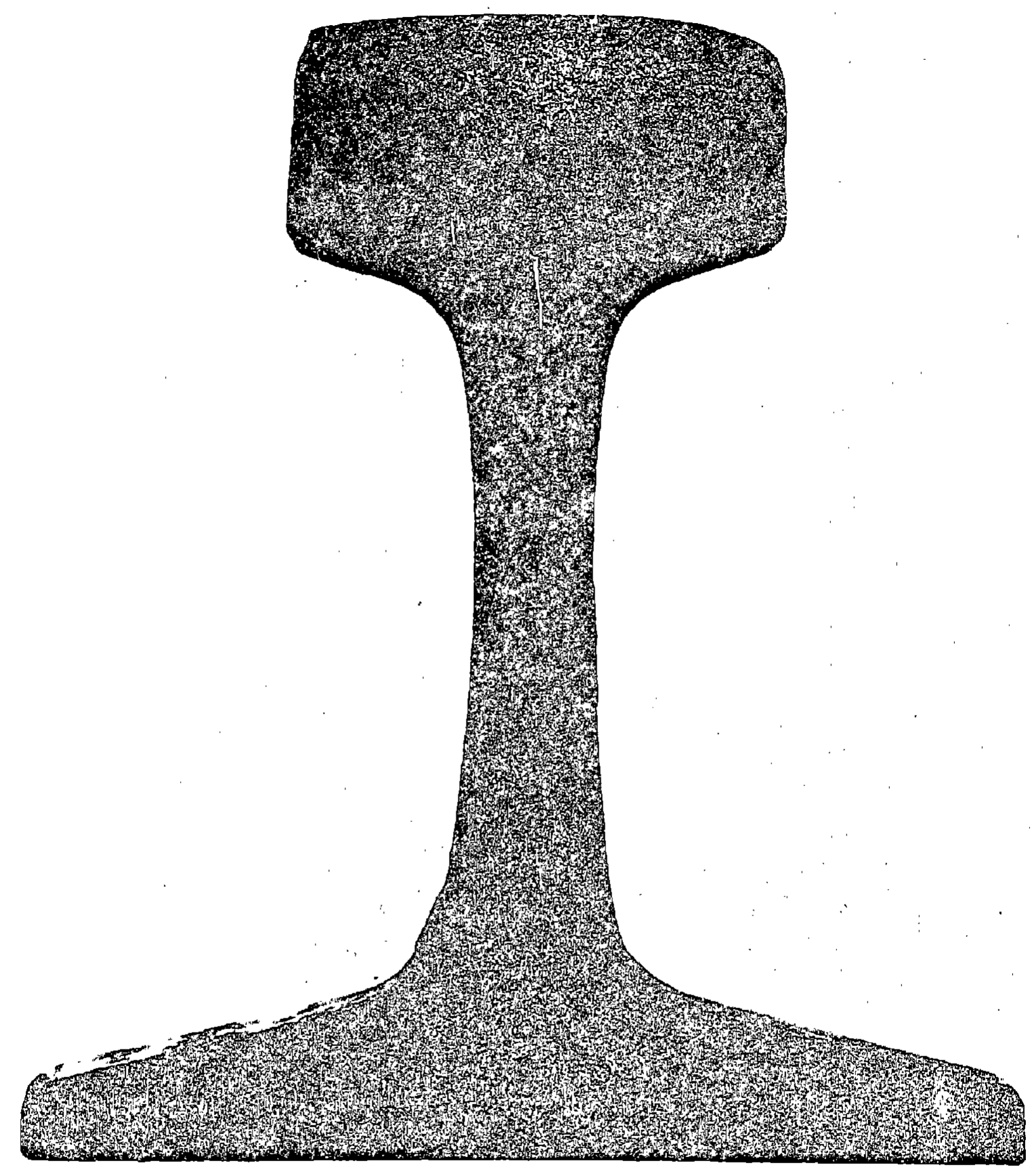

$1 \mathrm{X}$

FIGURE 2. TYPICAL FINE-TEXTURED MACROSTRUCTURE OF RAILS - SAMPLE OI9 


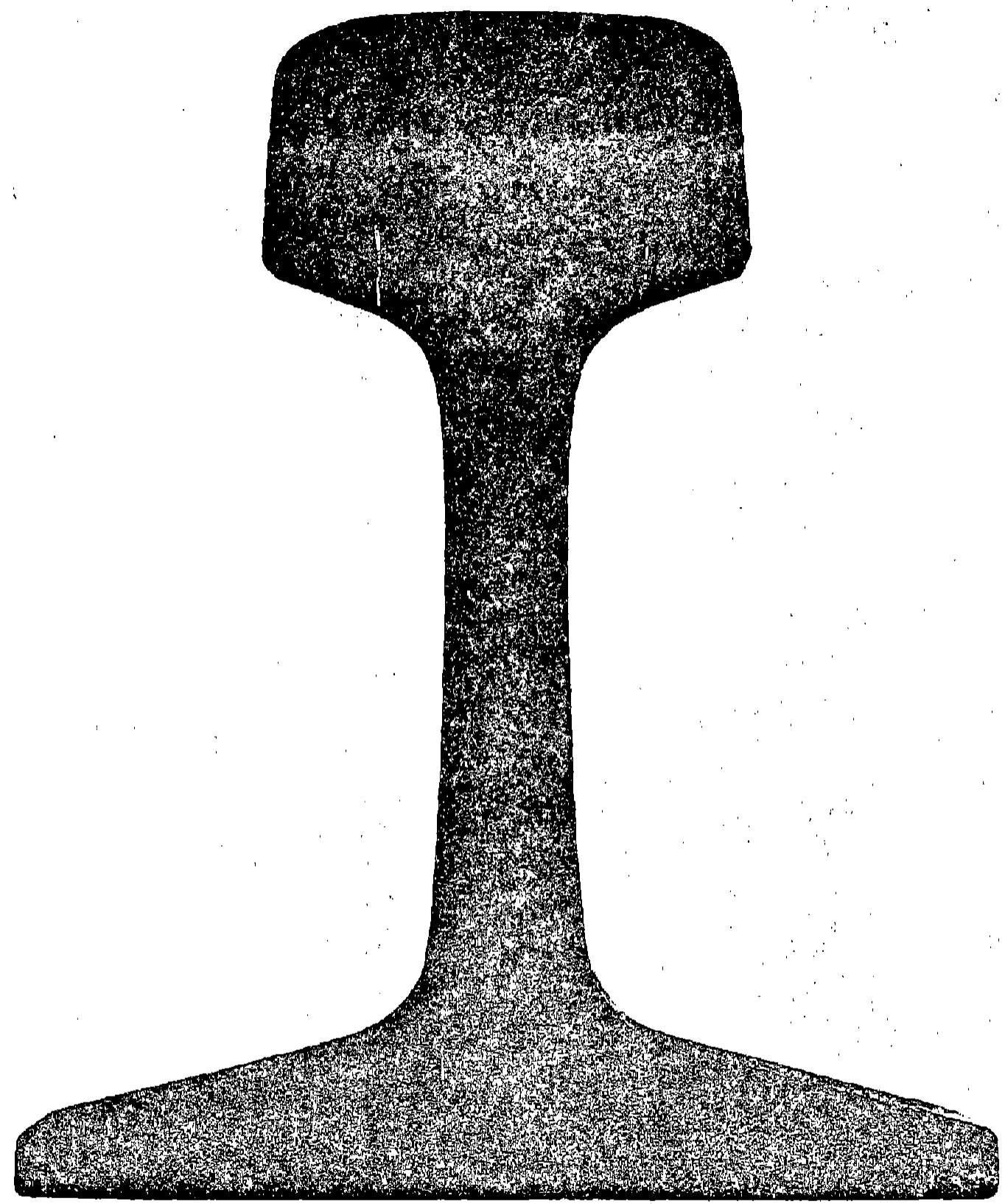

$1 \mathrm{X}$

FIGURE 3. MACROSTRUCTURE OF RAIL SAMPLE 058

Note lack of any structural pattern. 


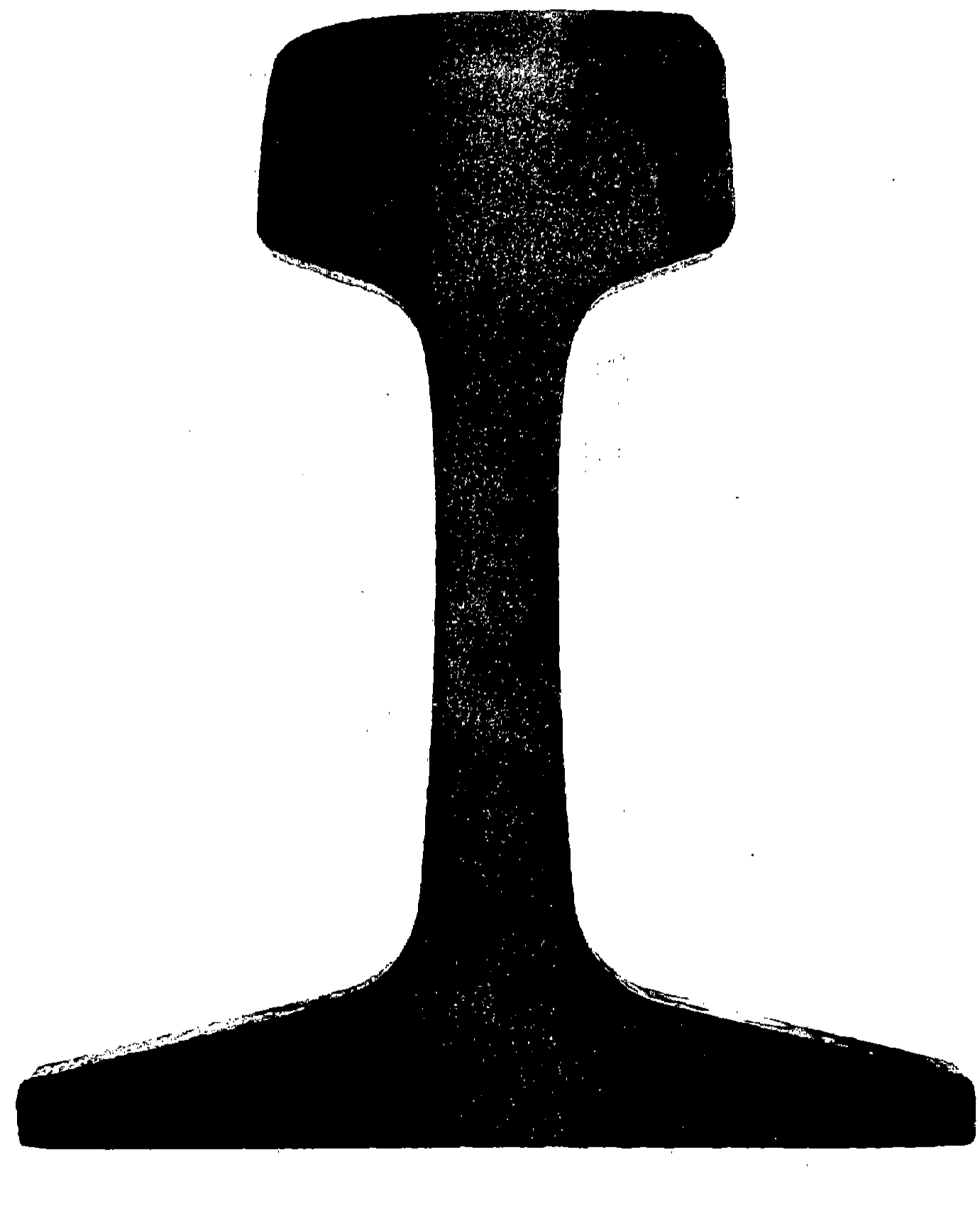

FIGURE 4. MACROSTRUCTURE OF A HEAT-TREATED RUNNING SURFACE - RAIL SAMPLE 059 


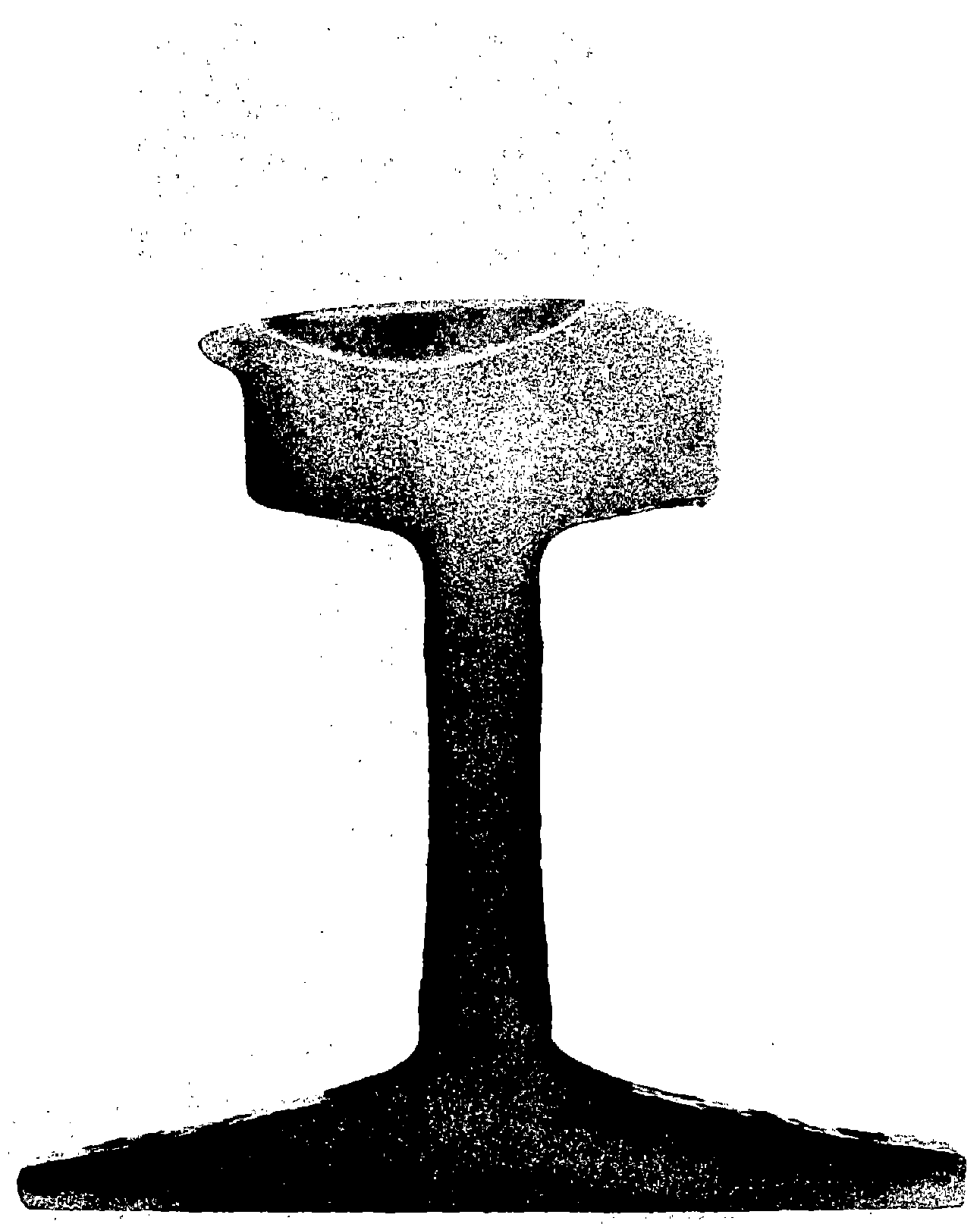

$1 \mathrm{X}$

FIGURE 5. MACROSTRUCTURE OF A REPAIRED RUNNING SURFACE - RAIL SAMPLE 002 


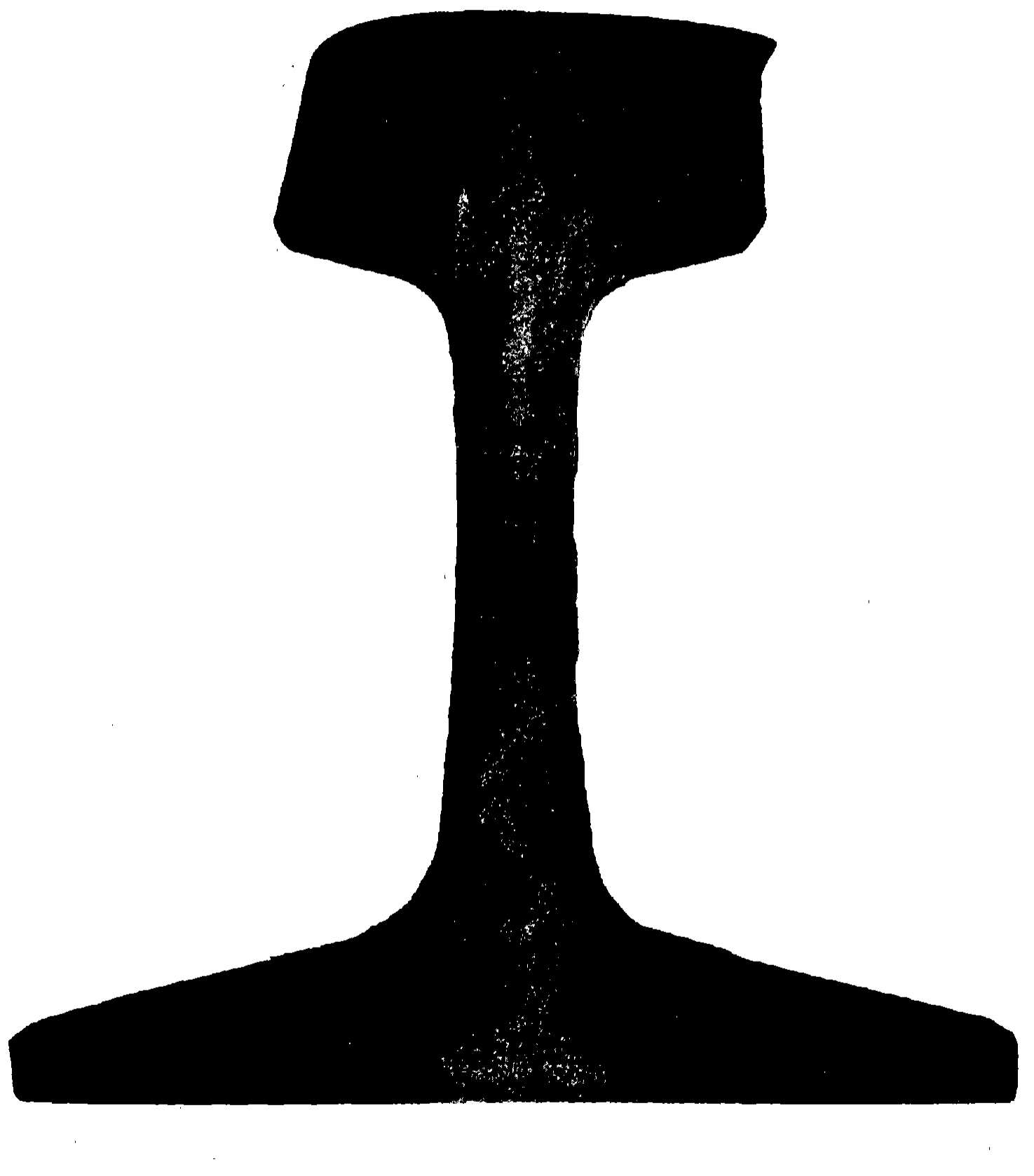

FIGURE 6. MACROSTRUCTURE OF RAIL SAMPLE 001 Note Internal fissures. 


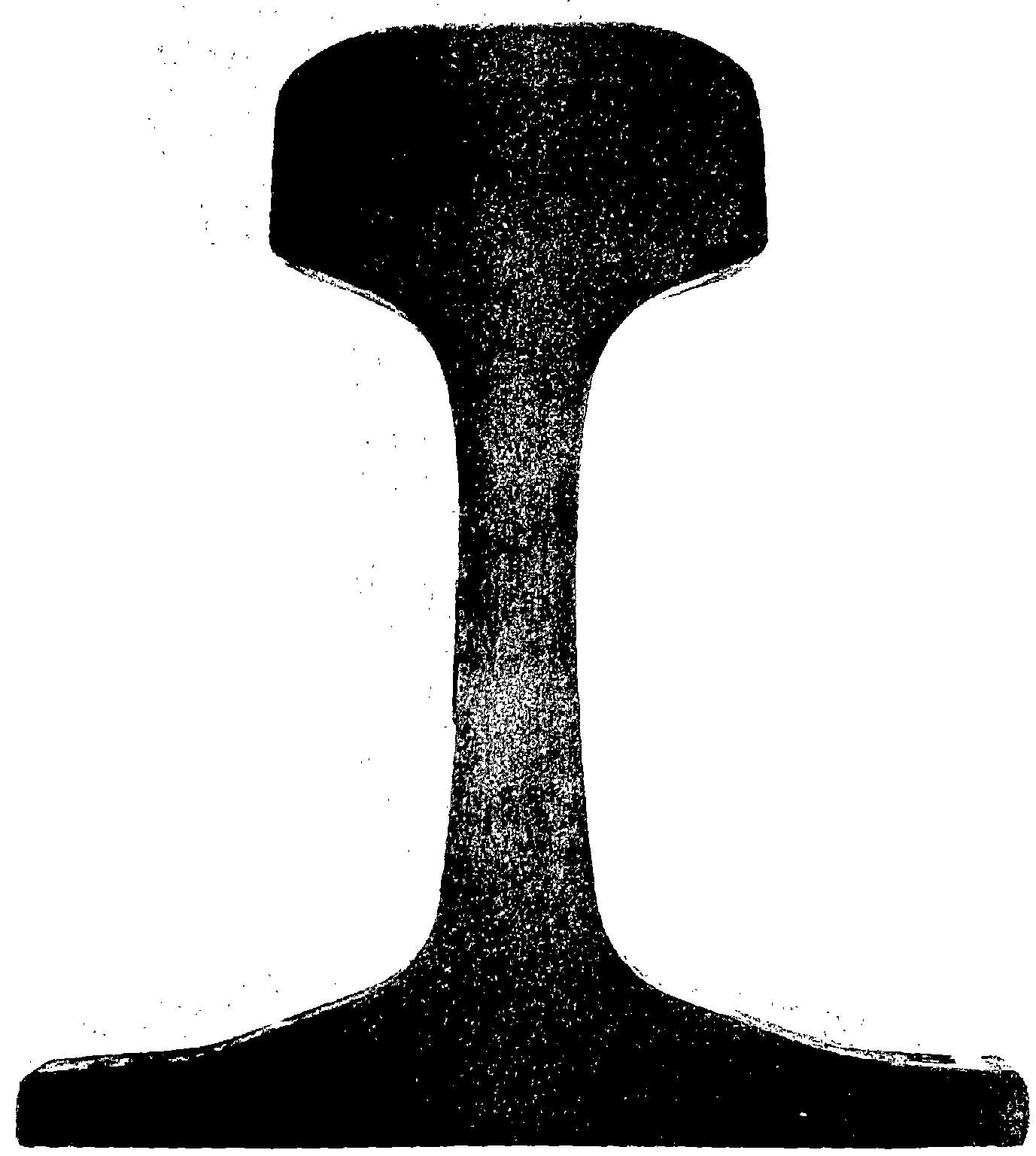

$1 \mathrm{X}$

FIGURE 7, MACROSTRUCTURE OF RAIL SAMPLE 061

Note crack in the web. 


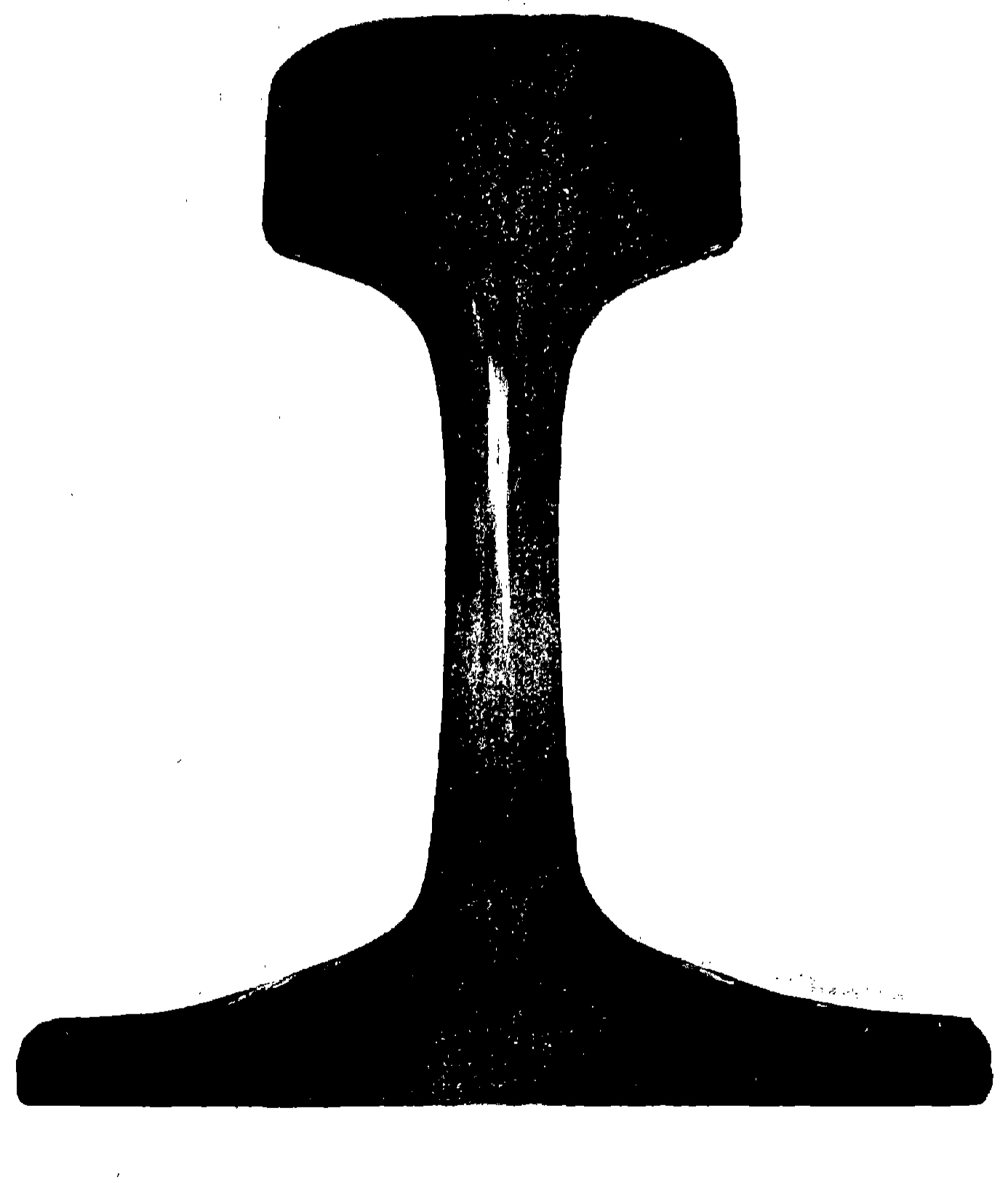

FIGURE 8. MACROSTRUCTURE OF RAIL SAMPLE 062

Note segregation and crack in the web. 


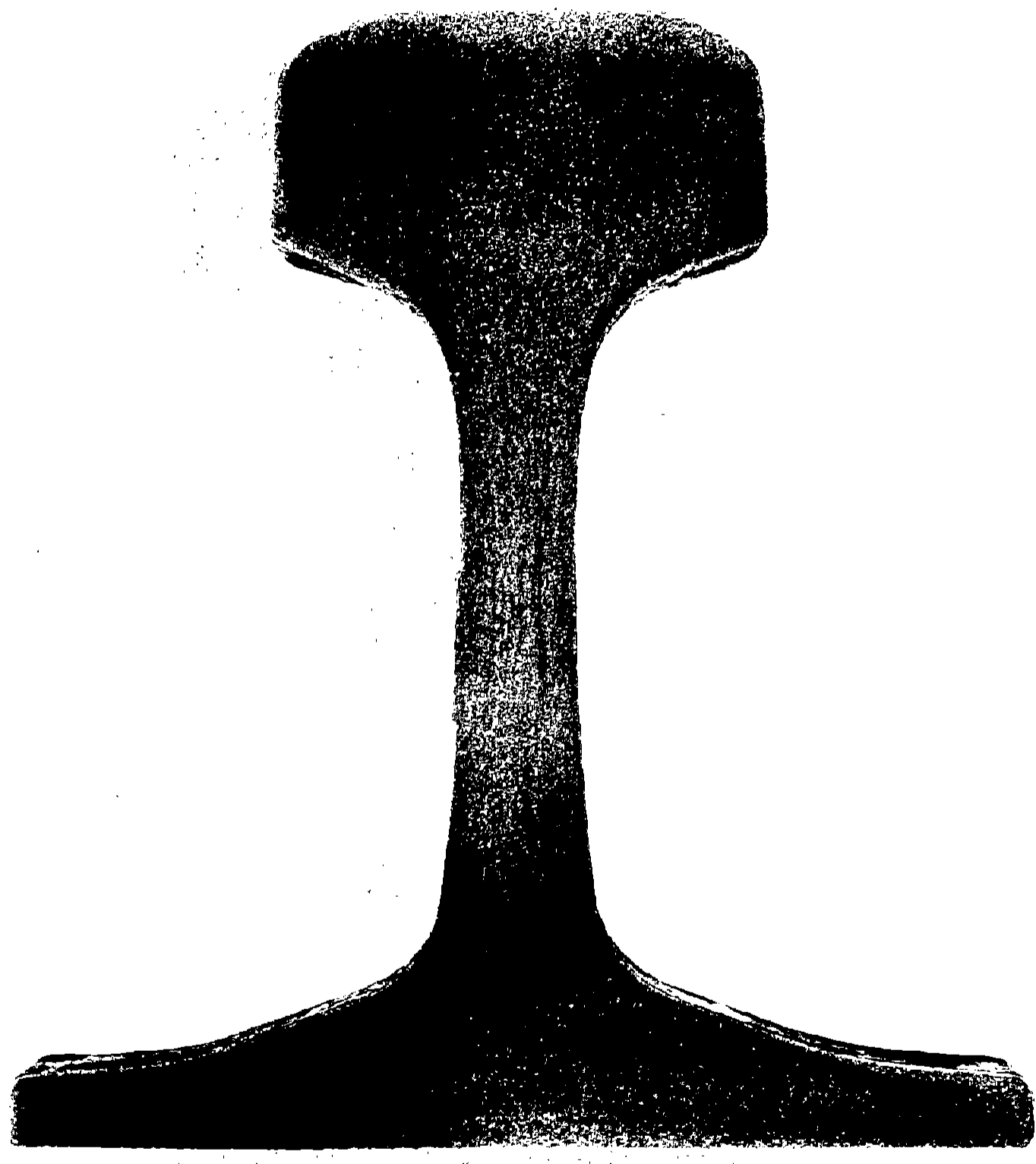

$1 \mathrm{X}$

FIGURE 9. MACROSTRUCTURE OF RAIL SAMPLE 063

Note hairline crack in the central area of the web. 


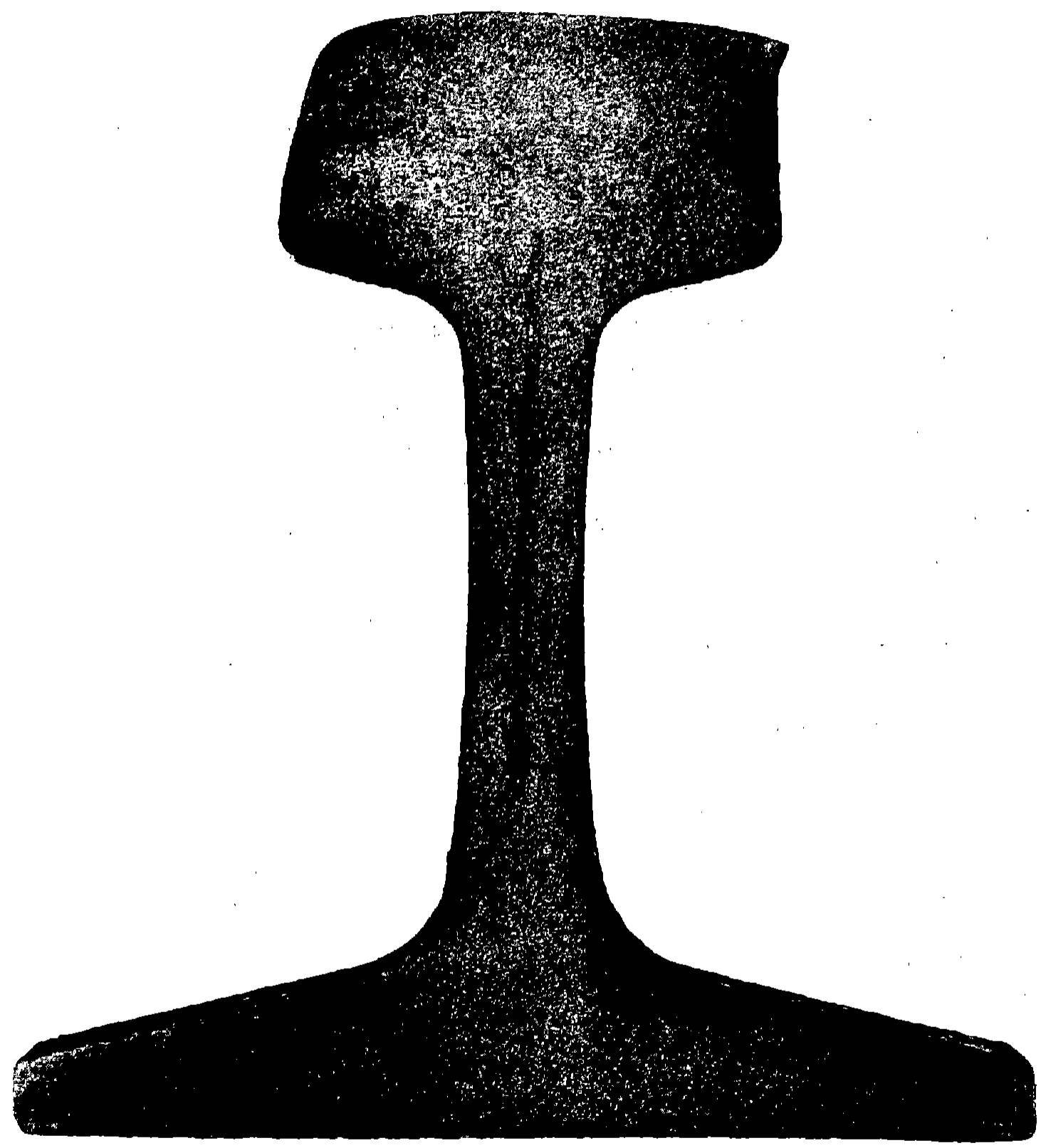

$1 \mathrm{x}$

FIGURE 10. MACROSTRUCTURE OF RAIL SAMPLE 003

Note segregation in the web. 


\subsection{MICROSTRUCTURES}

Microscopic examinations of longitudinal metallographic specimens of the rail samples showed that the microstructures of 48 rails consisted of essentially 100 percent fine pearlite with very minor amounts of free ferrite occurring adjacent to some manganese sulfide inclusions or along a few prior austenite grain boundaries. A typical microstructure is shown by the photomicrograph of Sample 051 in Figure 11. The microstructures of Samples 004, 010, 013, 028, 038 , $041,045,047$, and 052 consisted of 85 to 95 percent (visual estimates) fine pearlite with the remainder being free ferrite located primarily along prior austenite grain boundaries. Rail Samples 004 and 045 contained the most free ferrite in the form of a ferrite network along prior austenite grain boundaries. Figure 12 shows the microstructure of Sample 004 . The remaining Rail Samples, 002, 036, 037, 043, 054, 058, 064, 065, and 066, had microstructures consisting of about 96 to 99 percent (visual estimates) fine pearlite with the remainder being free ferrite scattered along, prior austenite grain boundaries and adjacent to some sulfide inclusions. The microstructure of Sample 058 (shown in Figure 13) had much finer pearlite and considerably smaller pearlite colonies than any of the other rails. This type of microstructure was suggested already by its fine macrostructure. The very small pearlite colony size is obvious by comparison with the pearlite colony size in Figure 11. This fine structure suggests Sample 058 was heat treated following hot rolling.

Internal cracks in Sample 001, which were evident during macroscopic observations, were clearly apparent during microscopic observations. Three principal cracks running generally parallel to the longitudinal direction of the rail were observed in the longitudinal metallographic specimen examined. An example of one of the cracks observed is shown in Figure 14. The cracks propagated primarily across pearlite colonies, but also some propagation was observed along pearlite colony interfaces. "In the specimen examined, the cracks" were located be low the running surface about $\frac{1}{2}$ inch and deeper. The longest crack observed was approximately $200 \mathrm{mils}$. The cracks are believed to be the result of a high hydrogen content in the steel when the rail was manufactured. 


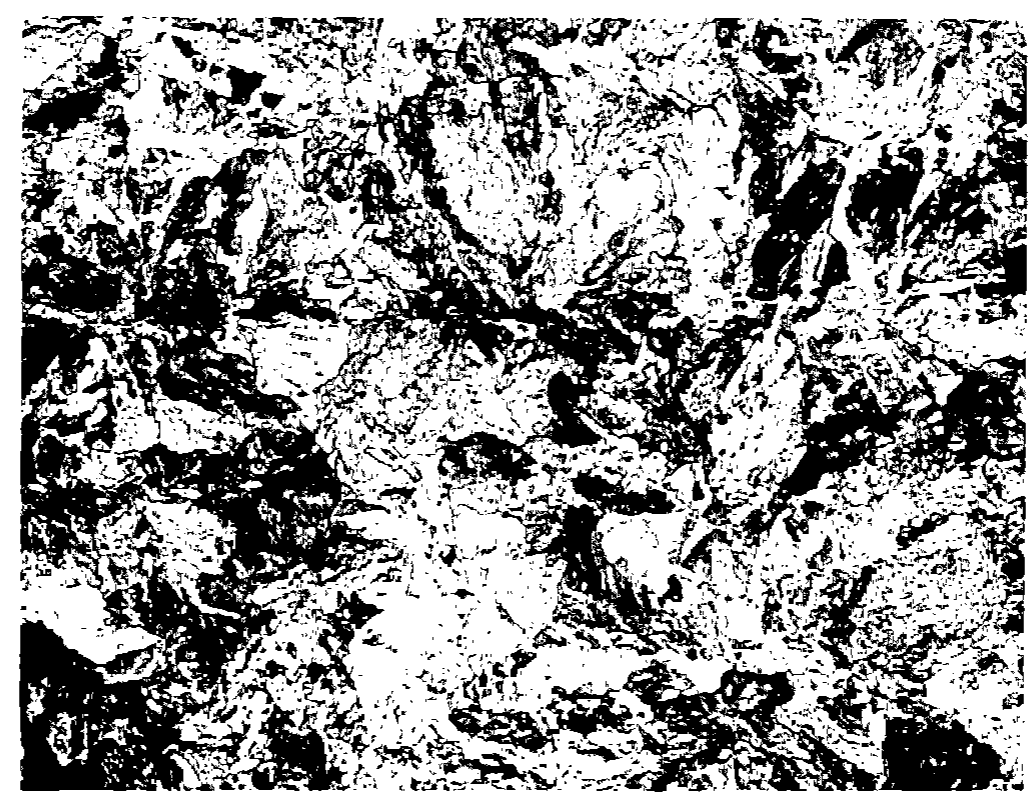

$100 \mathrm{X}$

FIGURE 11. PEARLITIC MICROSTRUCTURE TYPICAL OF THE MAJORITY OF RAILS - SAMPLE 051L

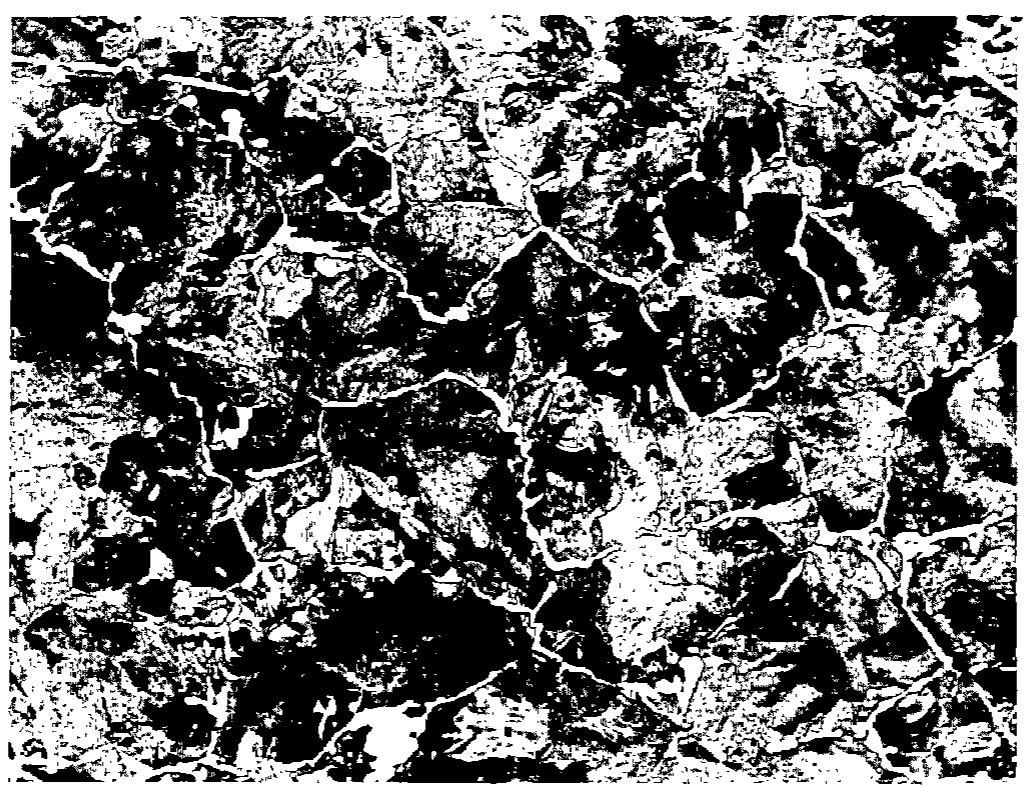

$100 \mathrm{X}$

FIGURE 12. FERRITE NETWORK IN A MATRIX OF PEARLITE SAMPLE 004 


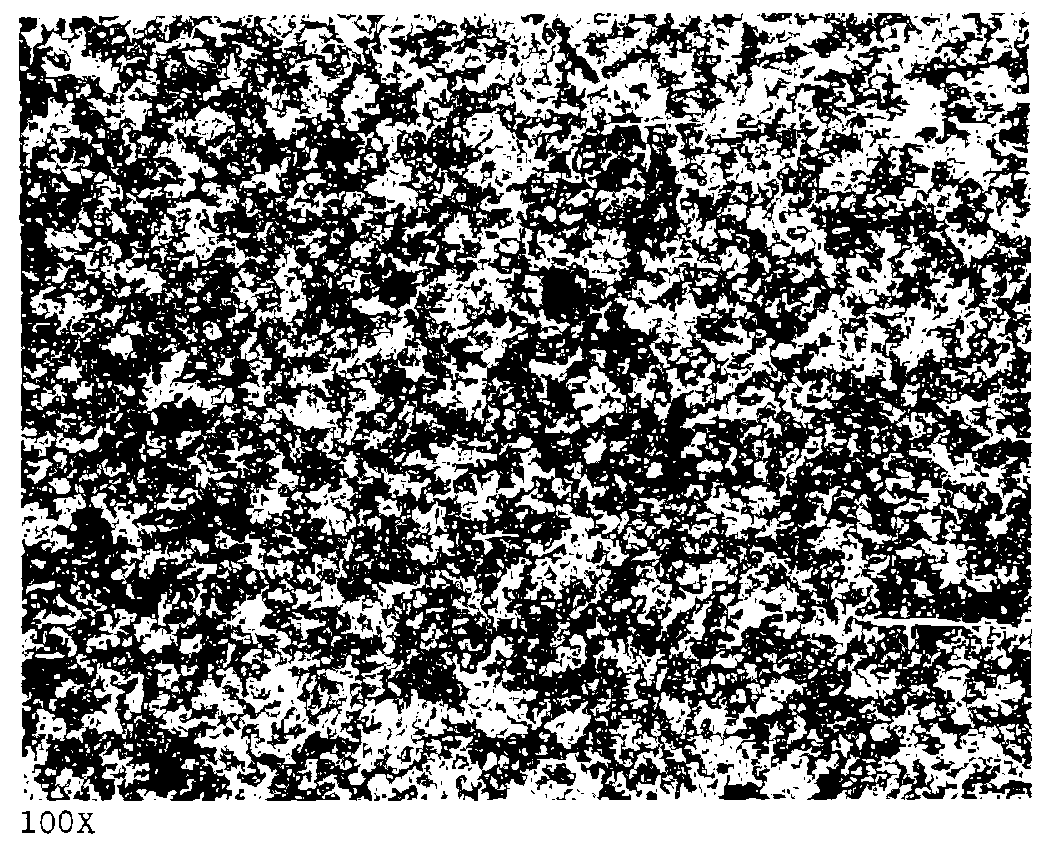

FIGURE 13. HEAT-TREATED PEARLITIC MICROSTRUCTURE OF RAIL SAMPLE 058L

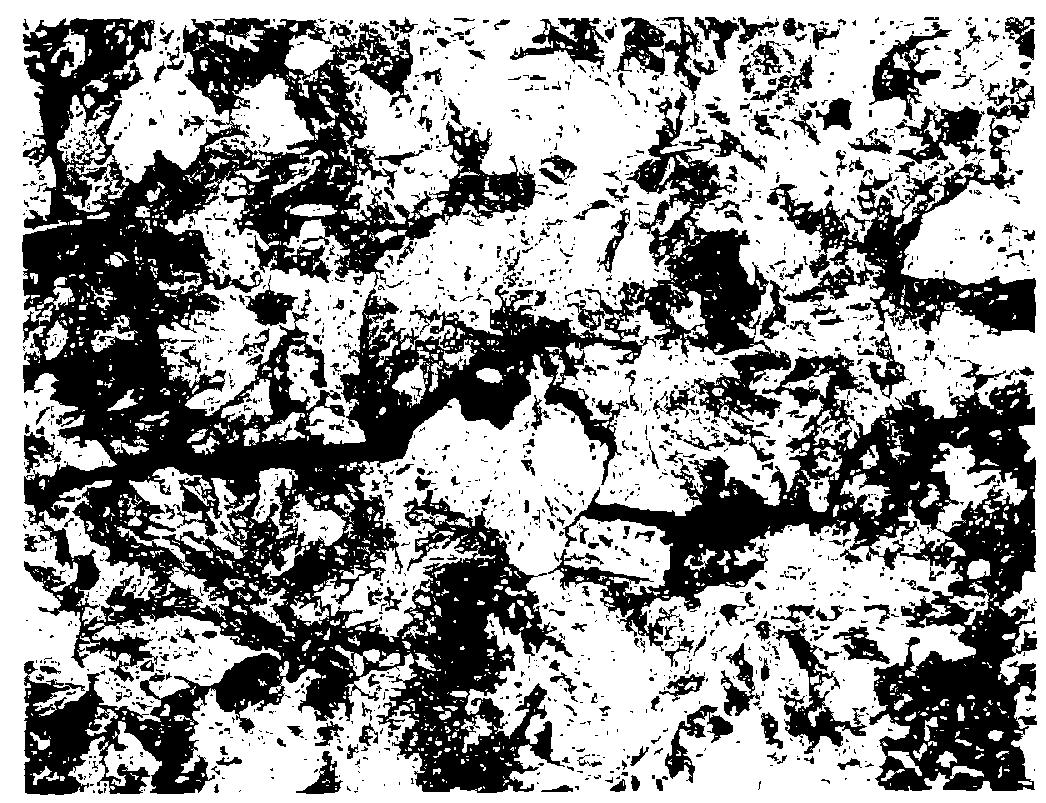

$100 \mathrm{X}$

FIGURE 14. INTERNAL CRACK IN RAIL SAMPIE 001L 


\section{EXPERIMENTAL DETAILS}

\subsection{SPECIMENS}

One tensile specimen and one fatigue-crack-growth specimen were machined from each rail sample. The orientation of the specimens is shown in Figure 15. Charpy $V$ specimens were taken from six rail samples - 023 and 030 which exhibited a high rate of fatigue-crack growth, 019 and 031 with medium crack-growth rates, and 001 and 036 with low growth rates. Forty-five Charpy specimens were made, 15 from each of the three growth-rate categories. From each categary, five specimens were taken in each of the three directions shown in Figure 15. The specimens were taken from the center of the rail head.

The tensile specimens were standard ASTM 0.25 -inch-diameter specimens. Charpy specimens were also of standard dimensions; i.e., 2.165-inch long, 0.394inch thick with a square cross section.

Fatigue-crack-growth specimens were of the compact tension (CT) type. Their dimensions are shown in Figure 16. The specimens were provided with a 1.650inch deep chevron notch ( 0.900 inch from the load line). Details of the notch can best be observed in Figure 17 which shows two specimens, one before and one after testing.

\subsection{TESTING PROCEDURES}

Tensile and Charpy tests were performed in accordance with standard procedures.

To expedite the crack-growth tests, specimens were precracked in a Krause fatigue machine. Crack-growth experiments were conducted in a 25-kipcapacity electrohydraulic servocontrolled fatigue machine. Figure 18 shows a specimen mounted in the fatigue machine. The tests were performed at constant amplitude, the load cycling between 0 and 2500 pounds, resulting in a stress ratio of $R=0$. Cycling frequency was $40 \mathrm{~Hz}$, but was reduced to $4 \mathrm{~Hz}$ toward the end of a test to enable more accurate recording of the crack size giving final failure. The laboratory air was kept at $68 \mathrm{~F}$ and 50 percent relative humidity.

Crack growth was meàsured visually, using a 30 power traveling microscope. The cracks were allowed to grow in increments of $0.050 \mathrm{inch}$, after which the test was stopped for an accurate crack size measurements. Crack size was recorded as a function of the number of load cycles. 


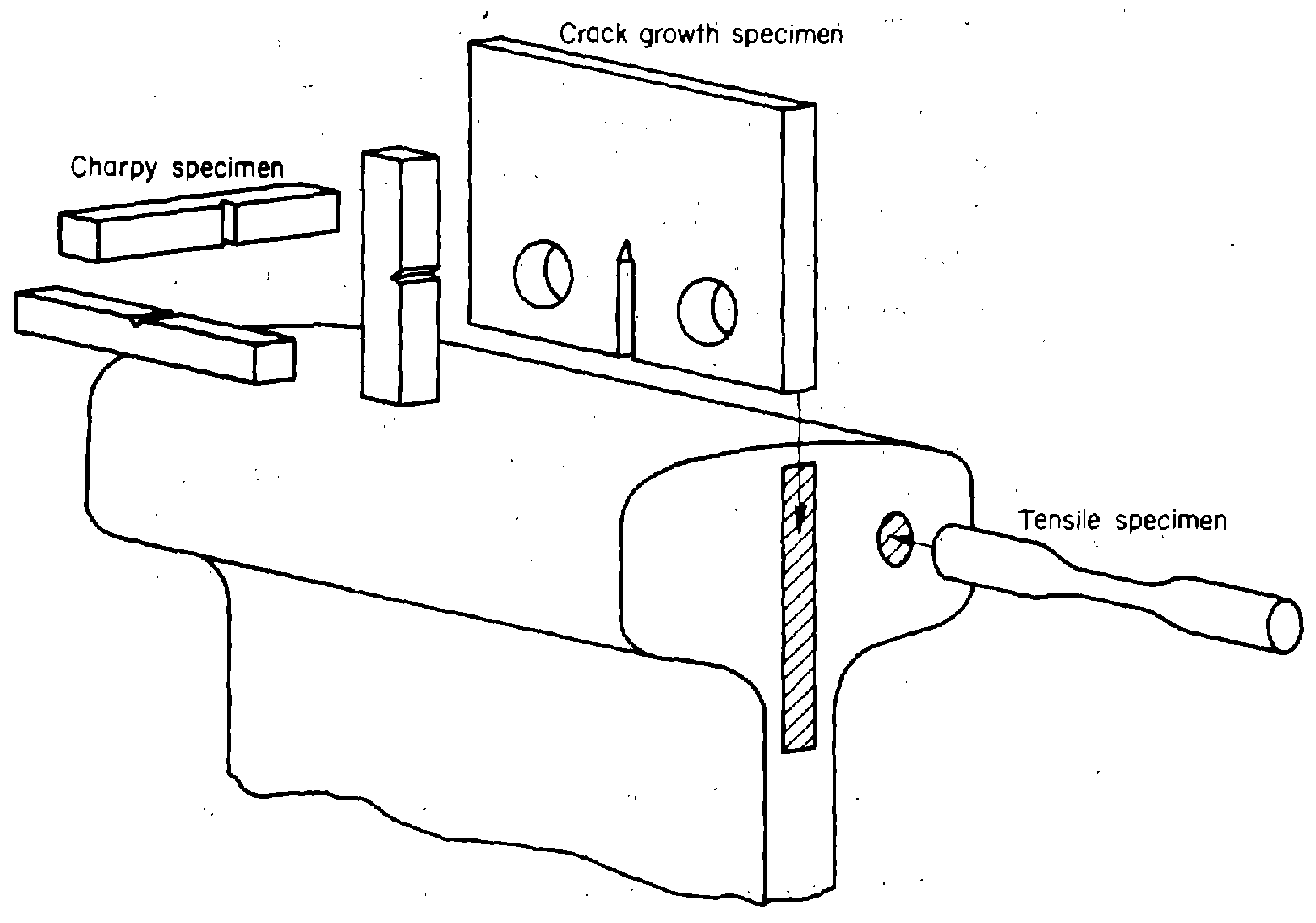

TIGURE 15 . ORIENTAT ION OF SPECIMENS 


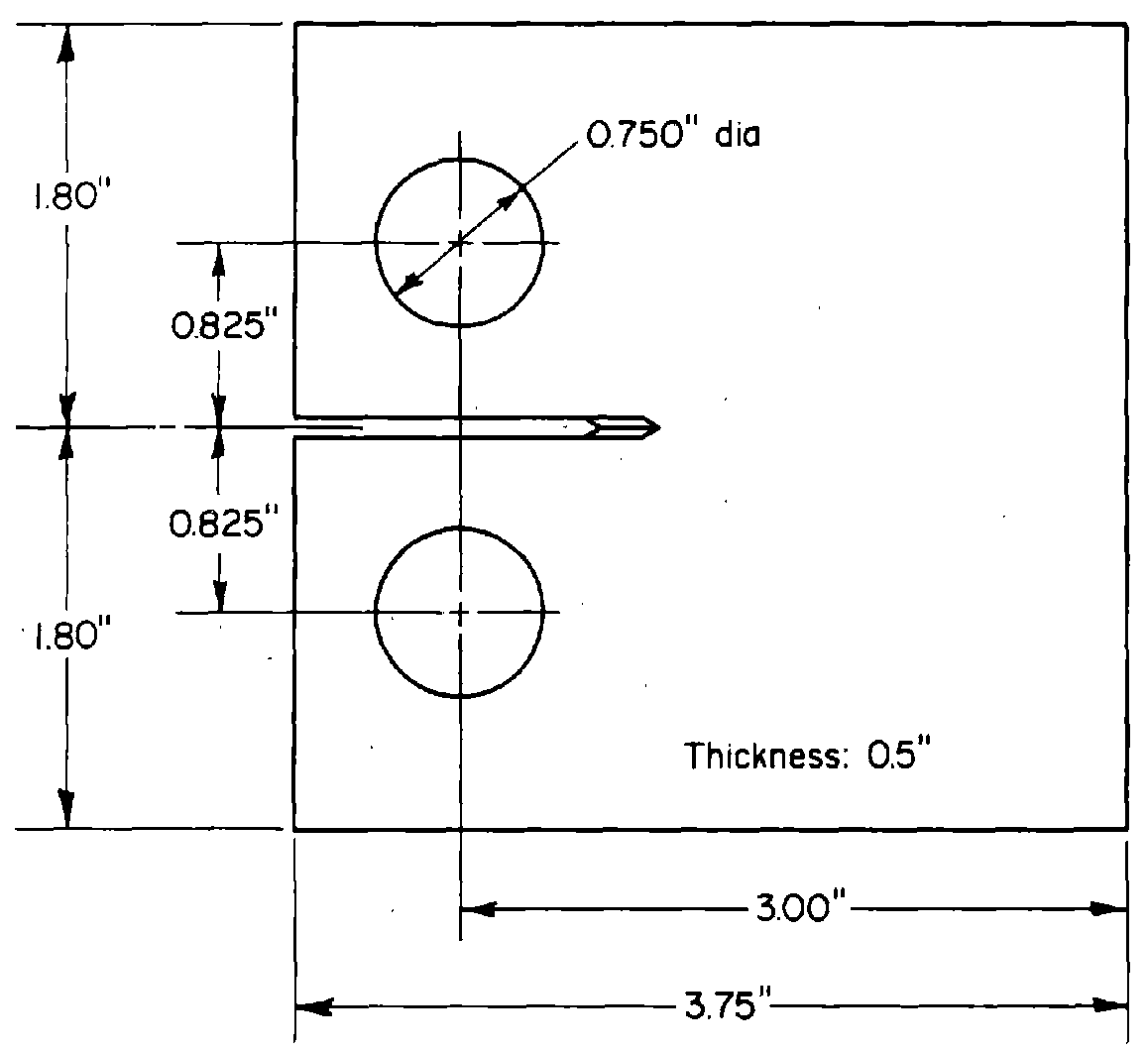

FIGURE 16. COMPACT TENSION FATIGUE CRACK GROWTH SPECIMEN 


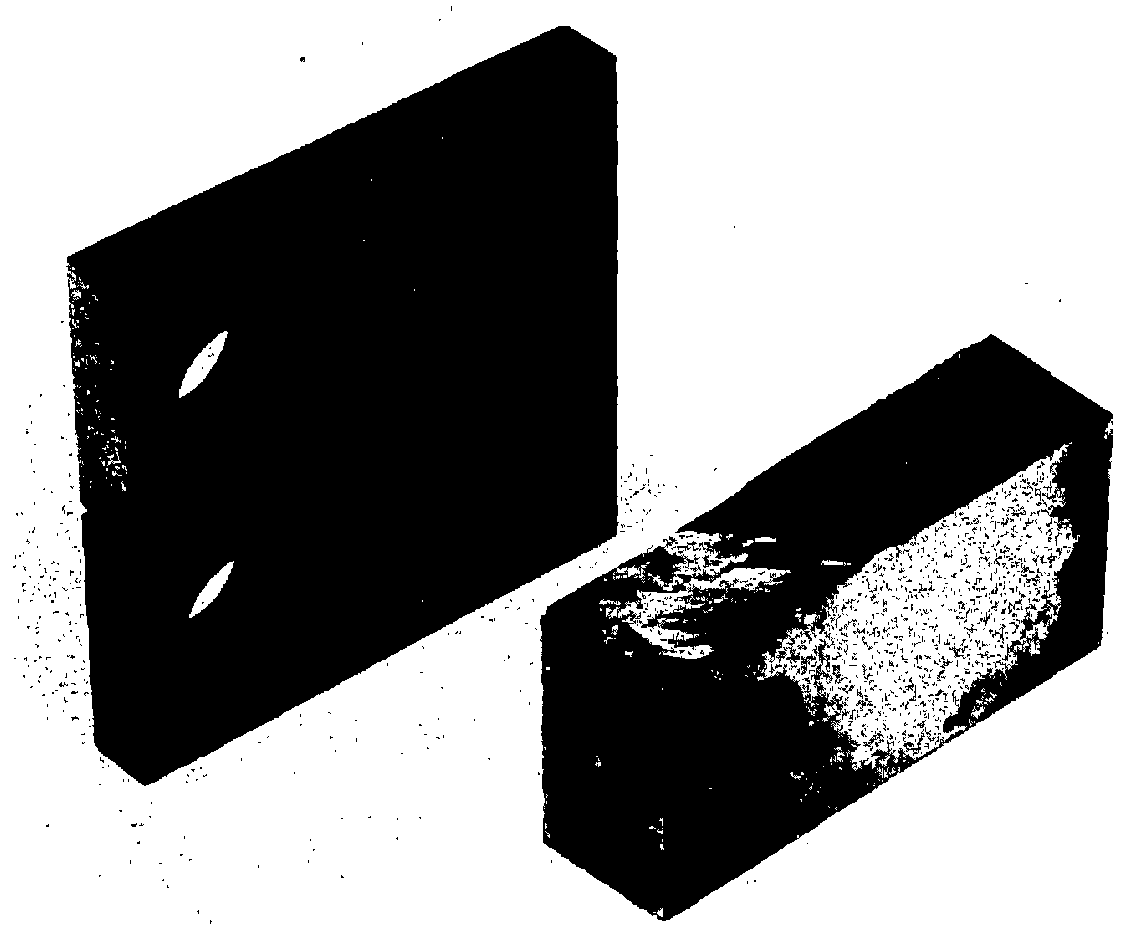

FIGURE 17. COMPACT TENSION SPECIMENS BEFORE AND AFTER TESTING 


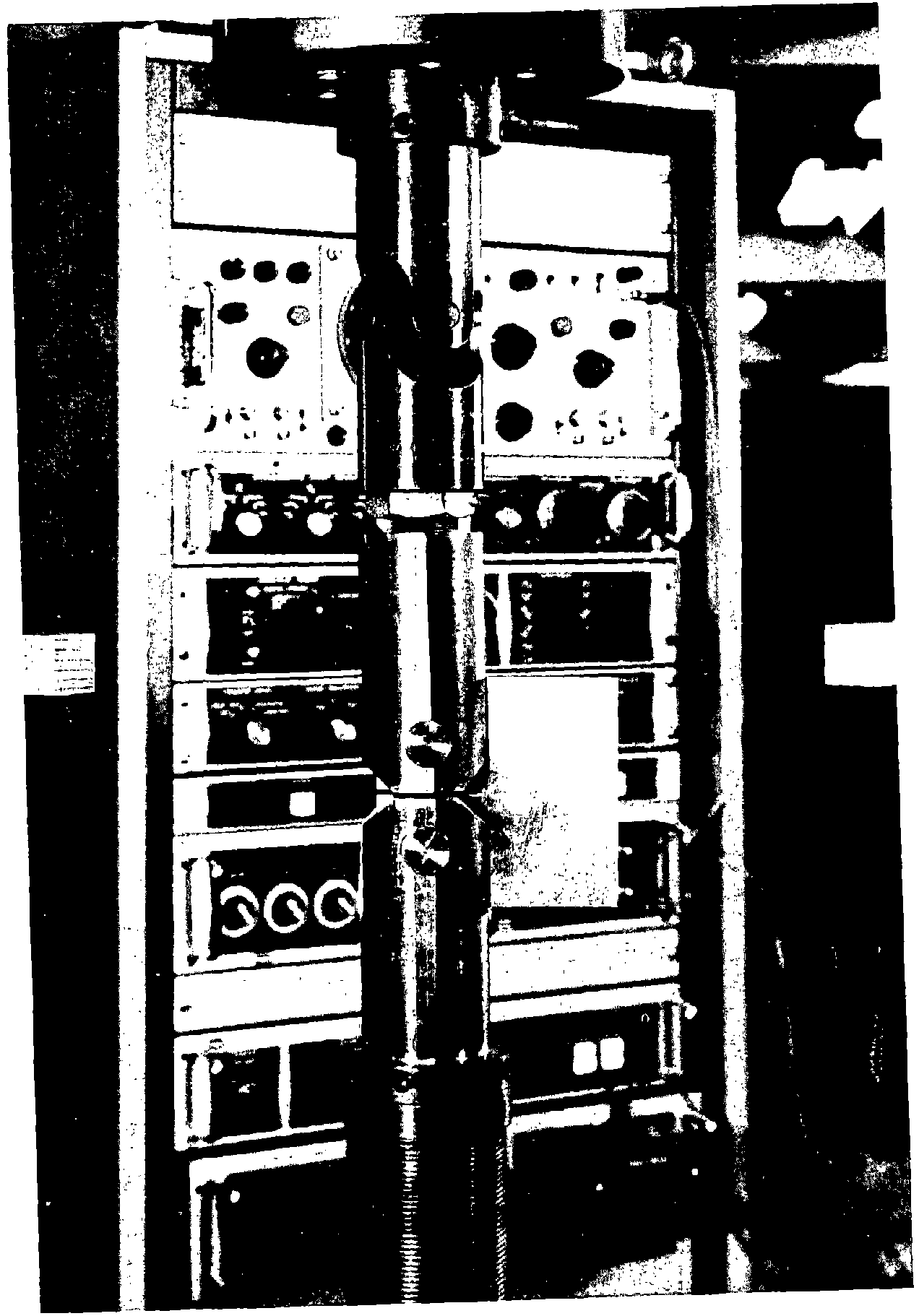

FIGURE 18. COMPACT TENSION SPECIMEN IN FATIGUE MACHINE 


\section{TEST RESULTS}

The tensile properties of the 66 rail samples are presented in Table 4. With a few exceptions, the tensile ultimate strength (TUS) and the tensile yield strength (TYS) are in the order of $130 \mathrm{ksi}$ and $75 \mathrm{ksi}$, respectively. One heat treated rail showed a high TUS of $188.3 \mathrm{ksi}$ and a TYS of $127.3 \mathrm{ksi}$. Two tensile specimens (030 and 045) contained longitudinal cracks as became apparent after fracture, since the fracture path partly followed these cracks. This resulted in the strength of those samples being low. It should be noted that these samples were different from the ones reported cracked in Section 3.2.

The Charpy data are presented in Tables 5, 6, and 7 . They show that in the range of ambient temperatures the Charpy energy is essentially the same for all these steels. Transition temperatures and upper shelf behavior show some variation, but these are of limited interest under operational conditions.

Some typical fatigue-crack-propagation curves are given in Figure 19. The curves show that the number of cycles to grow a 1-inch crack to failure showed a wide variation for the rails from which the specimens were taken. This will be reflected in the rate of growth, which is the basis on which the materials will be compared in the next section. Also the final crack size at failure showed quite a wide variation which will be reflected in the toughness number. The raw test data (crack size versus cycle number) of all specimens are given in Appendix A.

\section{DATA ANALYSIS}

In order to develop a failure model for track rail, one must identify and quantify the damage processes, couple them appropriately, provide a means for accumulating the damage (i.e., compile the crack growth), and establish the criterion for failure or fracture. The first step in implementing these tasks is the baseline effort of crack-growth characterization and metallurgical studies previously described. In the following sections, the approach to interpretation, quantification, and correlation of these data is discussed. In the next phase, this will be broadened to consider additional variables. 


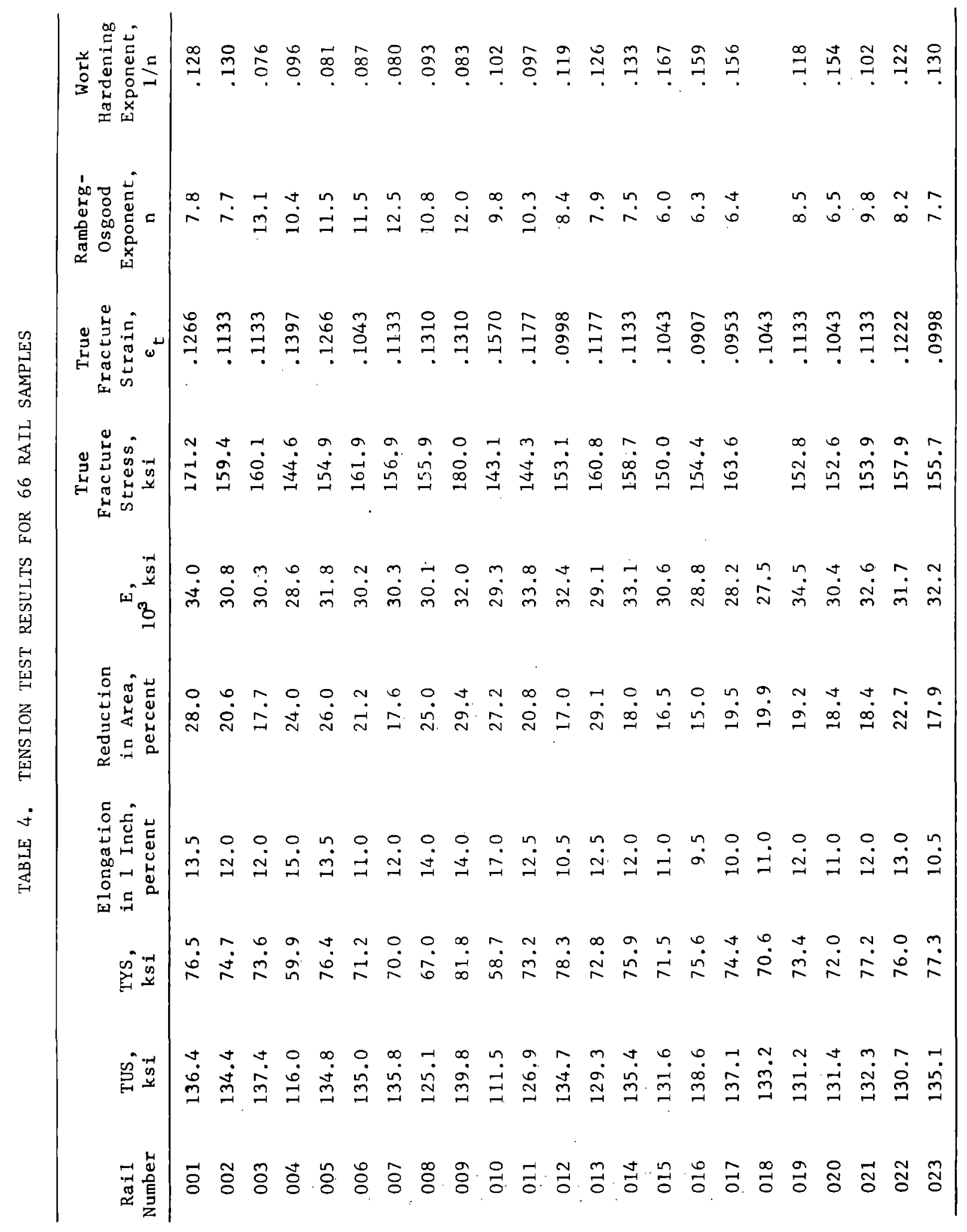




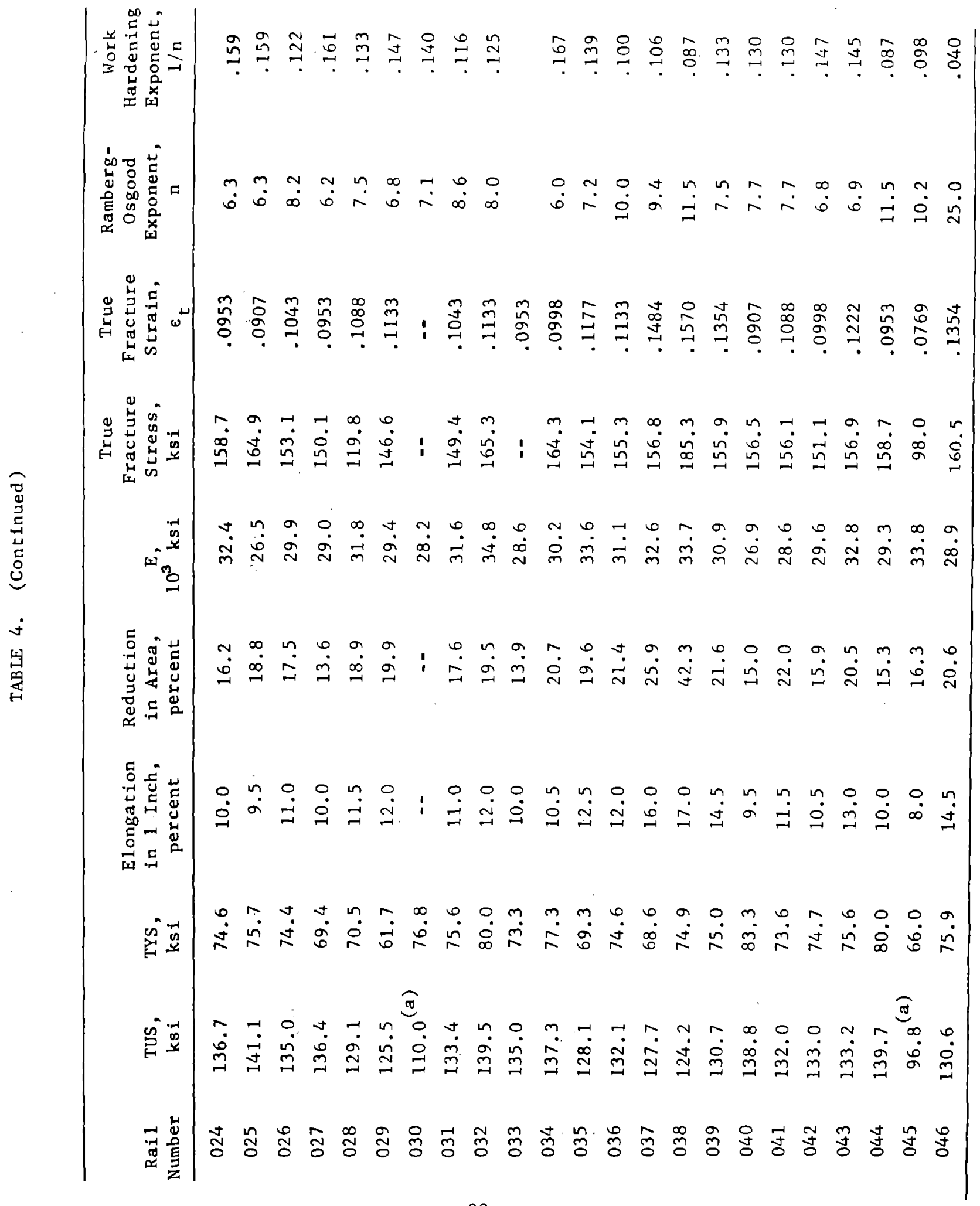




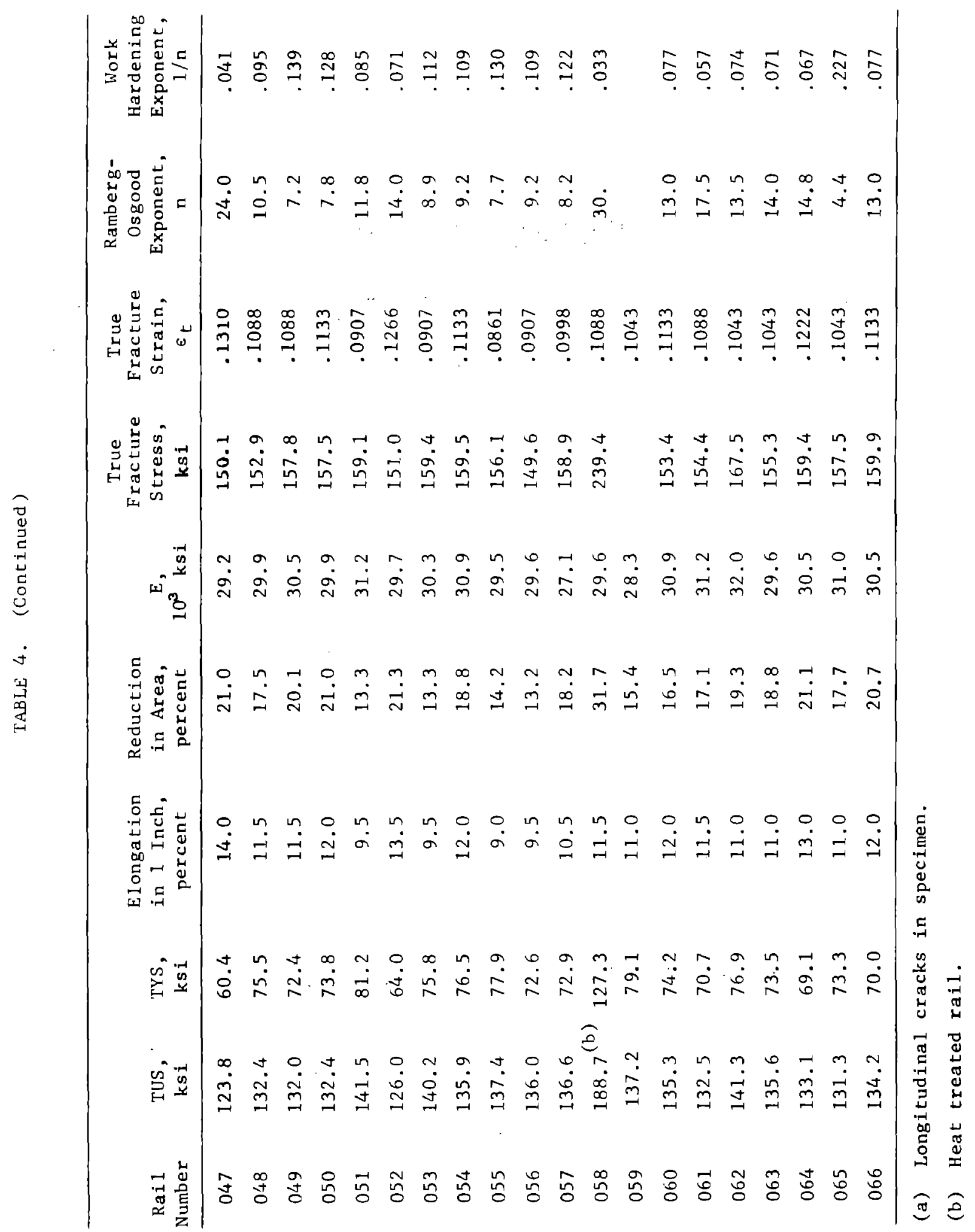


TABLE 5. CHARPY IMPACT TEST RESULTS FOR CATEGORY I RAILS (HIGH GROWTH RATE)

\begin{tabular}{|c|c|c|c|}
\hline $\begin{array}{c}\text { Specimen } \\
\text { Orientation }\end{array}$ & $\begin{array}{c}\text { Temperature, } \\
F\end{array}$ & $\begin{array}{c}\text { Energy } \\
\mathrm{ft} / \mathrm{Ib}\end{array}$ & $\begin{array}{c}\text { Shear Area, } \\
\text { percent }\end{array}$ \\
\hline $\mathrm{L}$ & 32 & 5 & 0 \\
\hline $\mathrm{L}$ & $\mathrm{RT}$ & 4 & 0 \\
\hline $\mathrm{L}$ & $\mathrm{R}^{\prime} \mathrm{T}$ & 5 & 0 \\
\hline $\mathrm{L}$ & 212 & 5.5 & 20 \\
\hline L & 300 & 18.5 & 99 \\
\hline $\mathrm{T}$ & 32 & 2 & 0 \\
\hline $\mathrm{T}$ & $\mathrm{RT}$ & 2 & 0 \\
\hline $\mathrm{T}$ & $\mathrm{RT}$ & 2 & 0 \\
\hline $\mathrm{T}$ & 212 & 2 & 40 \\
\hline $\mathrm{T}$ & 300 & 3 & 98 \\
\hline ST & 32. & 3 & 0 \\
\hline $\mathrm{ST}$ & $\mathrm{RT}$ & 4 & 0 \\
\hline $\mathrm{ST}$ & $\mathrm{RT}$ & 4 & 0 \\
\hline ST & 212 & 5 & 20 \\
\hline ST & 300 & 11.5 & 95 \\
\hline
\end{tabular}


TABLE 6. CHARPY IMPACT TEST RESULTS FOR CATEGORY 2 RAILS (MEDIUM GROWTH RATE)

\begin{tabular}{cccc}
\hline $\begin{array}{c}\text { opecimen } \\
\text { Orientation }\end{array}$ & $\begin{array}{c}\text { Temperature } \\
\text { F }\end{array}$ & $\begin{array}{c}\text { Energy, } \\
\text { ft/1b }\end{array}$ & $\begin{array}{c}\text { Shear Area, } \\
\text { percent }\end{array}$ \\
\hline L & 32 & 3.5 & 0 \\
L & RT & 4 & 0 \\
L & RT & 4 & 0 \\
L & 212 & 10 & 10 \\
L & 300 & 13 & 45 \\
& & & 0 \\
T & 32 & 2 & 0 \\
T & RT & 2 & 0 \\
T & RT & 2 & 5 \\
T & 212 & 3.5 & 45 \\
T & 300 & 6.5 & 0 \\
& & & 0 \\
ST & 32 & 3.5 & 25 \\
ST & RT & 3 & 95 \\
ST & RT & 4 & 7 \\
ST & 212 & 12 & \\
ST & 300 & & \\
\hline
\end{tabular}


TABLE 7. CHARPY IMPACT TEST RESULTS FOR CATEGORY 3 RAILS (LOW GROWTH RATE)

\begin{tabular}{|c|c|c|c|}
\hline $\begin{array}{c}\text { Specimen } \\
\text { Orientation }\end{array}$ & $\begin{array}{c}\text { Temperature, } \\
\text { F }\end{array}$ & $\begin{array}{c}\text { Energy, } \\
\mathrm{ft} / \mathrm{lb}\end{array}$ & $\begin{array}{c}\text { Shear Area, } \\
\text { percent }\end{array}$ \\
\hline $\mathrm{L}$ & 32 & 3 & 0 \\
\hline L & RI & 4 & 0 \\
\hline L & R'I $^{\prime}$ & 5.5 & 0 \\
\hline $\mathrm{L}$ & 212 & 11 & 45 \\
\hline $\mathrm{L}$ & 300 & 14 & 70 \\
\hline$T$ & 32 & 3 & 0 \\
\hline $\mathrm{T}$ & $\mathrm{RT}$ & 2 & 0 \\
\hline $\mathrm{T}$ & $\mathrm{R}^{\prime} \mathrm{T}$ & 2 & 0 \\
\hline $\mathrm{T}$ & 212 & 4.5 & 0 \\
\hline $\mathrm{T}$ & 300 & 10.5 & 65 \\
\hline ST & 32 & 2 & 0 \\
\hline ST & $\mathrm{RT}$ & 3 & 0 \\
\hline $\mathrm{ST}$ & $\mathrm{RT}$ & 3 & 0 \\
\hline ST & 212 & 5.5 & 15 \\
\hline ST & 300 & 13 & 95 \\
\hline
\end{tabular}




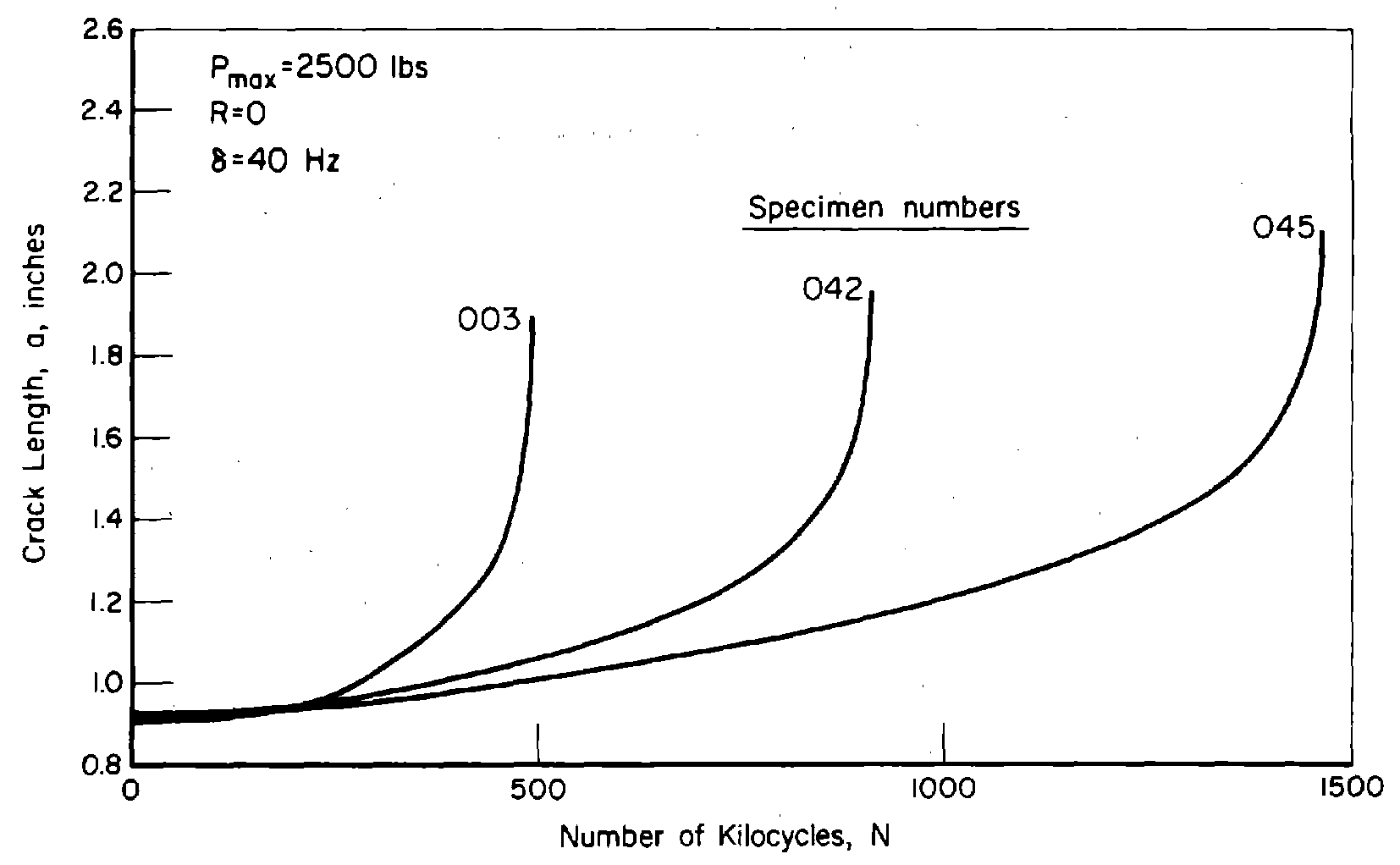

FIGURE 19. TYPICAL FATIGUE CRACK PROPAGATION CURVES 


\section{I ANALYSIS OF RATE DATA}

The rate of fatigue-crack propagation can be expressed as a function of the stress-intensity factor $K$. The stress-intensity factor (unit ksi/in.) is a measure for the stress singularity at the crack tip. If two cracks in the same material but under entirely different circumstances are subjected to the same stress intensity, their behavior will be the same. For the CT specimen used in this investigation, the stress intensity can be given as

$$
K=\frac{P}{2 B W^{2} / 2}(1+a / W)(1-a / W)^{-3 / 2}\left[7.000-7.050(a / W)+4.275(a / W)^{2}\right] \text {. }
$$

in which $P$ is the load on the specimen, $B$ is the specimen thickness, $W$ is the specimen width, and a is the crack size.

The rate of crack growth is related to $k$ through

$$
\frac{\mathrm{da}}{\mathrm{dN}}=\mathrm{f}(\Delta K, \mathrm{R})
$$

where $\mathrm{N}$ is the cycle number, $\mathrm{R}$ is the ratio between minimum and maximum load in a cycle, and $\Delta K$ is the range through which $K$ varies during the cycle. Thus, $\Delta K$ is found by substituting the load range $\Delta P$ into Equation (1). In the present tests, the load varied between $O$ and 2500 pounds so that $\Delta P=2500$ pounds and $R=0$.

Over a wide range of growth rates in steels and for fixed $R$, Equation (2) can be approximated by

$$
\frac{\mathrm{d} a}{\mathrm{dN}}=\mathrm{C}(\Delta \mathrm{K})^{\mathrm{n}}
$$

where $C$ and $n$ are constants for a given material. Hence, the various rail steels can be compared on the basis of their $C$ and $n$ values.

Equation (3) implies that a plot of da/dN versus $\triangle K$ on double-log paper is a straight 1ine. In reality there will be an upswing in the rate of crack growth towards the end of the test, because the failure conditions are being appraached. This is reflected in the following equation:

$$
\frac{\mathrm{da}}{\mathrm{dN}}=c \frac{(\Delta K)^{n}}{(1-R) K_{I c}-\Delta K}
$$

Not only does this equation take into account the effect of the stress ratio $R$, it also shows that the crack-growth rate becomes infinite if the stress intensity 
at maximum load becomes equal to $\mathrm{K}_{\mathrm{Ic}}$. The quantity $\mathrm{K}_{\mathrm{Ic}}$ is the fracture toughness of the material, which is the value of $\mathrm{K}$ at which fracture occurs. For the special case of $R=0$, the equation reduces to

$$
\frac{\mathrm{da}}{\mathrm{dN}}=C \frac{\Delta \mathrm{K}^{\mathrm{n}}}{\mathrm{K}_{\mathrm{Ic}}-\Delta \mathrm{K}}
$$

Both Equations (3) and (5) were evaluated for their applicability to the present data base. For this purpose, da/dN was calculated from the measured crack-growth data through the weighted average incremental slope approximation,

$$
\frac{\mathrm{da}}{\mathrm{dN}} \approx\left(\frac{\Delta \mathrm{a}}{\Delta \mathrm{N}}\right)_{i}+\frac{\Delta \mathrm{N}_{i}}{\left(\mathrm{~N}_{i+1}-\mathrm{N}_{i-1}\right)}{ }_{i}^{-}\left(\frac{\Delta \mathrm{a}}{\Delta \mathrm{N}}\right)_{i+1}-\left(\frac{\Delta \mathrm{a}}{\Delta \mathrm{N}}\right)_{i}:
$$

The results were plotted as a function of $\Delta \mathrm{K}$ as determined by Equation (1). Subsequently, curves were fitted through the data to give values for $C$ and $n$. A special computer program was used to find the best fit.

Examples of the resulting plots of da/dN versus $\Delta \mathrm{K}$ are given in Figure 20. An example of a computer printout giving the basic crack-growth data, crackgrowth rate, and the stress-intensity factor, is shown in Table 8 . The variability of crack-growth rates in the 66 samples can be appreciated from Figure 20 . The heat-treated rall appeared to have the lowest crack-growth rates. It did fall to the right of the scatter band containing all other samples. All the curve fitting data, in terms of $\mathrm{C}, \mathrm{n}$, and the correlation parameter, $\mathrm{R}^{2}$, are presented in Table 9 . The correlation parameter is generally close to unity which is an indication of the goodness of the fits. These results have been derived from the basic crack-growth data 1 isted In Appendix A.

Also presented in this table are the apparent toughness, defined as the stress-intensity factor, determined by Expression (1), for the last recorded crack measurement, and a life parameter,

$$
\mathrm{N}_{\mathrm{L}}=\mathrm{L}^{r}\left(\frac{\mathrm{n}}{2}-1\right) \cdot(\mathrm{da} / \mathrm{dN} ; \Delta \mathrm{K}=20]^{-1},
$$

which is a coupled function of $C$ and $n$ used to rank the growth rates.

Very few crack-growth data for rail. steels have been reported in the 1iterature. The data reported in References 1 and $2 *$ are useful for a comparison with the present results. The British rail steel tested contained 0.56 percent $C$, 1.02 percent $\mathrm{Mn}, 0.13$ percent $\mathrm{Si}$, and less than 0.05 of $\mathrm{P}$ and $\mathrm{S}$ each. The steel had a 0.1 percent yield strength of $67 \mathrm{ksi}$ and an ultimate tensile strength of 121 ks1. Test results for center cracked panels showed a value of 4 for the exponent $\mathrm{n}$ in Equation (3) for the case of $\mathrm{R}=0$ (Reference 1). Experiments at varlous $\mathrm{R}$ -

* References are listed on page 70. 


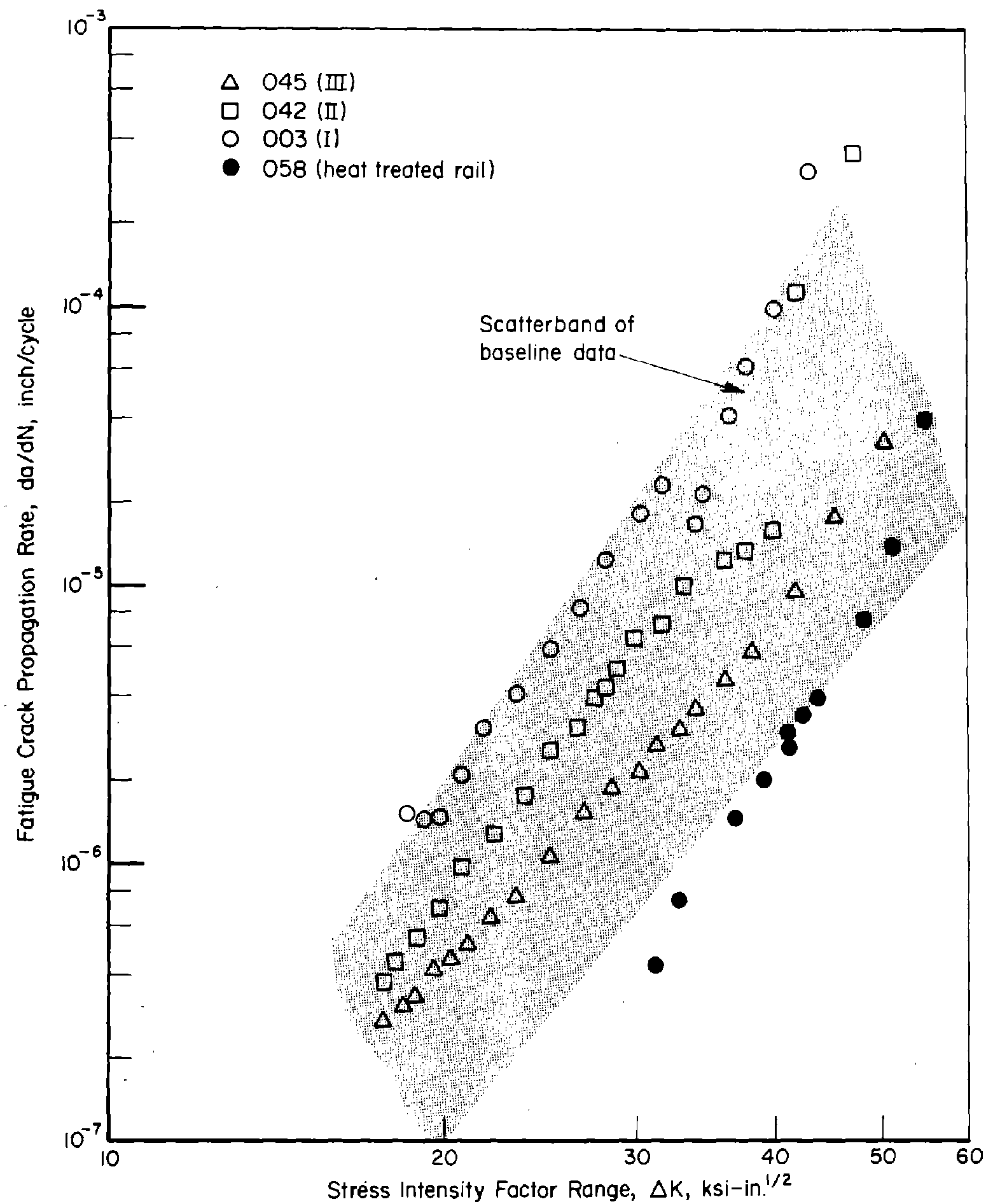

FIGURE 20. VARIABILITY OF FATIGUE CRACK PROPAGATION RATE BEHAVIOR 
TABIE 8. SAMPLE OF COMPUTER PRINTOUT OF BASIC DATA ALONG WITH FIRST STAGE OF RATE ANALYSIS

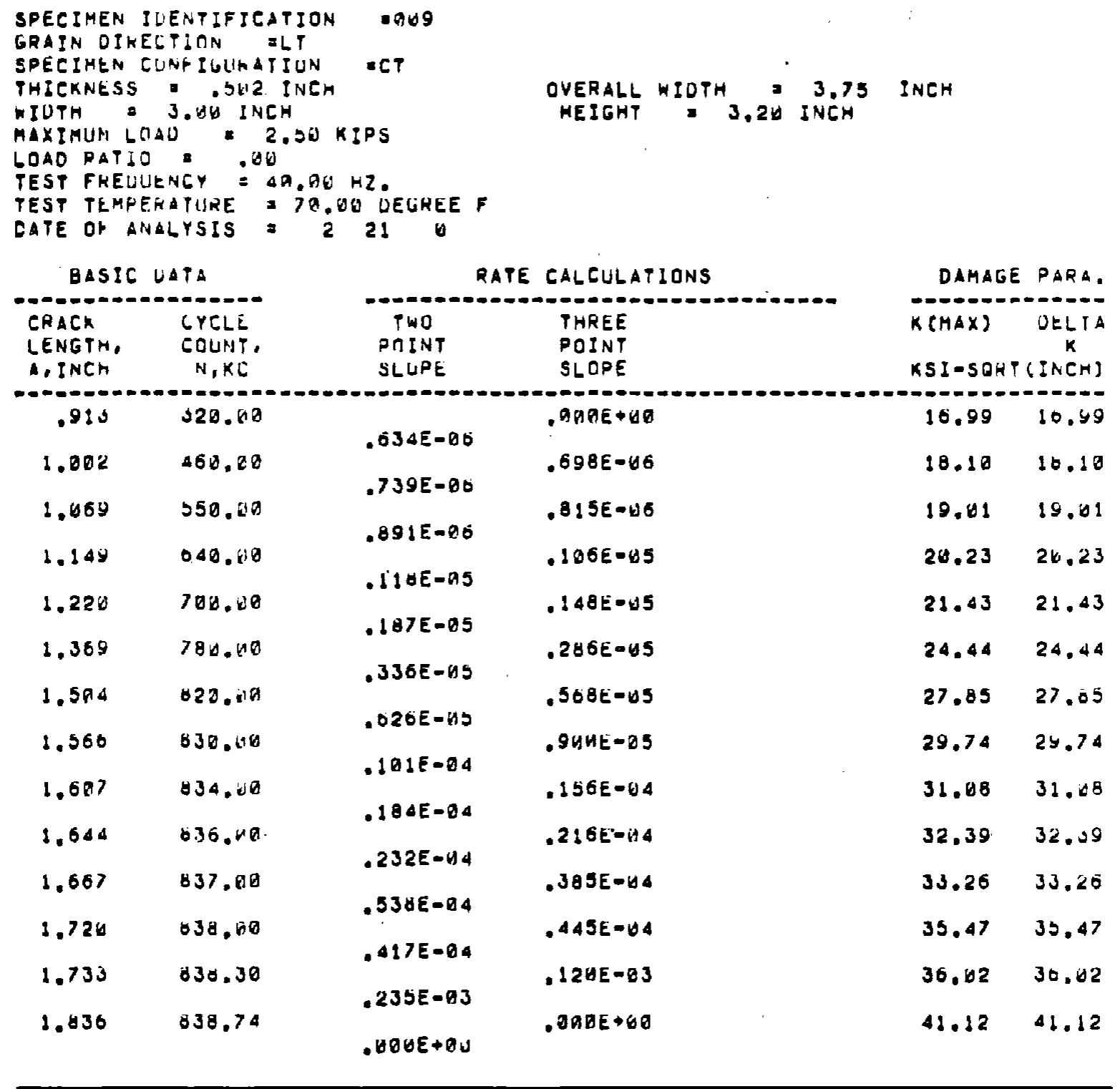




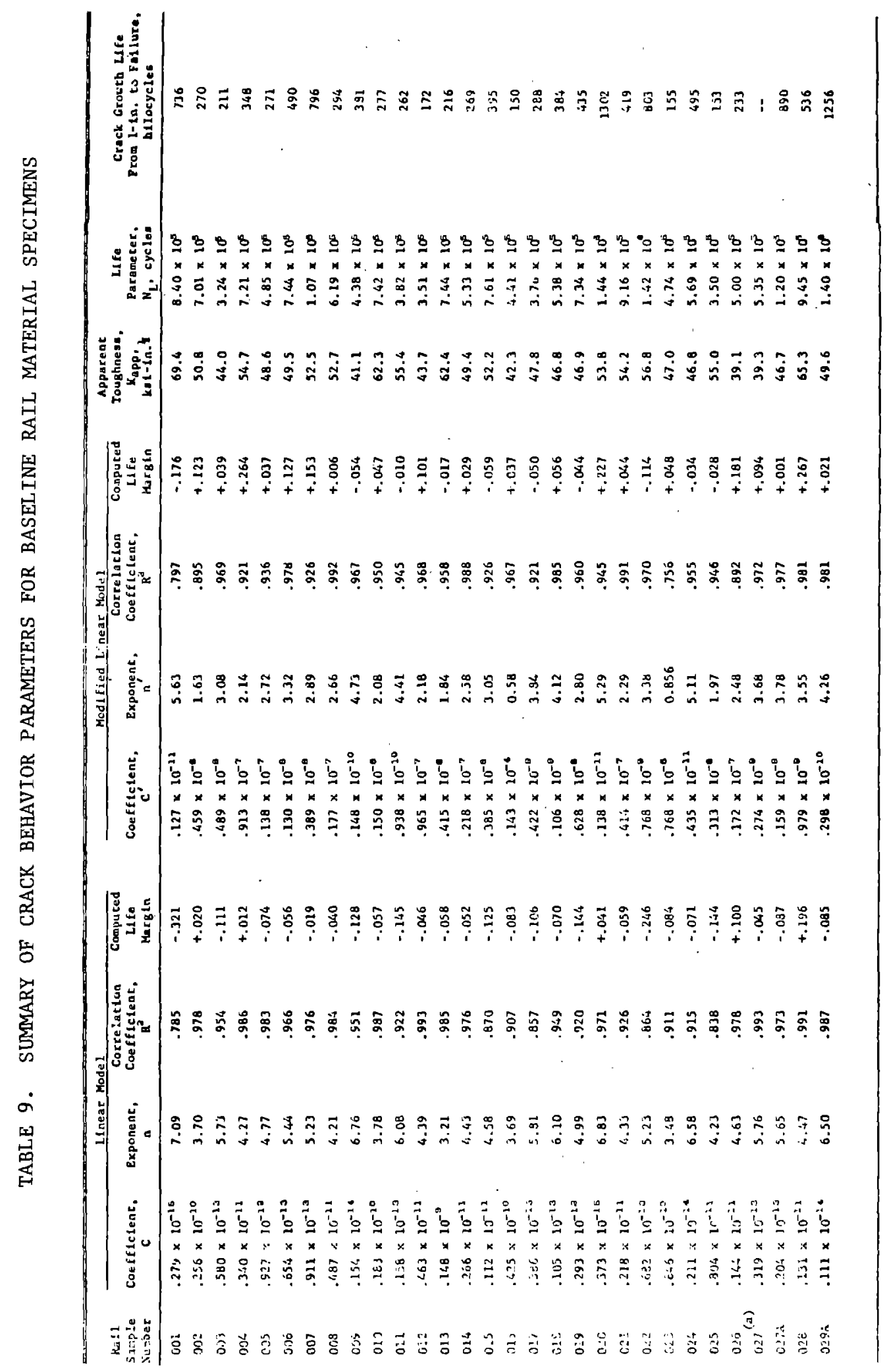




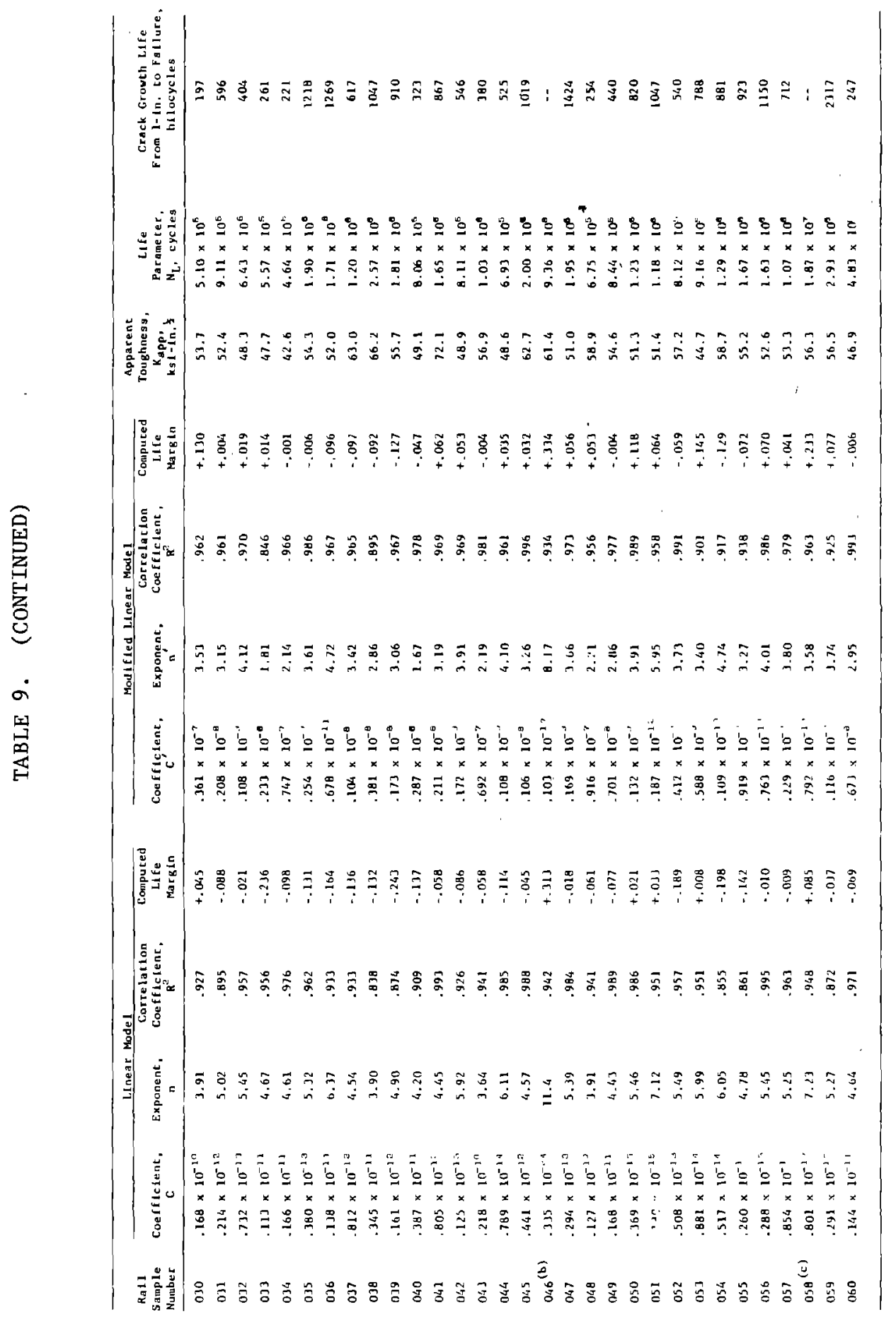



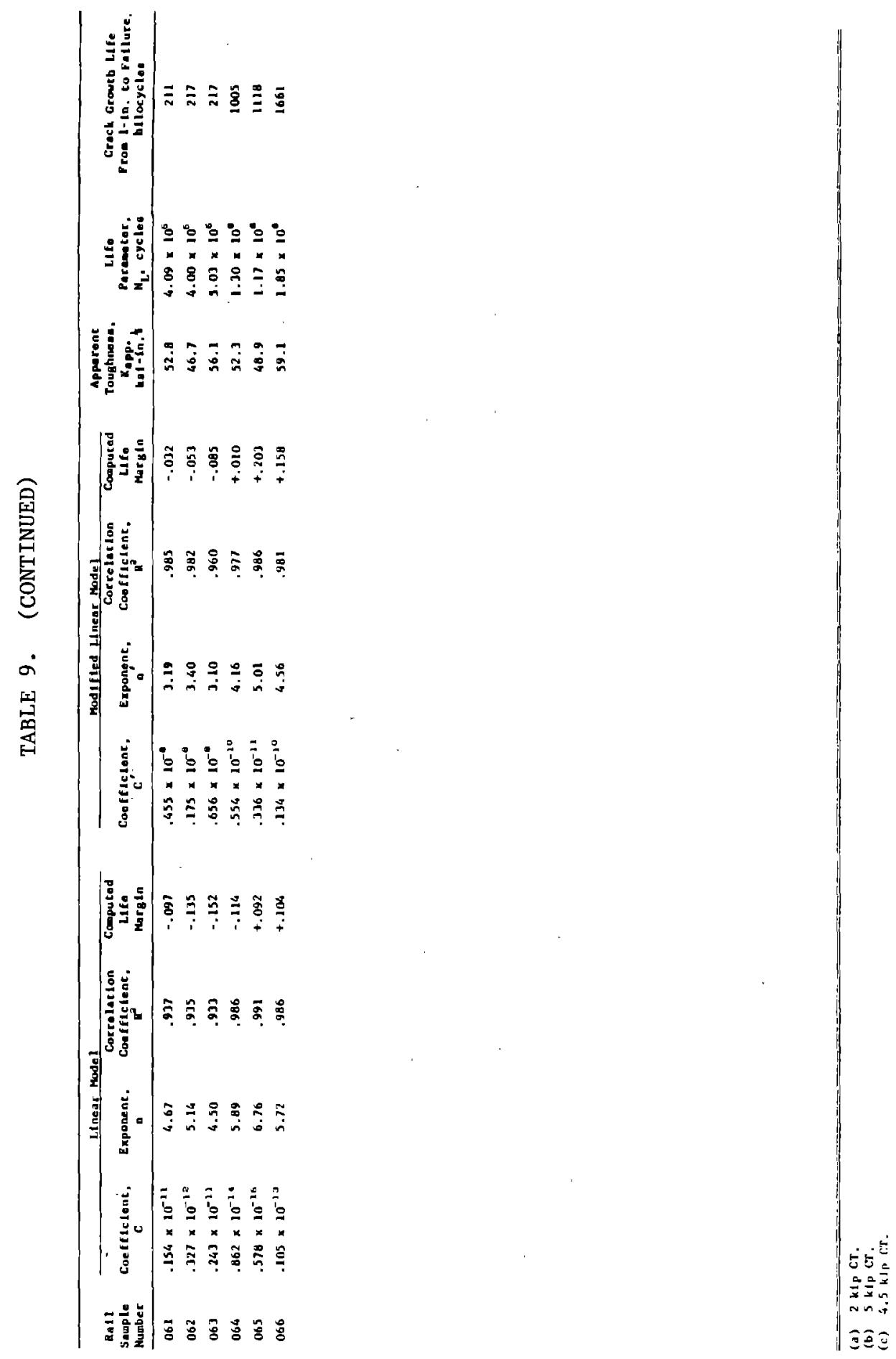
ratios indlcated that $\mathrm{n}=2.69$ in Equation: (4) gave the best fit. It appears that the material compares with the materials showing the lower growth rates in the present investigation.

\subsection{SYNTHESIS OF CRACK-GRONTH DATA}

As validation of the rate analysis, the crack-growth curves were reconstructed by integrating the rate data according to both the linear (Equation (3)) and the modifled-linear (Equation (5)) fatigue-crack-propagation models. In simple terms the integration can be expressed as

$$
\begin{aligned}
a & =\int \frac{d a}{d N} d N \\
N & =\int \frac{d a^{-1}}{d N} d a
\end{aligned}
$$

Since the crack-growth model cannot generally be integrated in closed form, the solution of the above expressions is accomplished by a numerical integration or summation procedure wherein the computational steps must be defined in detail. Basic sources of error include experimental error, material anomalies, and simplicity of the model.

An Incremental definition of Equation (8) can be expressed as

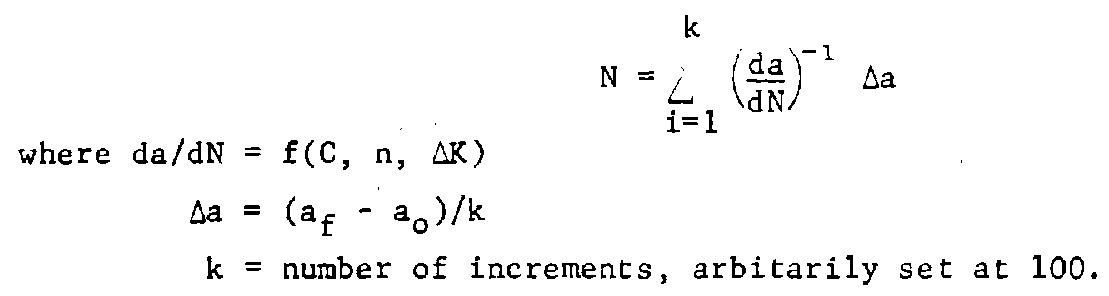

Two alternative schemes of crack-growth prediction are being adopted In the basic data analysis computer program. One scheme predicts the number of cycles to grow the crack from a precrack length, $a_{0}$, to a $f$ inal crack length, $a_{f}$; the other predicts the final crack length, $a_{f}$, which results from cycling the precrack, $a_{o}, N_{f}$ times. If the analysis as well as the data models provided a perfect correlation, the results would, of course, agree perfectly with the experiment. In reality, however, perfect correlation will not be achieved due to experimental error, material variation and mere oversimplicity (i.e., inadequacy) of the analysis. The contrast in the results of the two computational schemes will provide further insight to the source and degree of errors.

The measure of the effectiveness of these two schemes of analysis is expressed in the "cyclic life margin of safety". which is expressed as

$$
\text { M.S. } \text { life }=\frac{\mathrm{N}_{\text {actual }}}{\mathrm{N}_{\text {computed }}}-1
$$


and In the cyclic crack growth margin, which is expressed as

$$
\text { M.S. }{ }_{a}=\frac{{ }^{a} \text { actual }}{{ }^{a} \text { computed }}-1 \text {. }
$$

Posttive values of either of these margins infer that the computed value is less than the actual and, hence, conservative. The degree of conservatism $(+)$ or unconservatism (-) is reflected in the variation of margin from unity (1.0). (Note at the present time, only the life margin, Expression (10), has been tabulated in Table 9.)

\section{Synthesis Results}

The preceding crack-growth-synthesis procedure was applied to the 66 baseline data sets to obtain a set of life margins which in turn were analyzed statistically. These results are presented in Table 10 .

TABLE 10. RESULTS OF CRACK-GROWTH SYNTHESIS

\begin{tabular}{|c|c|c|c|c|c|}
\hline \multirow[b]{2}{*}{ Mode 1} & \multirow{2}{*}{$\begin{array}{l}\text { Predicted } \\
\text { Mean Life }\end{array}$} & \multicolumn{4}{|c|}{ Predicted Life Margin Statistics } \\
\hline & & Mean & Life Margin & Variance & Standard Deviation \\
\hline Linear & 0.936 & & -0.064 & 0.010 & 0.100 \\
\hline $\begin{array}{l}\text { Modified Linear } \\
\text { (Forman) }\end{array}$ & 1.035 & & +0.035 & 0.011 & 0.104 \\
\hline
\end{tabular}

From these results, several interesting observations can be made. First, it appears that the linear model tends to be unconservative in that it predicts, on the average, a larger crack lifetime than was encountered in the test. This is evidenced by the negative value of the mean life margin. In contrast, the modified linear model provides a conservative estimate of life and for that reason may be a more preferable model to use. Second, since the variance and standard deviation are nearly equivalent for each model, it is judged that lifetime scatter about the mean is not particularly affected by the model.

\section{3 CORRELATION OF RATE DATA WITH OTHER PROPERTIES}

\subsubsection{General Approach}

One of the basic objectives of this research program is to discern whether the crack behavior of rail materials can be linked to more fundamental mechanical, metallurgical, and processing variables. As a result, a key activity in data analysis is the broad scale assessment and evaluation of rate data with respect to other material properties. The following sections describe the initial efforts which have been undertaken and the results which have been ascertained to date. 
The detection and isolation of primary variables affecting crack behavior would be a straightforward procedure if all of the variables were truly independent. In reality, however, most of the mechanical, metallurgical, and processing variables are not mutually independent and interact in a very complex manner. As a result, the discrimination of the dominant factors and the determination of their order of precedence requires a deliberate search and involves considerable trial-and-error data scanning.

For the baseline fatigue-crack-propagation specimens of this program, a broad matrix of data was assembled. This consisted of the background, mechanical property, metallurgical and derived crack-behavior variables determined for each material sample. These were extensively examined by computerized analysis as well as by more intuitive technical review (i.e., engineering judgments). While some general trends were discerned, more in-depth probing, analysis, and data generation will be necessary to strength and more positively identify the trends. It appears that the broad scatter of the data will require more diligent screening and examination of individual tests. The following discussion of procedures and results presents the current status of this effort.

\subsubsection{Automatic Interaction Detector (AID) Analysis}

The AID computer program is a statistical tool for assessing the relative influence of a set of independent variables (termed predictors) on the behavior of a specified dependent variable. The correlation (or lack thereof) between the dependent variable and any given predictor is established by decomposing the total variance of the dependent variable (fixed for a given body of data) into a within-subset and a between-subset variance of successive splits (1.e., two-part divisions) of the set of values of the dependent variable. For each predictor, the set of values of the dependent variable are ordered by either the order of the predictor (if a monotonic predictor) or the order of the dependent variable (if a free predictor). The set of values of the dependent variable is then divided (or split) successively into two subsets along the domain of the predictor. At each split, the within-subset variance and between-subset variance is computed. The split which produces the largest ratio of between-subset variance to within-subset variance (i.e., F ratio or signal-to-noise ratio) is considered the optimum split for that predictor. The predictor which exhibits the largest ratio of between-subsets variance to total variance is the dominant or primary predictor for the dependent variable. 
The computational scheme is semiquantitative in that the independent variables are linearly scaled and coded to integral values from 0 to 63 . However, since known correlations do not exist, a method that compares data on such a normalized basts can provide a clearer discrimination of the dominance (if such (xists) of the primary independent variables.

Once the optimum split of the primary variable has been defined, the procedure is repeated for the two groups at each side of the split and so on. The resulting cascade of splits which is generated in this repetitive procedure can be graphically displayed in the AID "tree", a sample of which is shown in Figure 21. only the salient features of the analysis are included in this pictorial summary.

In this particular illustration, the influence of a range of compositional variables--the carbon equivalents (CE), later discussed--on the logarithm of crack life (the dependent variable or criterion scale) is evaluated. The body of data consisted of 57 specimens (selectively called from a total data set of 67 specimens). The primary variable, CEl, revealed an optimum split into two groups of 37 and 20 at a life value of 5.90. These two resulting groups subsequently split on predictors CE4 and CE6. The mean and standard deviation values are given along with the coded predictor values. Subsequent splits and their related numerical detalls are also given. Note that the dependent variable is noted as the common logarithm of the life parameter.

At the outset of this task, the widest variety of independent varlables was chosen and put into the AID "hopper" to see what would be sorted out. These variables included

- $\left.\begin{array}{l}\text { Rail weight } \\ \text { - Year produced }\end{array}\right\}$ Background

- Tensile ultimate strength

- Tensile yield strength

- Elongation

- Reduction of area

- Elastic modulus

- Hardness

- Carbon

- Manganese

- Sillcon

- Sulfur Metallurgical

- Oxygen

- Hydrogen

- Pear1ite.

These were then related to the life parameter, $N_{I}$, as a dependent variable. 


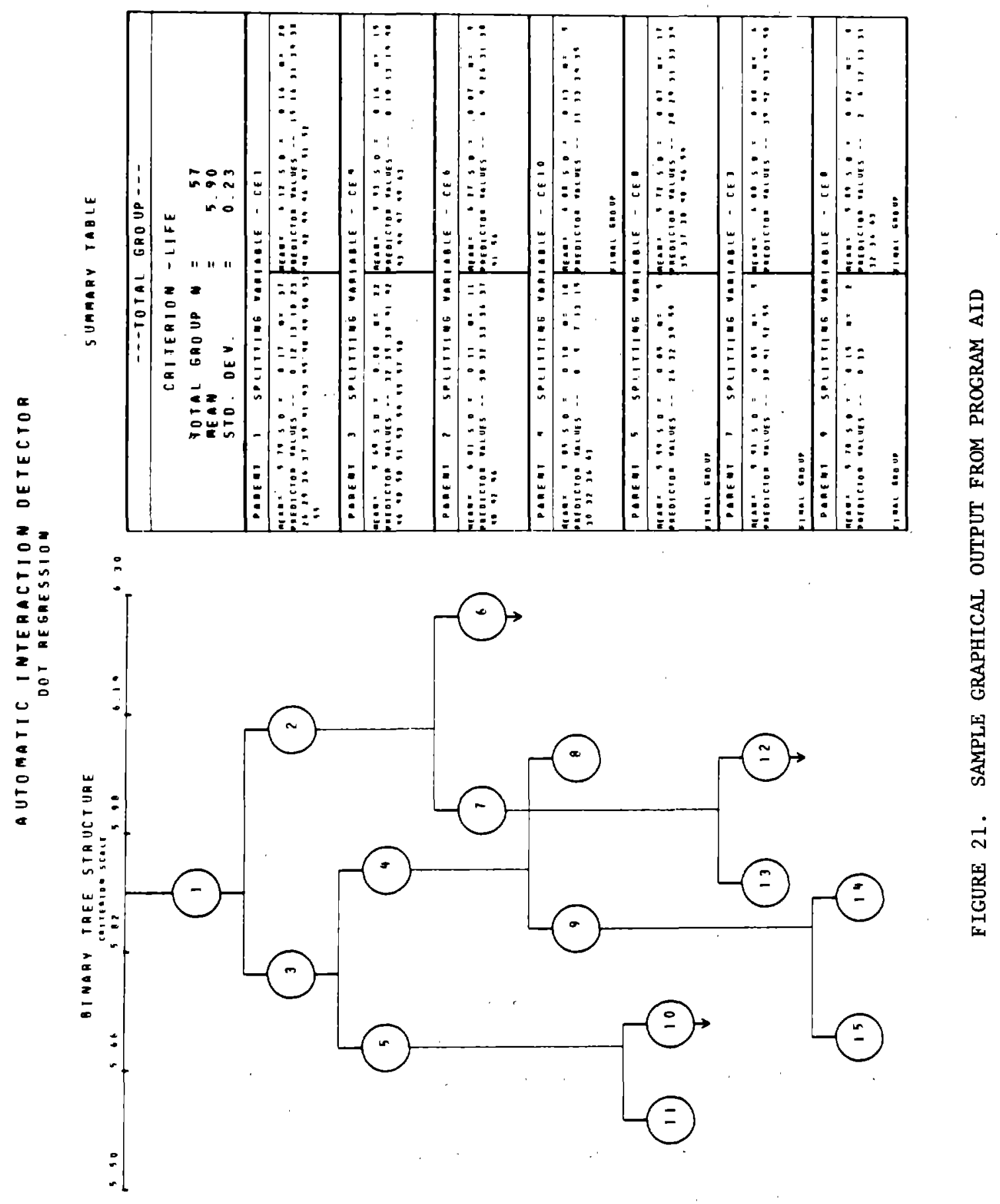




\subsubsection{Process of Analysis}

The AID analysis proceeded through several stages. It became obvious at the outset that the variables were not mutually independent. An interspersion of varlous metallurgical and mechanical variables became apparent when all the variables were considered. This inferred that the mechanical property variables were, in essence, a restatement of the compositional variables (or vice-versa)--a not too surprising result. This led to selective regrouping and fitting of the variables to discern those that were most dominant.

\subsubsection{Results of Analysis}

The dominance of a particular independent variable may be expressed as the percentage contribution of its BSS to the TSS of the dependent variable. The results of the AID analysis of independent variables for leading contenders can be summarized as follows:

\begin{tabular}{|c|c|c|}
\hline Category & Variable & $\begin{array}{c}\text { Contribution } \\
\text { to Variance, } \\
\text { percent }\end{array}$ \\
\hline \multirow{2}{*}{ Mechanical Property } & Tensile U1timate Strength & 13 \\
\hline & Hardness & 14 \\
\hline \multirow{5}{*}{ Metallurgical } & $\%$ Pearlite & 19 \\
\hline & $\%$ Carbon & 8 \\
\hline & $\%$ Oxygen & 8 \\
\hline & $\%$ Sulfur & 5 \\
\hline & $\%$ Manganese & 4. \\
\hline
\end{tabular}

For the mechanical property category, the nearly equivalent dominance of strength and hardness is not surprising because of their well-documented interrelationship. However, the statistical impact is lessened when one then views the graphical relationship of strength and life as shown in Figure 22(a).

A similar disillusionment is encountered when one observes the display of percent pearlite versus life in Figure $22(\mathrm{~b})$. The latter part of the above tabulation suggested the consideration of a carbon equivalent (CE) which was expressed as

$$
\% \mathrm{CE}=\% \mathrm{C}+\alpha[\% \mathrm{Mn}-1.7(\% \mathrm{~S})] \quad .
$$

The factor 1.7 is the ratio between the atomic weights of $\mathrm{Mn}$ and $\mathrm{S}$. As a result, the term between brackets is the percentage of free Mn, i.e., total Mn minus the fraction tied up in the compound MnS. The free Mn is in solid solution where it 


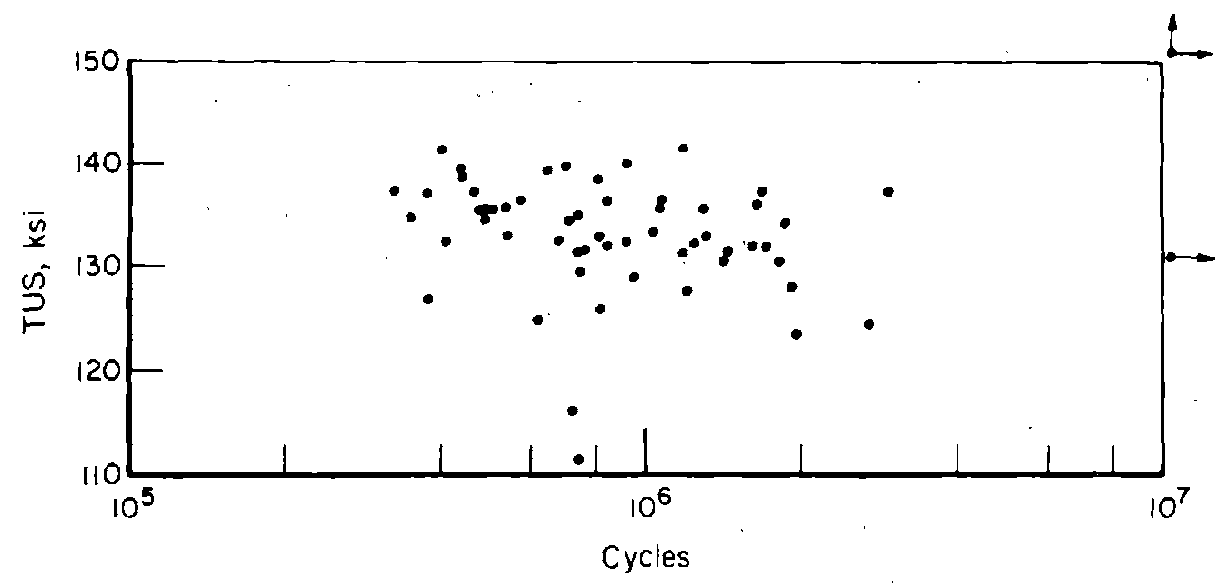

(a) Effect of Tensile Ultimate Strength

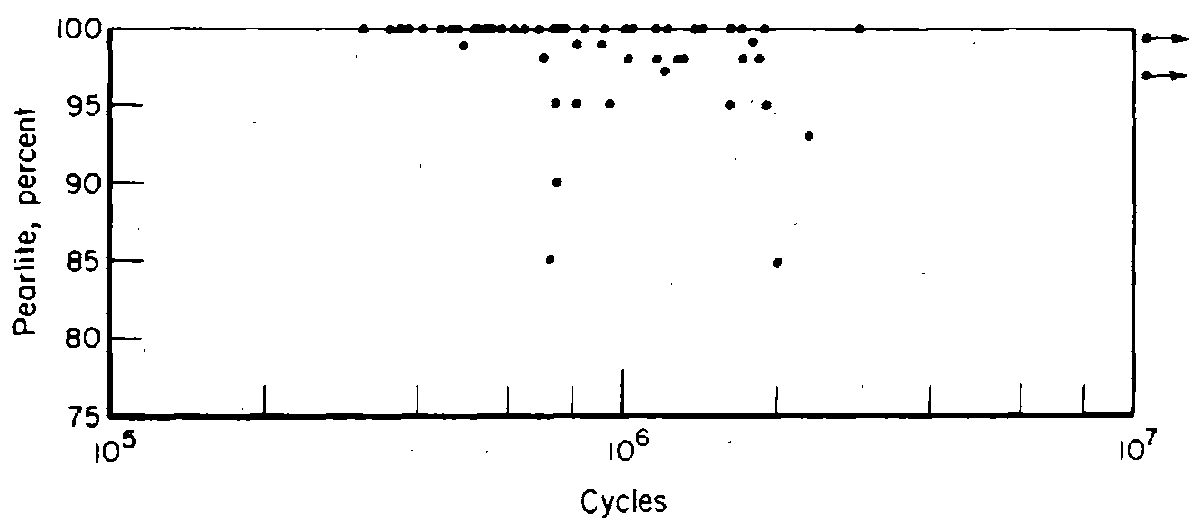

(b) Effect of Pearlite

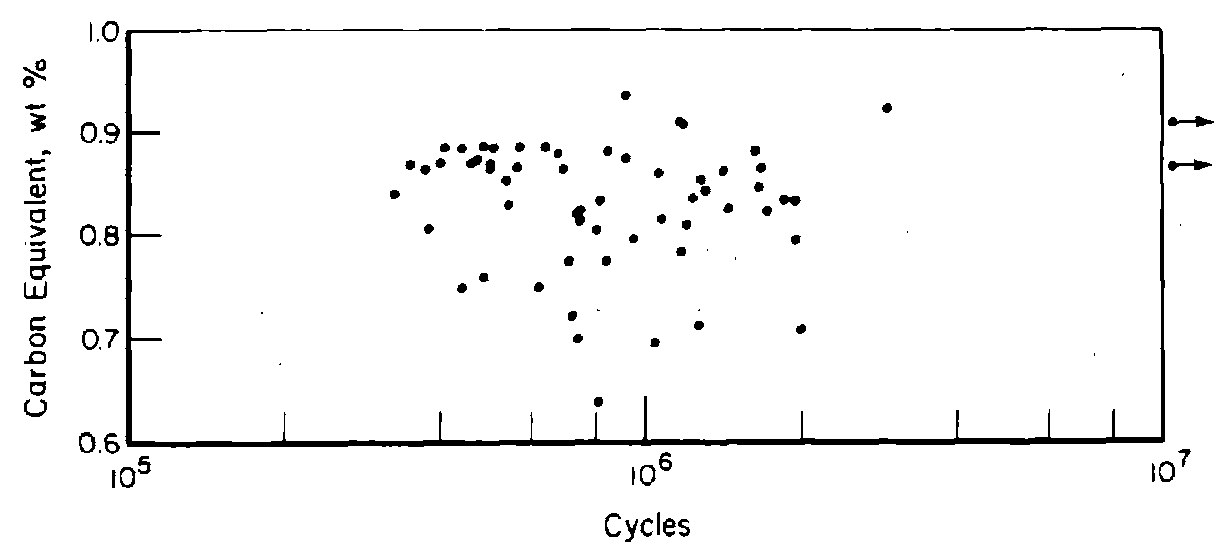

(c) Effect of Carbon Equivalent

FIGURE 22. VARIATION OF LIFE WITH LEADING PREDICTORS 
has a similar, but less effective, strengthening effect as Carbon. This is reflected by the factor $\alpha$. An AID analysis for incremental values of $\alpha$ was conducted from which a value of $\alpha=0.1$ was obtained as providing a 21 percent contribution to variances. Again, however, the statistical analysis was poorly supported with the "shotgun" pattern of Figure $22(\mathrm{c})$.

\subsubsection{Correlation Analysis}

The contrast between the statistical AID analysis and the weak evidence of the graphical displays suggests that any numerical correlation is a coincidence of "noise" in the data. At the same time, however, the complexity of a carbon or other equivalent as suggested by other investigators (3) requires that other microstructural detalls be included. In Reference (3), correlation functions were derived between the TUS, TYS, and $20 \mathrm{ft}-1 \mathrm{~b}$ Charpy impact temperature for ferritepearlite steels. The functions are complex equations containing the percentage of the varlous chemical constituents, volume fraction of pearlite, interlamellar spacing and cementite plate thickness. At the present time, a positive conclusion is not tendered. The analysis will be advanced as additional metallurgical detalls are generated. However, the complex correlation functions as derived in Reference (3) suggest that any correlation function may be very artificial. Consequently, the generality of such functions is doubtfuI.

\section{CATEGORIES FOR FURTHER RESEARCH}

\subsection{SELECTION OF CATEGORIES}

The present test data provide the baseline information for the computational failure model to be developed during the second phase of this research program. However, for a complete failure model, more information is needed concerning crack growth under various circumstances. The effect of the following parameters will have to be evaluated:

(a) Stress ratio, $\mathrm{R}$

(b) Cycling frequency, F

(c) Temperature, $\mathrm{T}$

(d) Specimen orientation.

In addition, the behavior of elliptical flaws and the behavior under mixed-mode loading and variable-amplitude loading should be studied. 
It is prohibitive to perform all this experimentation on all 66 rail materials. Therefore, it is necessary to make a selection of a few materials to be studied In more detail, under the assumption that the results obtained can be generalized relattve to the baseline behavior as observed in the present tests. Although various possibilities exist to select the materials, the most obvious criterion for selection is the rate of crack growth, because the differences in crack-growth rates were so large.

Therefore, three categories were selected for further characterization, consisting of materials with high (I), medium (II), and low (III) growth rates, respectively. The basis for categorization was the crack propagation life from a l-inch crack size to failure. This reflects the combined effects of $n, C$, and $K_{a p p}$ in a natural way. As a practical concern, the length of the sample available for specimen manufacture was also a consideration.

The materials sejected for Category I have crack growth Iives (from 1 inch to failure) varying from 150 to 270 kilocycles. In Category II the lives vary from 380-600 kilocycles, and in Category III the lives are 700 kilocycles and higher. An appreciation of the crack growth behavior of the materials in the three categories can be obtained from Figure 20. Specimen 3 in Figure 20 had a life of 211 kllocycles which is typical for Category I. The life of Spectmen 42 was 546 kilocycles, typical for Category II, and the life of Specimen 45 was 1,018 kilocycles, which is typical for Category III.

The samples selected for each category are listed in Table 11. Subsequent testing will be done primarily on those materials. A more detailed metallographic and fractographic characterization of these materials will be required. This effort is already under way and some preliminary results are presented in the following sections.

Some additional samples will be used for more detailed characterization and testing. These samples will be selected on the basis of the AID analysis. The criteria for selection will be discussed in Section 7.4. A test matrix and experimental plan for the second phase of this program is presented in Section 7.5 . 
TABLE 11. THE TIIREE CATWGOKIES FOR PHASE IT

\begin{tabular}{|c|c|c|c|c|}
\hline Category & $\begin{array}{l}\text { Rail Sample } \\
\text { Number }\end{array}$ & C & Mn & $\begin{array}{c}\text { Crack Growth Life } \\
\text { From } 1 \text { Inch to Failure, } \\
\text { kilocycles }\end{array}$ \\
\hline \multirow[t]{7}{*}{ I } & 002 & .74 & .61 & 270 \\
\hline & 013 & .74 & .89 & 216 \\
\hline & 014 & .78 & .74 & 269 \\
\hline & 016 & .81 & .93 & 150 \\
\hline & 023 & .79 & .92 & 155 \\
\hline & 025 & .80 & .91 & 153 \\
\hline & 030 & .80 & .90 & 197 \\
\hline \multirow[t]{7}{*}{ II } & 006 & .72 & .97 & 490 \\
\hline & 009 & .61 & 1.46 & 381 \\
\hline & 018 & .75 & .89 & 384 \\
\hline & 019 & .74 & .88 & 435 \\
\hline & 024 & .81 & .83 & 495 \\
\hline & 031 & .79 & .76 & 596 \\
\hline & 032 & .80 & .94 & 404 \\
\hline \multirow[t]{7}{*}{ III } & 001 & .63 & 1.48 & 736 \\
\hline & 007 & .73 & .93 & 796 \\
\hline & 020 & .75 & .83 & 1302 \\
\hline & 022 & .78 & .87 & 803 \\
\hline & 029 & .72 & .89 & 1256 \\
\hline & 035 & .76 & .80 & 1218 \\
\hline & 036 & .75 & .80 & 1269 \\
\hline
\end{tabular}




\subsection{MICROSTRUCTURAL ANALYSIS OF THREE CATEGORIES}

\subsubsection{Ra11 Samples Used}

From the three categories of rails established on the basis of crackgrowth rate, ftve rail samples were chosen for more detailed microstructural analyses. They were Samples 002 and 030 from Group I, Samples 006 and 024 from Group II, and Sample 001 from Group III. The selection of the two samples from Groups I and III was based primarily on major differences in their chemistry. Sample 001 was selected because of the presence of internal fissures. Sample 004, which was not categorized, was selected for further microstructural analysis, since its microstructure consisted of a relatively high percentage $(\sim 15 \%)$ of ferrite in a network morphology.

\subsubsection{Grain-Size Measurements}

Since standard metallographic preparation techniques do not reveal prior austenite grain boundaries in pearlitic steels, an attempt was made to heat treat the samples in such a way that the grain sizes could be measured. The heat treatment employed was a partial isothermal transformation at approximately $1100 \mathrm{~F}$, designed to develop a structure consisting of a network of fine pearlite nodules at austenite graln boundaries in a martensitic matrix. Partial isothermal transformation was successful using very small specimens, but the nucleation sites of pearlite nodules were too random to discern a grain-boundary network. Attempts to reveal prior austenite grains were made also using special etching reagents on quenched and tempered specimens of rail samples. The reagents used were (1) Vilella's reagent, an alcoholic solution of $1 \%$ picric - $5 \%$ hydrochloric acids, (2) a saturated aqueous solution of picric acid containing 1 gram of sodium trlolecyl benzene sulfonate per $100 \mathrm{ml}$ of solution, (3) a saturated aqueous solution of plcric acid containing $2 \mathrm{ml}$ of Teepol (sodium alkyl sulfonate) per $100 \mathrm{ml}$ of solution, and (4) a solution of 1 gram of potassium metabisulfite and 2 drops of Teepol in $100 \mathrm{ml}$ of water. None of these etchants revealed prior austenite grains satisfactorily for grain size measurements. Special etching techniques were also used on quenched and tempered specimens of rail samples in attempts to reveal the prior austenite grains, but these too were unsuccessful.

The prior austenite grains were revealed in Sample 004 by the ferrite network present in its microstructure. A similar network was present in the other five samples at the rail surfaces where decarburization occurred during hot 
rolling. The depth of decarburization was sufficient to produce a ferrite network zone below the surface. The width of the zone generally encompassed several prior iustentte grains. Therefore, grain-size determinations on the other five rails were made in the decarburized surface zones.

Grain sizes were determined by the line jatercept method. The number of grains at $100 \mathrm{X}$ magnification intersected by a test line $10 \mathrm{~cm}$ long was obtained three times on each specimen. The ASTM grain size, G, was calculated from Hill1ard's equation:

$$
G=10.00-6.64 \log \mathrm{L}_{3}
$$

where $\mathrm{L}_{\mathrm{a}}=\frac{\text { Total length of test lines }}{\text { Total no. intersections } x \text { magnification }}$

The results of prior austenite grain size measurements of the six rafl samples, and values computed from the grain-size measurements for average grain diameters and average number of grains per unit volume also are given in Table 12 .

TABLE 12. PRIOR AUSTENITE GRAIN-SIZE MEASUREMENTS

\begin{tabular}{|c|c|c|c|}
\hline $\begin{array}{l}\text { Rail Group } \\
\text { and/or } \\
\text { Sample No. }\end{array}$ & $\begin{array}{l}\text { ASTM Grain } \\
\text { Size No. }\end{array}$ & $\begin{array}{c}\text { Calculated } \\
\text { Diameter of } \\
\text { Average Grain, } \mathrm{mm}\end{array}$ & $\begin{array}{c}\text { Average No. } \\
\text { of Grains } \\
\text { per } \mathrm{mm}^{3}\end{array}$ \\
\hline \multicolumn{4}{|l|}{ Group I - } \\
\hline 002 & 4.3 & 0.081 & 1880 \\
\hline 030 & 4.7 & 0.071 & 2850 \\
\hline \multicolumn{4}{|l|}{ Group II - } \\
\hline 006 & 3.5 & 0.107 & 820 \\
\hline 024 & 4.9 & 0.066 & 3500 \\
\hline \multicolumn{4}{|l|}{ Group III - } \\
\hline 001 & 4.4 & 0.078 & 2100 \\
\hline 004 & 3.2 & 0.12 & 600 \\
\hline
\end{tabular}

\subsubsection{Pearlite Interlamellar Spacing}

True interlamellar spacing, $S_{0}$, is the perpendicular distanse between the planes of a single pair of contiguous lamellae. Because true spacing is difficult to measure directly on metallographically prepared cross sections, the mean random spacing, $\sigma$, of the pearlite lamellae observed in the six samples was measured. The mean random spacing is defined as the reciprocal of $N_{L}$, where $N_{L}$ is 
the number of alternate lamellae intersected per unit length of random test lines. True spacing was then calculated using $\mathrm{S}_{0}=\frac{\sigma}{2}$, the validity of which has been confirmed experimentally.

The mean random spacing of pearlite lamellae was measured on scanning electron microscope (SEM) micrographs of the pearlite structures photographed at 5000x. No unresolved pearlite lamellae were observed at this magnification. Examples of the pearlite, as revealed by the SEM micrographs, are shown in Figure 23.

Thirteen random fields on each specimen were photographed using the SEM. Intercept measurements were made along six different test lines on each micrograph. Each test line was $10 \mathrm{~cm}$ long. Thus, a total of 78 (6 x 13) test-line measurements were made on each rail sample. A statistical analysis of the data for each sample indicated the accuracy of the interlammelar spacings obtained to be \pm 10 to 14 percent.

The results of interlamellar spacing measurements are presented in Table 13 .

TABLE 13. PEARLITE INTERLAMELLAR SPACING

\begin{tabular}{|c|c|c|c|}
\hline $\begin{array}{l}\text { Rail Group } \\
\text { and/or } \\
\text { Sample No. }\end{array}$ & $\begin{array}{l}\text { Number of } \\
\text { Intersections } \\
\text { per mm, } \mathrm{N}_{\mathrm{L}}\end{array}$ & $\begin{array}{c}\text { True Spacing, } \\
\mathrm{S}_{\mathrm{o}}, \AA\end{array}$ & $\begin{array}{l}\text { Accuracy, } \\
\pm \text { percent }\end{array}$ \\
\hline $\begin{array}{c}\text { Group I - } \\
002 \\
030\end{array}$ & $\begin{array}{l}1705 \\
1385.5\end{array}$ & $\begin{array}{l}2932 \\
3608\end{array}$ & $\begin{array}{l}10.2 \\
10.6\end{array}$ \\
\hline $\begin{array}{c}\text { Group I I - } \\
006 \\
024\end{array}$ & $\begin{array}{l}1861.5 \\
1464.5\end{array}$ & $\begin{array}{l}2686 \\
3414\end{array}$ & $\begin{array}{l}10.9 \\
13.8\end{array}$ \\
\hline$\underset{001}{\text { Group }}$ III - & 2025 & 2470 & 10.4 \\
\hline 004 & 1202 & 4159 & 12.2 \\
\hline
\end{tabular}

\subsubsection{Other Microstructural Parameters}

Determinations of the pearlite colony size and characterizations of the nonmetallic inclusions in the six rail samples are planned but, as yet, have not been made. Visual estimates of the volume fraction of free ferrite in the samples are reported elsewhere. More precise determinations of volume fractions of ferrite using established quantitative metallographic techniques also are planned. 


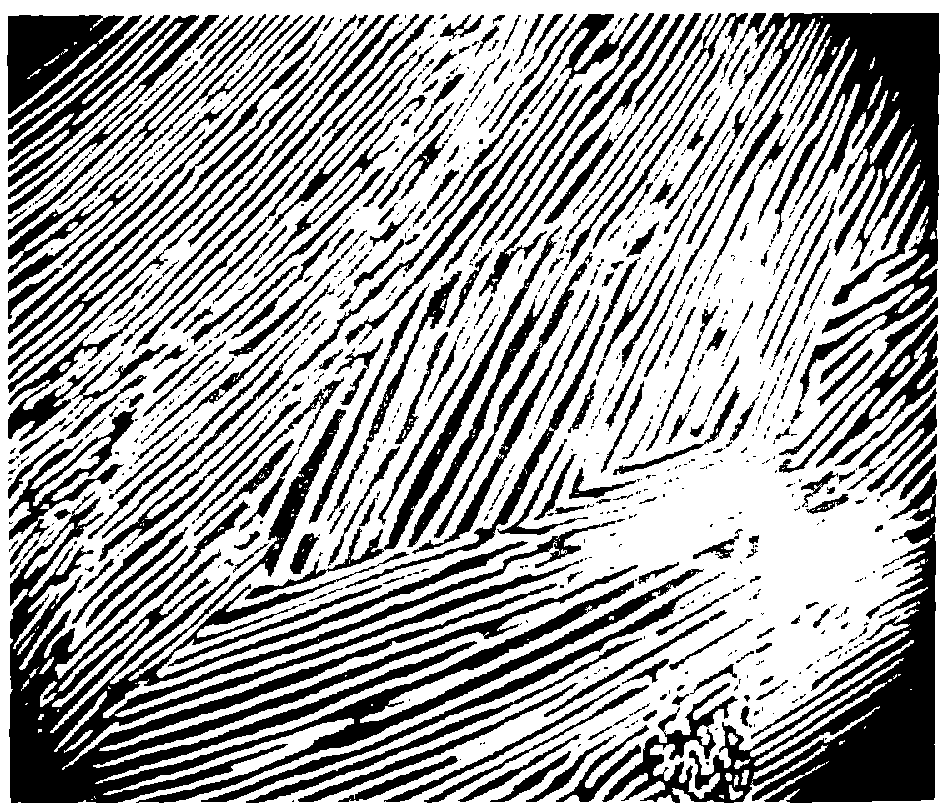

$5000 x$

(a) Sample 002L, Field 7

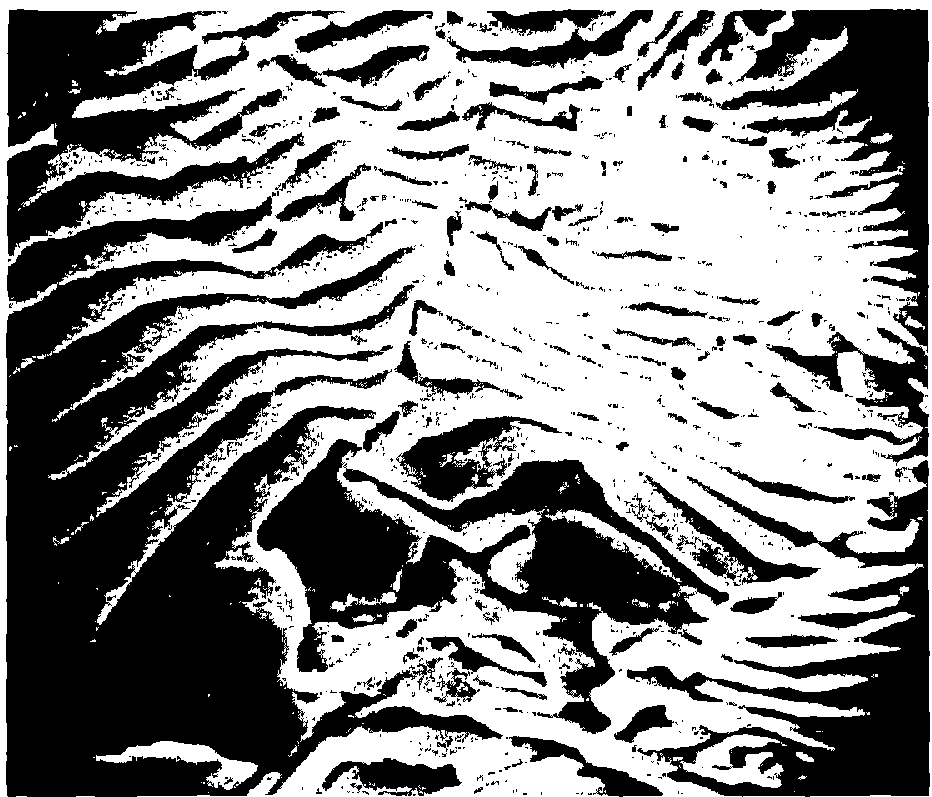

$5000 \mathrm{X}$

(b) Sample 006L, Field 13

FIGURE 23. TYPICAL SCANNING ELECTRON MICROSCOPE VIEWS OF PEARLITE IN RAIL SAMPLES 


\section{3 FRACTOGRAPHY}

A photomacrograph of the fatigue-test fracture surfaces of the six rails is shown in Figure 24. The encircled areas on the fracture surfaces denote the fracture surface locations along the direction of fatigue-crack propagation where fractographic studies are being made. The locations were selected from the plots of crack lengths versus the number of load cycles and correspond to the approximate midpoints of significant changes in the slopes (crack-growth rates) of the curves. In addition to these locations, the following fracture surface locations also are being examined: (1) the precrack fatigue origin, (2) the approximate midpoint of the length of precrack propagation, (3) the approximate beginning of constant cyclic load crack propagation, (4) a location approximately midway between the point where the load frequency was lowered and the point of unstable crack propagation, and (5) an area of unstable crack propagation. The locations in terms of distance from the tip (origin of the precrack) of the notch on the test specimen are given in Table 14.

TABLE 14. LOCATIONS OF FRACTOGRAPHIC STUDIES

\begin{tabular}{ccccccc}
\hline \hline $\begin{array}{c}\text { Sequence of } \\
\text { Location }\end{array}$ & 004 & 002 & 030 & 006 & 001 & 024 \\
\cline { 2 - 7 } & 0 & 0 & 0 & 0 & 0 & 0 \\
1st & 0.18 & 0.17 & 0.17 & 0.17 & 0.18 & 0.18 \\
2nd & 0.31 & 0.33 & 0.30 & 0.26 & 0.31 & 0.27 \\
3 rd & 0.41 & 0.43 & 0.58 & 0.32 & 0.46 & 0.37 \\
4 th & 0.47 ample Identification \\
5 th & 0.86 & 0.79 & 1.15 & 0.47 & 0.64 & 0.56 \\
6 th & 1.26 & 1.25 & 1.41 & 0.81 & 0.96 & 0.82 \\
7 th & -- & -- & -- & 1.22 & 1.36 & 1.20 \\
8 th & -- & -- & -- & -- & -- & 1.38
\end{tabular}

NOTE: Numbers shown represent distance from notch root in Inches. 


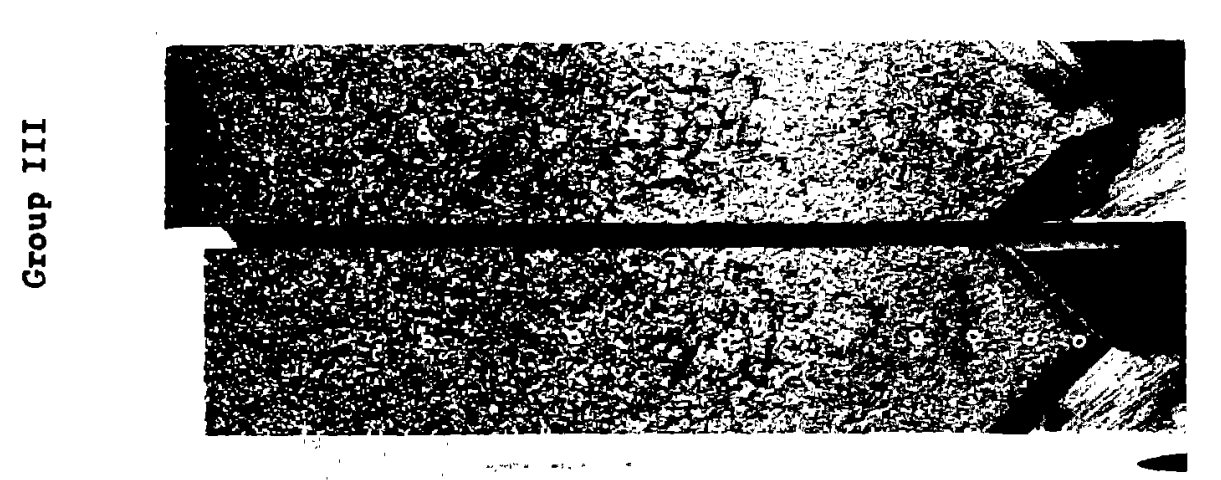

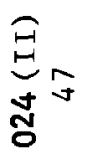

용

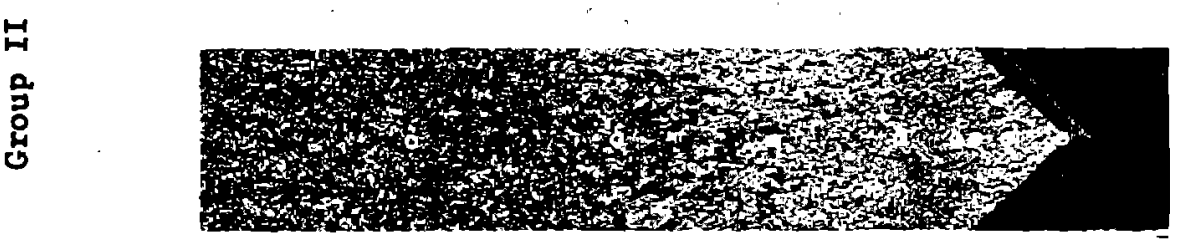

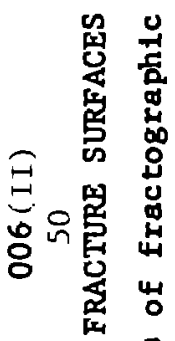

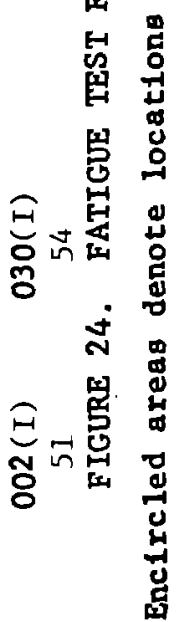
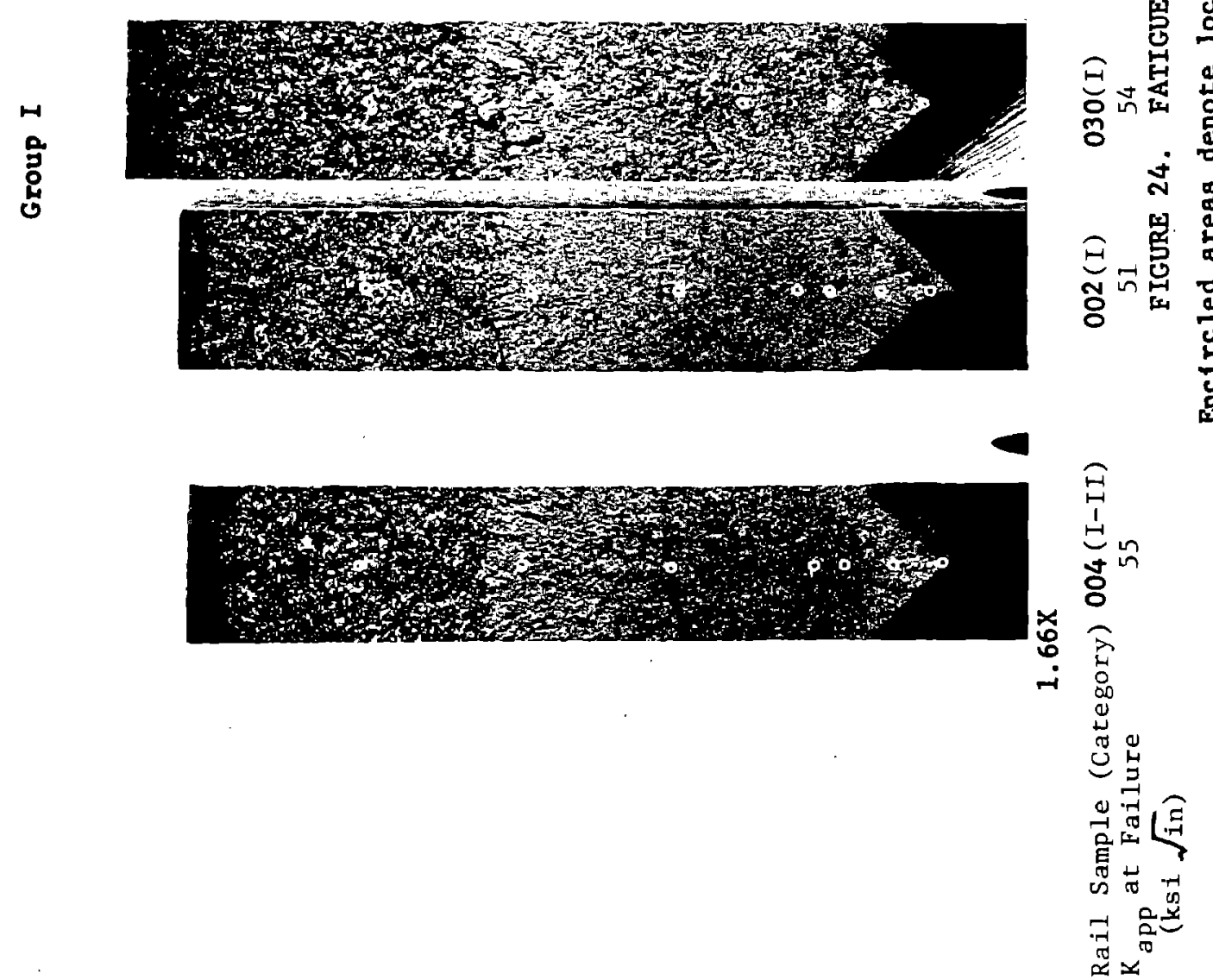
Some general fracture surface characteristics are apparent in the fracture surfaces shown in Figure 24. Significant observations made at magnifications up to $100 \mathrm{X}$ using optical microscopy are described in Table 15 .

TABLE 15. GENERAL FRACTLRE-SURFACE CHARACTERISTICS

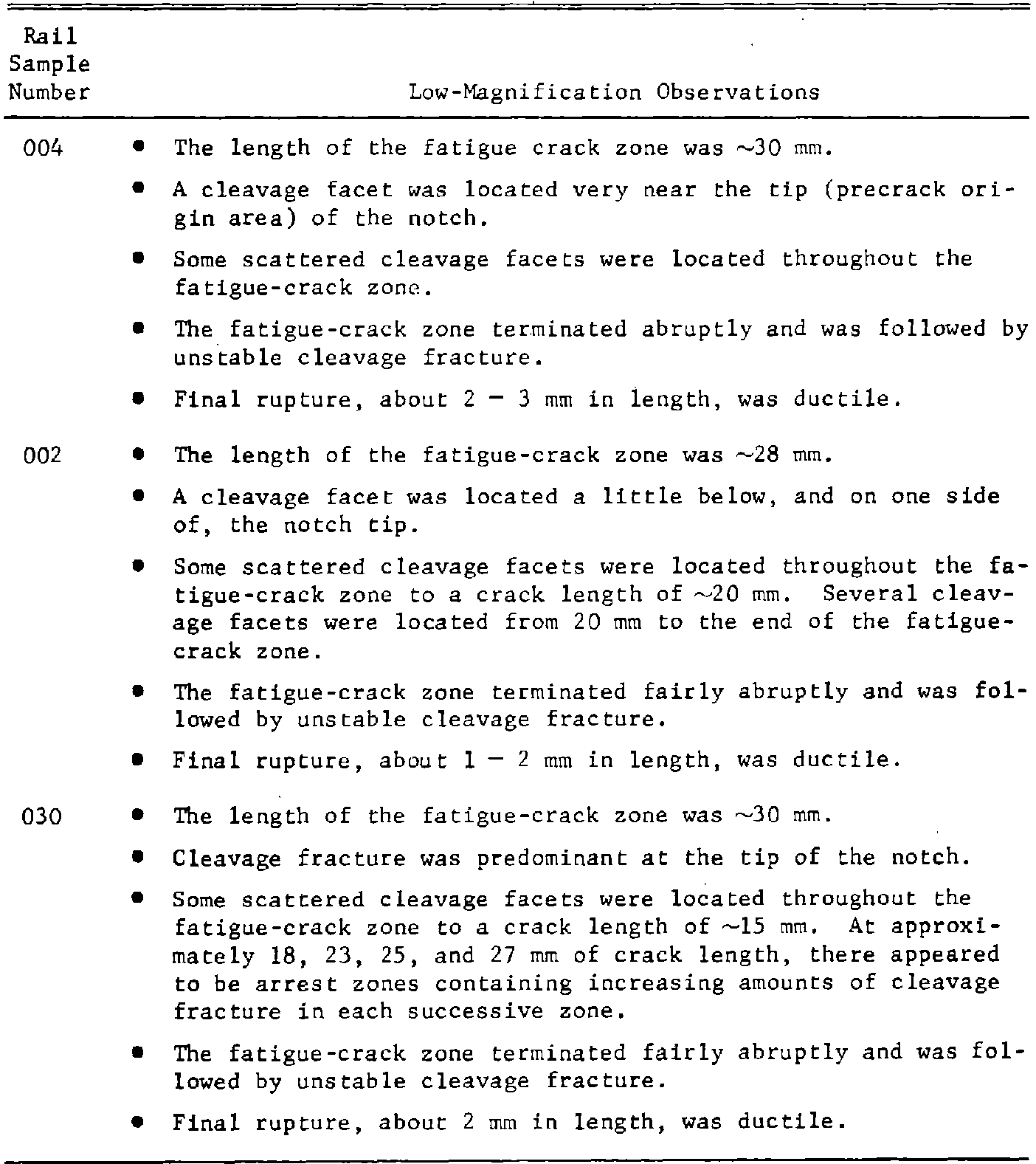


TABLE 15. (Continued)

\section{Ra11}

Sample

Number
Low-Magnification Observations

006 - The length of the fatigue-crack zone was $\sim 25 \mathrm{~mm}$.

- Several cleavage facets were located a short distance from the notch tip.

- Some scattered cleavage facets were located throughout the fatigue-crack zone to a crack length of $\sim 12 \mathrm{~mm}$. Beyond $12 \mathrm{~mm}$, the amount of cleavage fracture increased rapidly to more than 50 percent at the termination of the fatigue-crack zone. From 17 to $25 \mathrm{~mm}$ of crack length there was some tendency for cleavage to concentrate in apparent arrest zones.

- The fatigue-crack zone seemed to terminate by a gradual transition from fatigue to cleavage fracture over the last $13 \mathrm{~mm}$ of fatigue-crack length and was followed by unstable cleavage fracture.

- Final rupture, about $0.5 \mathrm{~mm}$ or less in length, was ductile.

001 - The length of the fatigue-crack zone was $\sim 21 \mathrm{~mm}$.

- Some cleavage facets were located in the area of the notch tip. However, fracture-surface features were partially obliterated by corrosion.

- Some scattered cleavage facets were located throughout the fatigue-crack zone to a crack length of $\sim 10 \mathrm{~mm}$. The amount of cleavage increased between 10 and $21 \mathrm{~mm}$ of crack length. Cleavage tended to be concentrated in $\sim 3$ arrest zones between 15 and $19 \mathrm{~mm}$ of crack length.

- The fatigue-crack zone terminated in a rapid transition from fatigue to cleavage over the last $6 \mathrm{~mm}$ of fatigue-crack length.

- Final rupture, less than $0.5 \mathrm{~mm}$ in length, was ductile.

024 - The length of the fatigue-crack zone was $25 \mathrm{~mm}$.

- Very little cleavage was located in or near the notch tip.

- Some scattered cleavage facets were located throughout the fat1gue-crack zone to a crack length of $\sim 13 \mathrm{~mm}$. Beyond $13 \mathrm{~mm}$, cleavage occurred in increasing amounts.

- The fatigue-crack zone terminated in a rapid transition from fatigue to cleavage over the last $7-8 \mathrm{mr}$ of crack length.

- Final rupture, $\sim 1.5 \mathrm{~mm}$ in length, was ductile. 
Fractographic studies of the six rails using electron microscopy are incomplete. Initial scanning electron microscopic (SEM) examinations resulted in some confusion with respect to the interpretation of detailed fracture features. Similar difficulties were encountered during replication transmission electron microscopic (RTEM) examinations. However, it is anticipated that continued examinations by both techniques will bring clarification.

Observations of the fracture surface at the tip of the notch (the fatigue precrack origin) made during SEM examinations of the six rails are shown in Figures 25 through 30. Cleavage facets, indicated by the letter " $\mathrm{C}$ " in the figures, are apparent in some cases. Fatigue striations do not seem to be discernible at the lower magnifications. The features which appear to be bubbles at the top and to the right in most of the micrographs are globules of molten metal on the electrical discharge machined surface of each test specimen. The globules are most evident in Figure 30.

Two SEM views of an area of the fracture surface located 0.17 inch from the notch tip of Sample 002 are shown in Figure 31. The views are considered to be typical of the appearance of the fracture surface areas of most of the samples when using the SEM. Note the fibrous striated brittle appearance of the crack surface. The lines in Figure 31 appear to be fatigue striations but they are actually pearlite lamellae on the fracture surface. Note the similarity between the pearlite interlamellar spacing shown in Figure 23(a) at 5000X magnification and the spacing of the lines in Figure 31 at 5000x magnification.

Some random RTEM views of fracture surfaces are shown in Figures 32 through 35. The RTEM micrograph in Figure 32 has an appearance similar to the SEM micrograph in Figure 31 ; however, the magnifications differ by a factor of 4. Some striations observed in Sample 004 which appear to be clearly fatigue striations are shown in Figure $33(a)$. These striations may be located in ferrite, since sample 004 contained a high percentage of ferrite in the microstructure. On the other hand, similar striations in Figure $33(\mathrm{~b})$ were observed on the fracture surface of Sample 030 which contained essentially no ferrite.

Occasionally, cross-hatched lines were observed as shown in Figure 34. Since the replicas were shadowed in a direction toward the crack origin, the lines in Figure 34 most nearly perpendicular to the direction of shadowing are likely to be fatigue striations. (These are the striations running approximately up and down in Figure 34.) The other lines, those that are parallel to the direction of shadowing, are likely to be pearlite lamellae.

The RTEM view presented in Figure 35 shows primarily cleavage fracturing. No evidence of ductile overload cracking has been observed in any of the fatigue fracture zones. 

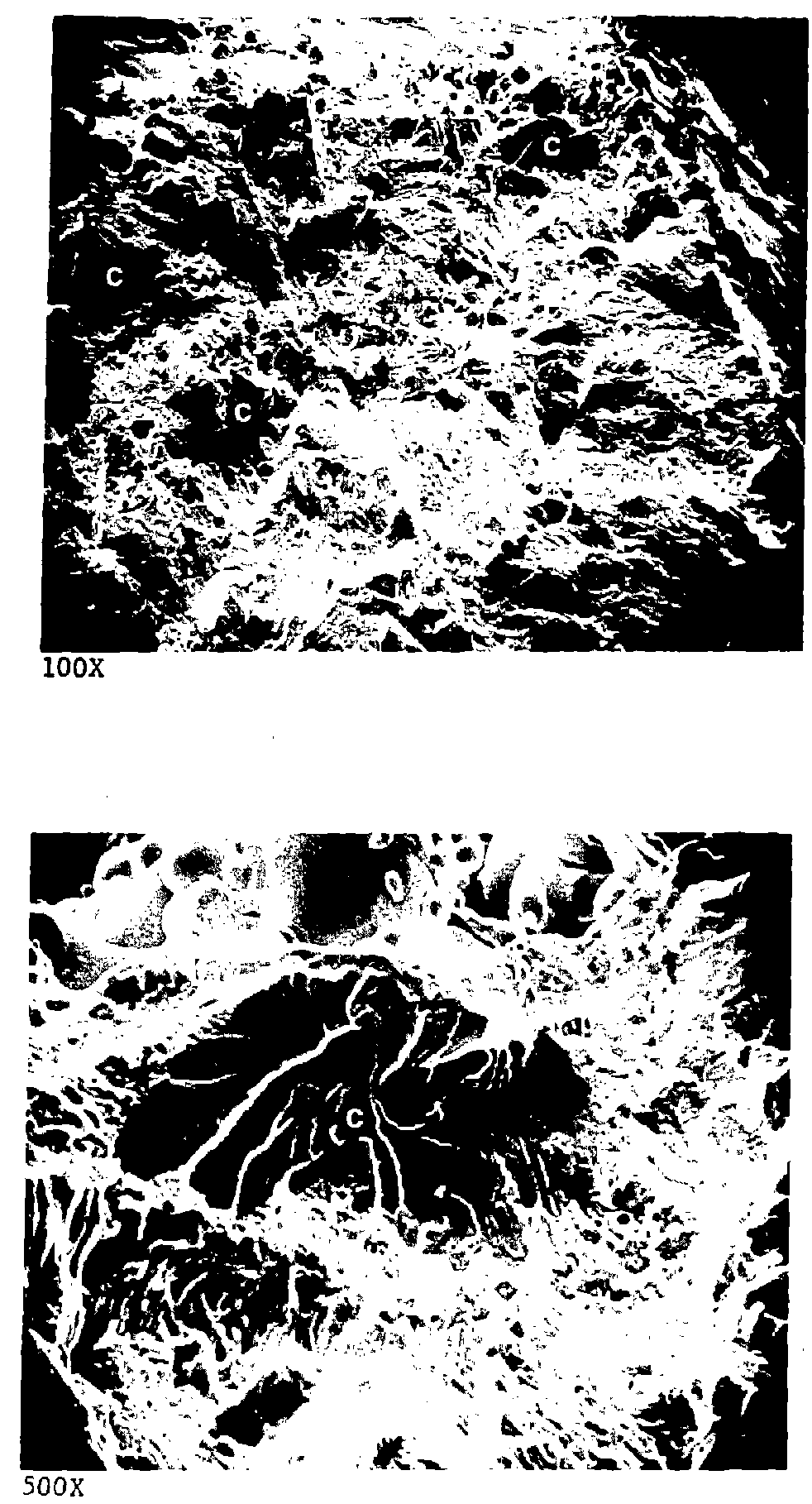

FIGURE 25. FRACTURE SURFACE OF SAMPLE 004 AT THE NOTCH TIP

" $C$ " denotes cleavage fracture.

Tip of notch is at upper right. 

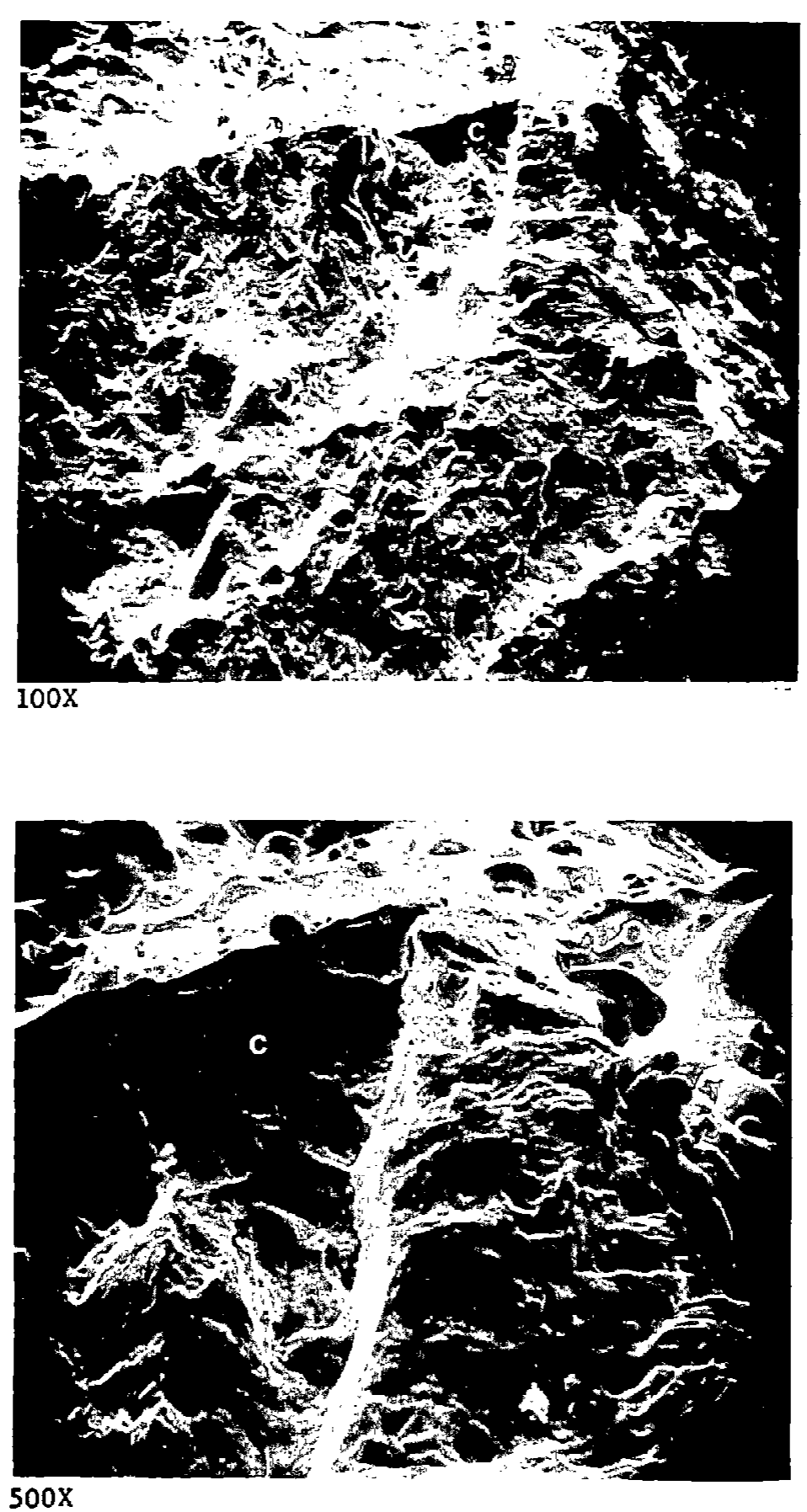

FIGURE 26. FRACTURE SURFACE OF SAMPLE 002 AT THE NOTCH TIP

"C" denotes cleavage fracture.

Tip of notch is at upper right. 


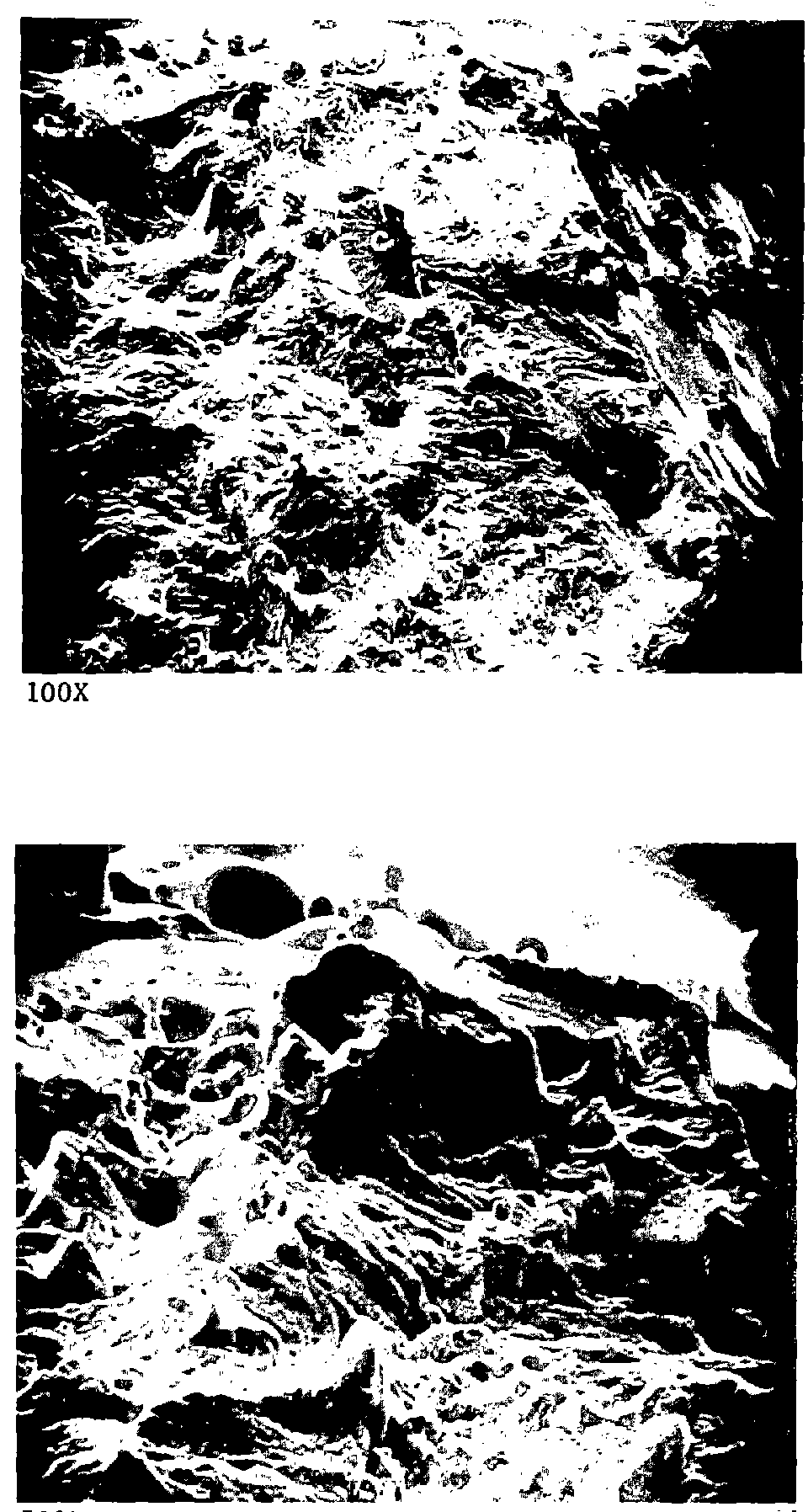

$500 \mathrm{x}$

FIGURE 28. FRACTURE SURFACE OF SAMPLE 006 AT THE NOTCH TIP

"C" denotes cleavage fracture.

Tip of notch is at upper right. 


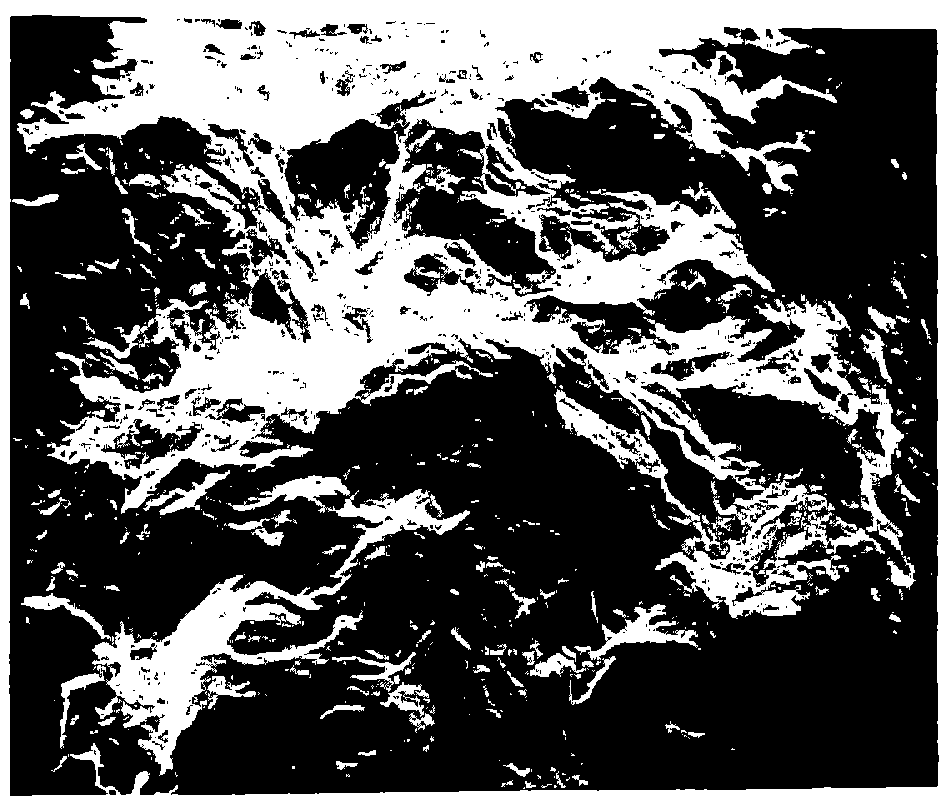

$100 \mathrm{x}$

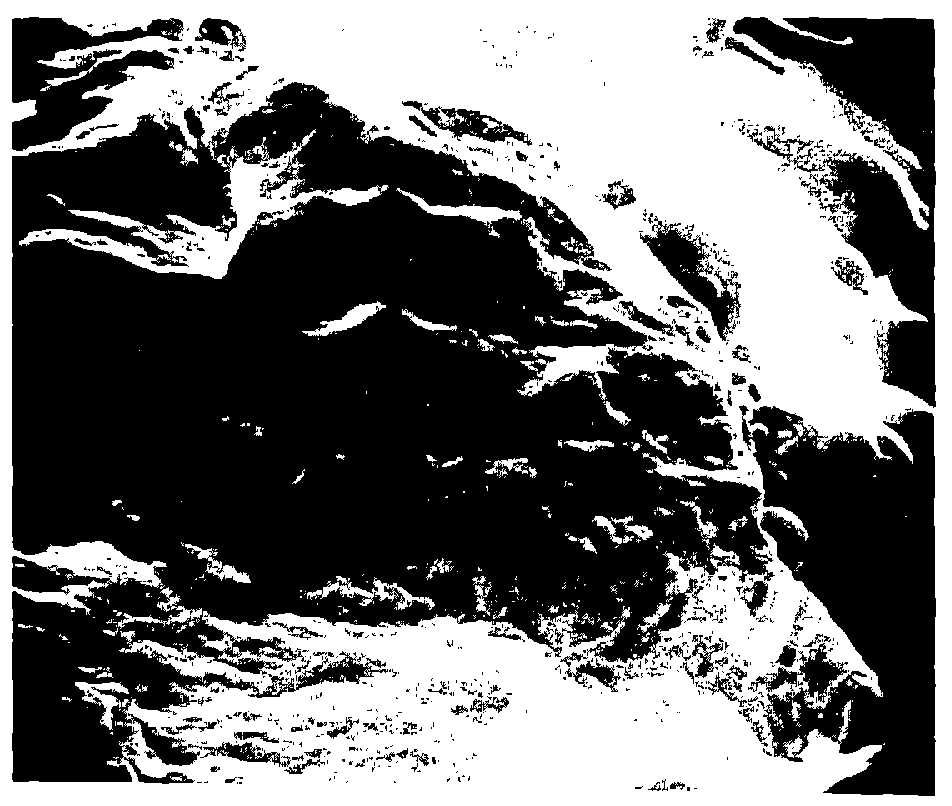

$500 x$

FIGURE 29. FRACTURE SURFACE OF SAMPLE 001 AT THE NOTCH TIP

Tip of notch is at upper right. 


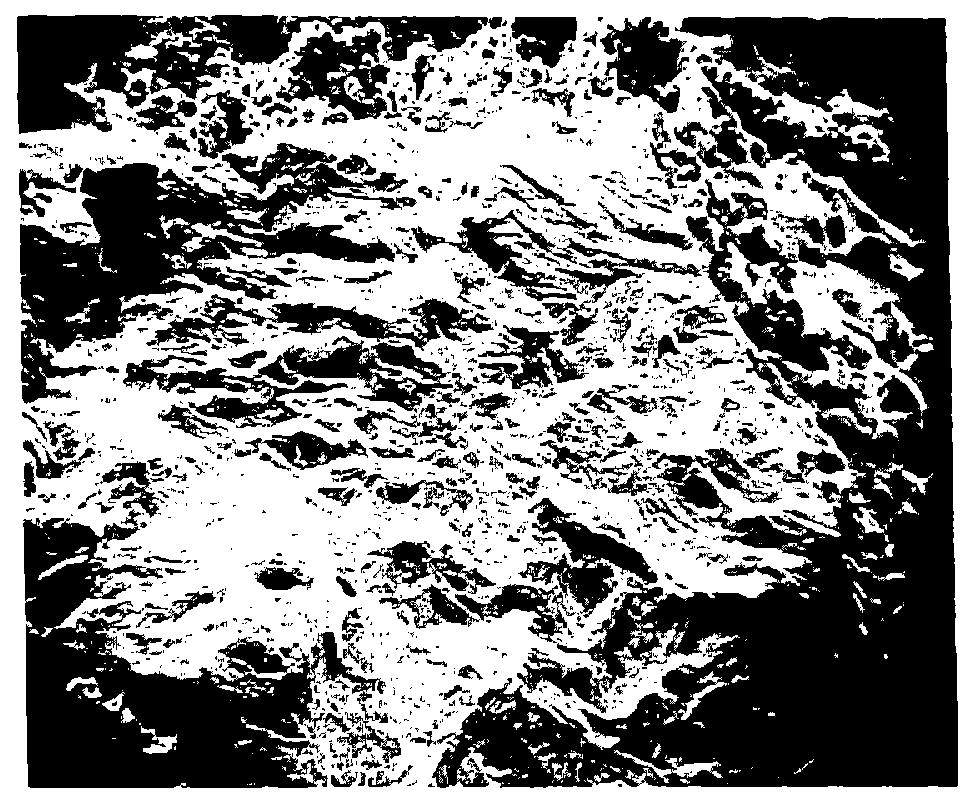

$100 \mathrm{x}$

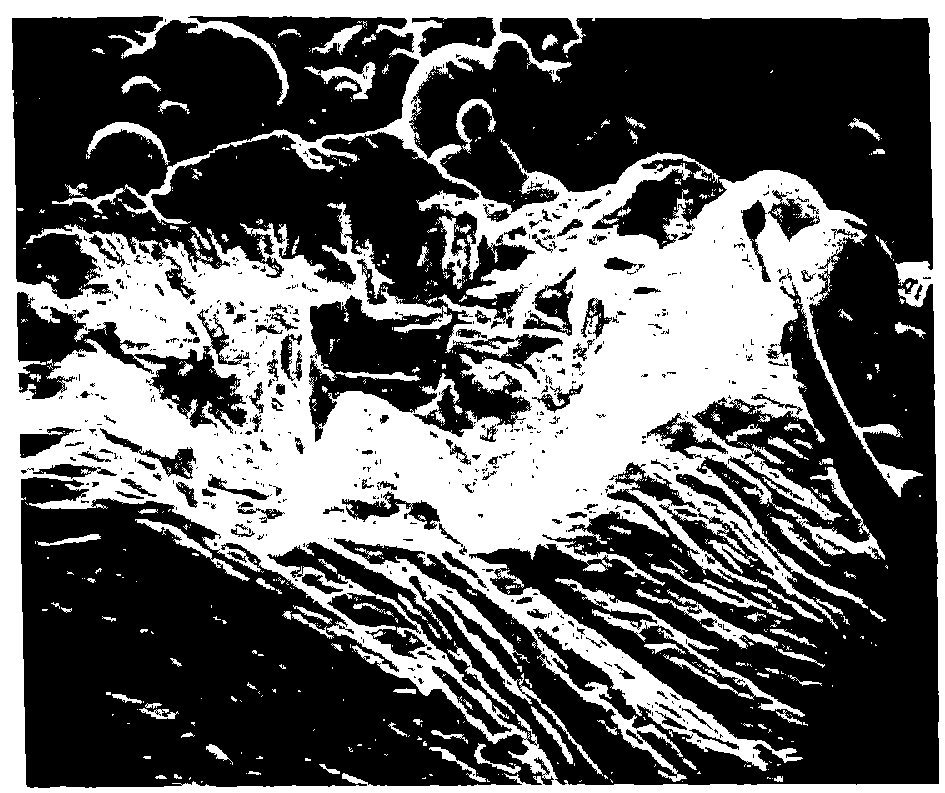

$500 x$

FIGURE 30. FRACTURE SURFACE OF SAMPLE 024. AT THE NOTCH TIP

Tip of notch is at upper right. 


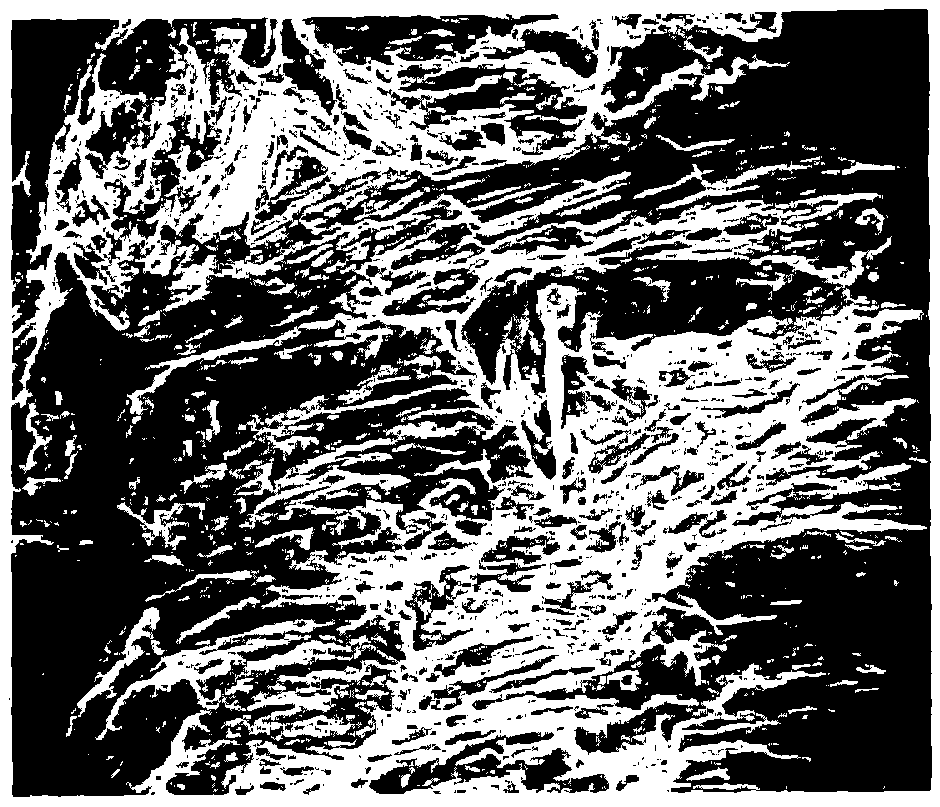

$1000 \mathrm{x}$

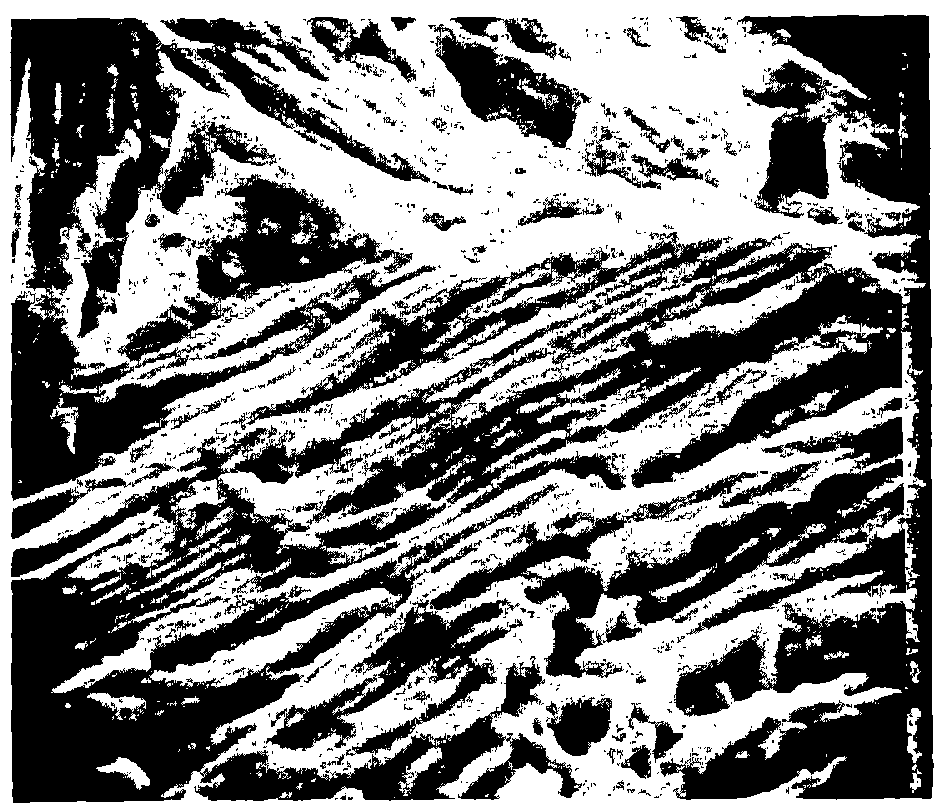

$5000 \mathrm{X}$

FIGURE 31. FRACTURE SURFACE OF SAMPLE $0020.17 \mathrm{INCH}$ FROM THE NOTCH TIP, $\triangle \mathrm{K} \approx 17 \mathrm{ksi}-\mathrm{in} . \frac{1}{2}$

Compare lines at 5000X with Figure 23(a). 


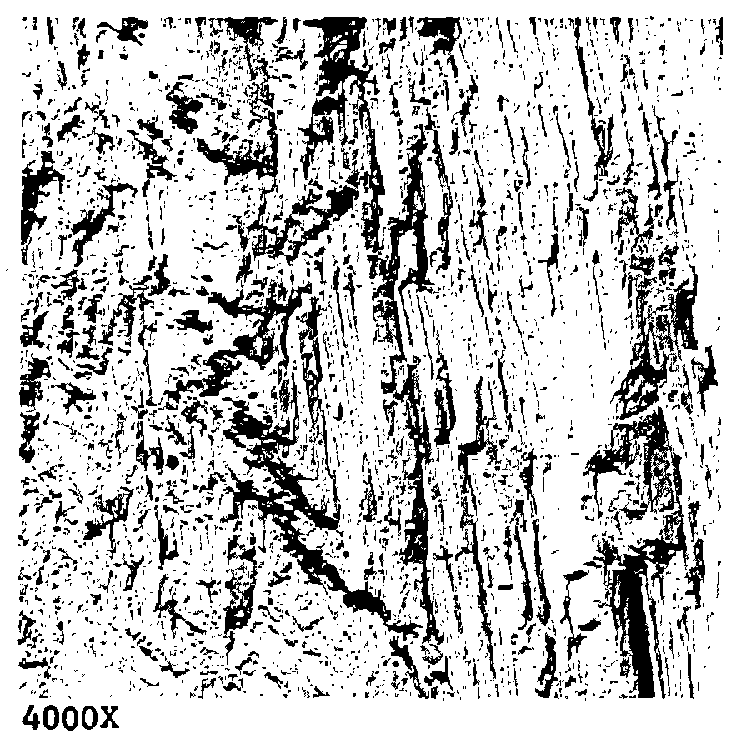

FIGURE 32. FRACTURE SURFACE OF SAMPIE 024 0.56 INCH FROM THE NOTCH TIP, $\Delta \mathrm{K} \approx 22 \mathrm{KSI}-\mathrm{IN}^{\frac{1}{2}}$

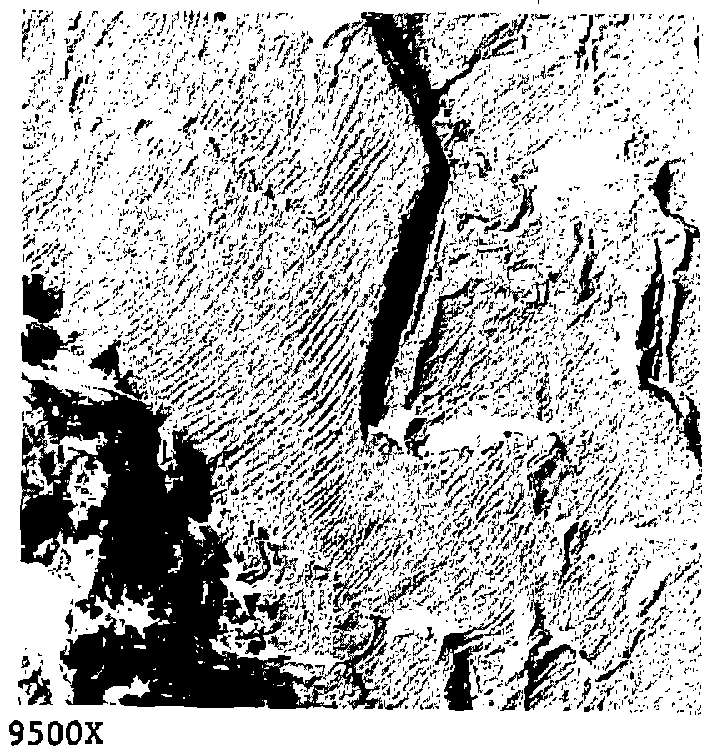

(a) Sample 004, 0.86 inch Prom Notch $\mathrm{Ti}_{\mathrm{P}}, \Delta \mathrm{K} \approx$ FIGURE 33. EXAMPLES OF FRACTURE SURFACE STRIATIONS

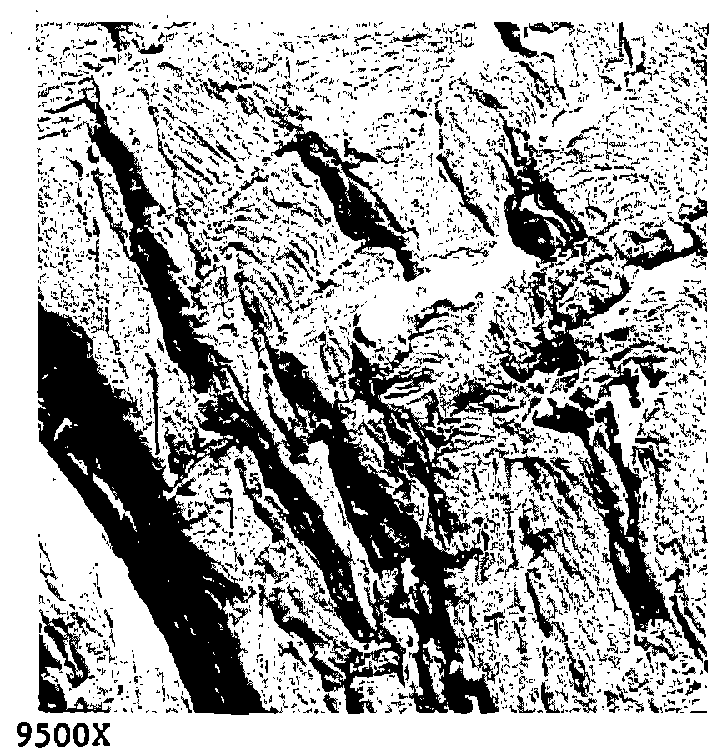

(b) Sample 030,1.15 inches

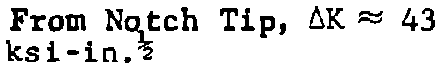

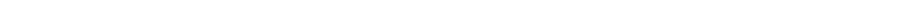




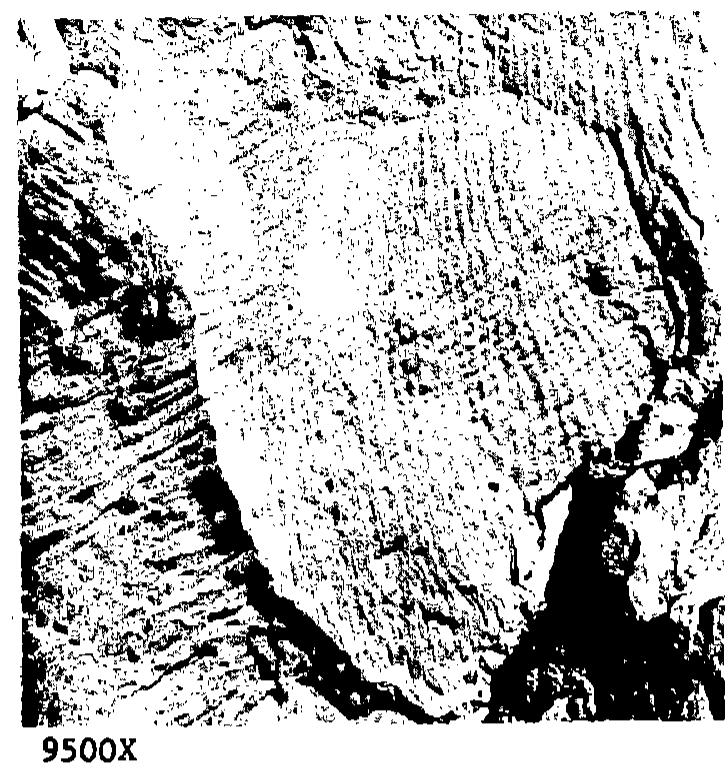

FIGURE 34. CROSS-HATCHED LINE PATTERN SAMPLE 024, 1.21 INCHES FROM NOTCH TIP, $\Delta K \approx 45 \mathrm{KSI}-\mathrm{IN}, \frac{3}{2}$

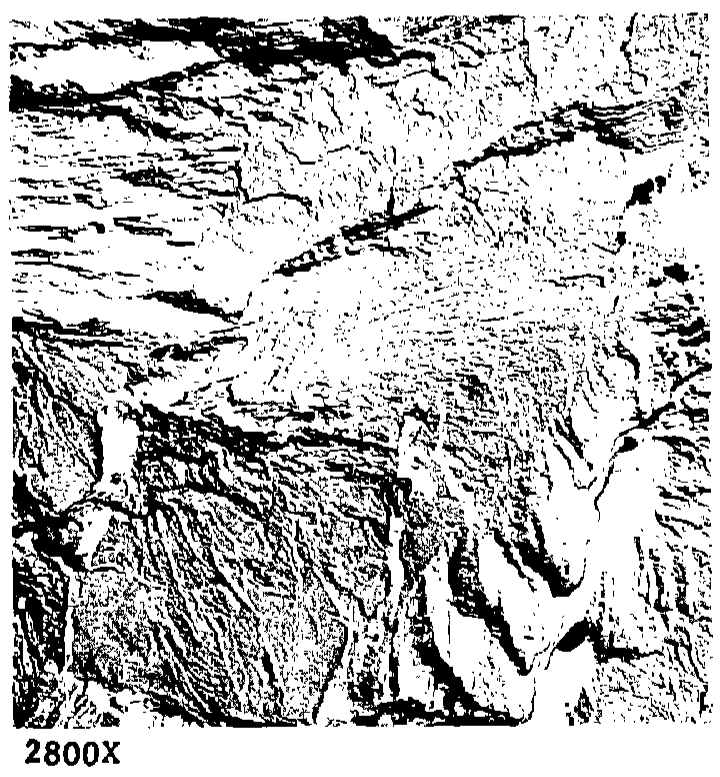

FIGURE 35. CLEAVAGE FRACTURE SAMPLE 024, 1.21 INCHES FROM NOTCH TIP, $\triangle \mathrm{K} \approx$ $45 \mathrm{KSI}-\mathrm{IN}, \frac{\frac{1}{2}}{2}$ 
The fractographic results obtained so far are in agreement with those reported In references 1 and 2, The two referenced publications indicate that the topography of the examined fatigue fractures is as complex with an irregular occurrence of striations, transgranular poirlite cracking, and some cleavage.

The observation of a gradual increase in the amount of cleavage fracture is in agreement with other reports. $(4,5)$ During Phase II of the program, quantitative estimates will.be made of the amount of cleavage encountered during the fatigue crack growth in various rail steels.

The scattered cleavage facets observed close to the notch tip in various specimens will also be a point of further examination. A two-component mechanism for crack extension at very low growth rates was proposed in reference 6 . This mechanism accounts for planar fracture damage (controlled by $\Delta K$ ) in favorably oriented grains, followed by failure of the unbroken grains (controlled by $\mathrm{K}_{\max }$ ). It is expected that the tesis at different $R$-ratios and the threshold experiments may shed some further light on this matter.

\subsection{PROJECTED EXPERIMENTS FOR PHASE II}

The objective of Phase II is to obtain the more detailed information on fatigue-crack propagation necessary for the development of the failure model. As pointed out in the foregoing sections, this information will be generated for a limited number of rail samples. For this purpose, three groups of samples were selected with low, medium, and high crack propagation rates. ' It was attempted to compose each group of rail samples with nearly the same carbon and manganese content (Table 11).

In addition to these three groups, other samples were to be selected for further testing on the basis of the data analysis. However, no clear-cut correlations with other properties as might appear from between fatigue-crack growth rates and metallurgical variables emerged. Therefore, the selection of the additional samples were somewhat arbitrary. The weak correlations found with carbon and manganese content, carbon equivalent, and fraction of pearlite were used as a starting point for the selection.

The 10 samples chosen are listed in Table 16. Reasons for selection are indicated, and it is also shown in which growth rate category each sample would belong. Two additional experiments will be performed on each sample in order to obtain further information for the AID analysis. In addition, detailed metal1ography and fractography will be performed on 20 samples used in Phase II. This work involved the determination of pearlite lamella size, pearlite colony size, 
TABLE 16. SAMPIES SELECTED FOR ADDITIONAL TESTING

\begin{tabular}{lcccc}
\hline $\begin{array}{c}\text { Rail } \\
\text { Sample } \\
\text { Number }\end{array}$ & Category & $(:$ & Mu & \multicolumn{1}{c}{ Reason for Sclection } \\
\hline 004 & I-II & .61 & .62 & $85 \%$ pearlite, high sulfur \\
010 & I & .63 & .74 & $90 \%$ pearlite, low sulfur \\
014 & I & .78 & .74 & low sulfur $:$ \\
026 & I & .78 & .94 & 10w sulfur \\
027 & III & .78 & .87 & low ratio, TYS/TUS \\
037 & II & .72 & .93 & low sulfur \\
038 & III & .57 & 1.48 & $93 \%$ pearlite, low C, high Mn \\
040 & I-II & .58 & .64 & $99 \%$ pearlite, low C, low Mn \\
045 & III & .65 & .65 & $85 \%$ pearlite, low sulfur \\
058 & III & .83 & .84 & heat treated \\
\hline \hline
\end{tabular}

TABLE 17. EXPERIMENTS IN PHASE III

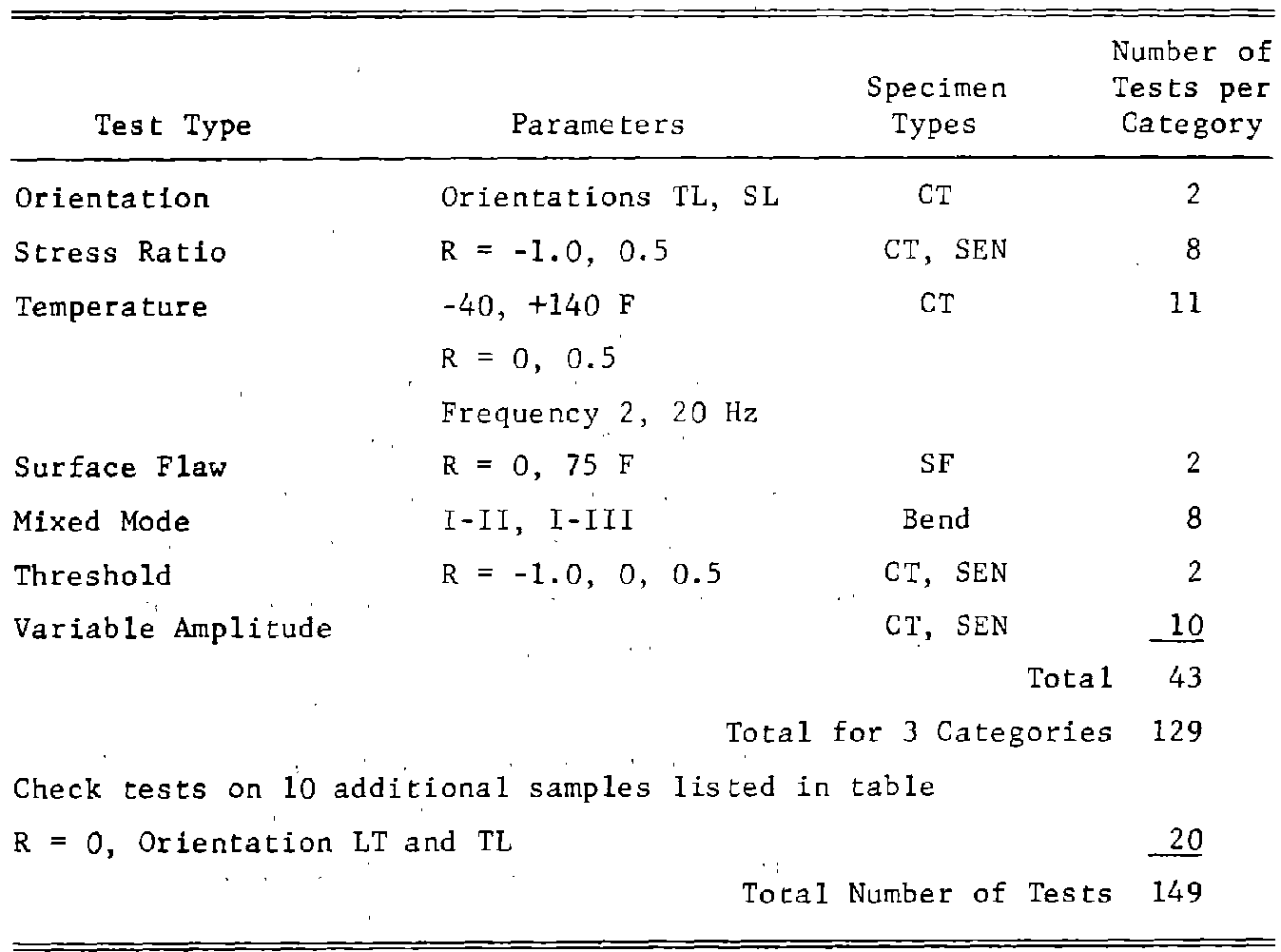


prior austenite grain size, inclusion content and fraction of various fracture mechanisms. This will permit an exercise of complex correlation functions as presented in reference 3 .

The test matrix for Phase II is presented in Table 17. The top part shows the detail testing to be performed on the three categories. The parameters for investigation are indicated. All this information will be used in the development of the fallure model. It requires 129 crack growth tests.

The bottom part of Table 17 shows the experiments to be performed on the 10 additional samples listed in Table 16. Hence, a total of 149 experiments will be performed in Phase II. All experimental data will be used for a further evaluation with the AID program.

\section{REFERENCES}

1. Evans, P. R. V., Owen, N. B., and Hopkins, B. E., "Fatigue Crack Growth and Sudden Fast Fracture in a Rail Steel", J. of the Iron and Steel Inst., June 1970, pp 560-567.

2. Evans, P. R. V., Owen, N. B., and McCartney, L. N., 'Mean Stress Effects on Fatigue Crack Growth and Failure in a Rail Stee1", Eng. Fracture Mechanics, 6, 1974, pp 183-193.

3. Gladman, T., McIvor, I. D., and Pickering, F. B., "Some Aspects of the Structure-Property Relationships in High-Carbon Ferrite-Pearlite Steels", J. of the Iron and Steel Inst., Dec. 1972, pp 916-930.

4. Beevers, C. J., et al., "Some Considerations of the Influence of Subcritical Change Growth During Fatigue Crack Propagation in Steel", Metal Science, $\underline{9}, \underline{3}(1975)$, pp 119-126.

5. Cooke, R. J., and Beevers, C. J., "Low Fatigue Crack Propagation in Pearlitic Steels", Mat. Science Engineering, 13 (1974), pp 201-210.

6. Robinson, G. L., and Beevers, C. J., "The Effects of Load Ratio, Interstitial Content and Grain Rise on Low-Stress Fatigue-Crack Propagation in $\alpha-T i t a n i u m "$, Metal Science, 고 (1973), pp 153-159. 


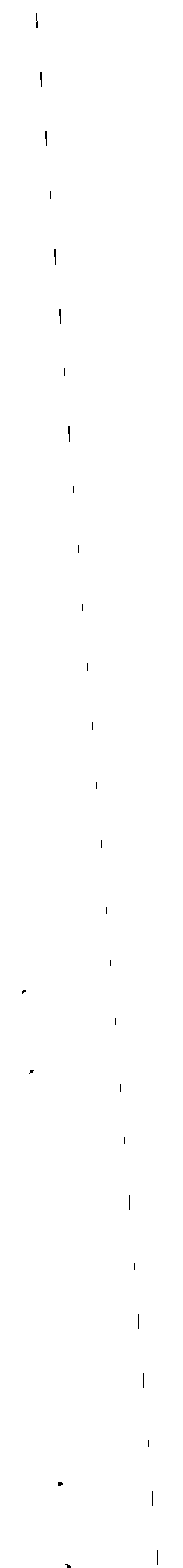


The following tabulations present the crack length measurements and associated cycle count for the 66 material samples received for evaluation in this program. A total of 67 data sets are presented with a reproducibility demonstration provided in duplicate testing of Specimen Nos. 027 and 027A. Specimen No. 029A replaced Specimen. No. 029 for which unanticipated crack growth to failure occurred during an untended cycling period.

These crack growth data sets are presented sequentially in ascending order of sample number. The first measurement point represents the precrack length on the specimen surface after crack initiation and generation out of the chevron notch. The final crack length represents the last crack length that could be moriitored by visual following with a traveling microscope.

Note: Specimen 27 was cycled at 2 kips, Specimen 46 at 5 kips, Specimen 58 at 4.5 kips. All other specimens were cycled at 2.5 kips. $R=0$ for all tests. 


\begin{tabular}{ll} 
CFACK & CYCLE \\
LENGTH, & COUNT, \\
$A$, INCH & $N$ KE \\
\hline SPECIMEN OU1 \\
\\
\end{tabular}
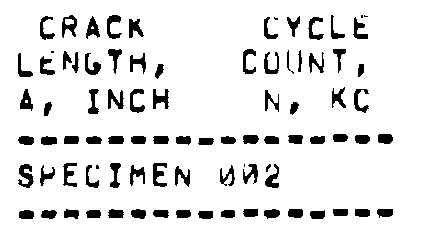

$.930 \quad 354.40$

.986 J9u. पर

1.027

1.082

1.122

1.174

1.224

1.295

1.050

1.430

1.492

1.520

$1.56 \mathrm{~V}$

1.046

1.054

1.709

$1.75 \mathrm{~s}$

1.789

1.0104

1.820

$1.35 y$

1.990

1.964

$1 . y 3 y$
4.31 .40

47 . HA

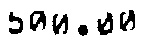

$530,0 \theta$

56iv. ज्ञ

590.00

614.09

o3n. 14

040.45

045.610

$65 n .00$

055.49

60 . 00

064.08

$05 \% .40$

$069 . \Delta a$

670.49

671.00

073.110

675.00

677.08

077.19

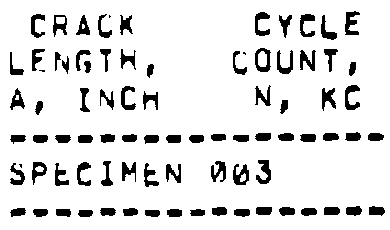

.974

265.00

1.045

1.089

1.131

1.178

1.254

1.324

1.396

1.462

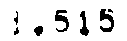

1.588

1.628

1.601

1.894

1.741

1.778

1.807

1.869

1.885
310.00

340.00

379.00

400.00

439.00

430.08

465.06

475.00

489.06

485.00

487.06

489.00

490.08

491.36

492.80

492.50

493.06

493.85 


\begin{tabular}{ll} 
CNACK & CYCLE \\
LFETH, & COUNT, \\
4, INCH & N, NC \\
\hline SPECIMEN 914 \\
\\
\end{tabular}

\begin{tabular}{|c|c|}
\hline $\begin{array}{l}\text { CRACK } \\
\text { LENGTH, }\end{array}$ & $\begin{array}{l}\text { CYCLE } \\
\text { COUNTE }\end{array}$ \\
\hline \multicolumn{2}{|c|}{ SPECIMEN AUS } \\
\hline$=$ & $=--\infty$ \\
\hline$y 05$ & 225.69 \\
\hline $98 n$ & $\operatorname{san} \cdot n a$ \\
\hline 1.641 & 350.46 \\
\hline $1.07 n$ & 375.01 \\
\hline $1.09 y$ & 400.06 \\
\hline 1.131 & 430.00 \\
\hline 1.197 & $46 \mathrm{~B}, 4 \mathrm{G}$ \\
\hline 1.230 & $4 B G \cdot V H$ \\
\hline 1.282 & 536.48 \\
\hline $1.32 v$ & 515.49 \\
\hline 1.365 & 534.69 \\
\hline 1.42 .4 & $545.0 A$ \\
\hline $1.46 y$ & 555.66 \\
\hline 1.524 & 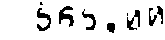 \\
\hline 1.010 & 575. \\
\hline 1.052 & 580.00 \\
\hline 1.090 & 582.67 \\
\hline $1 . / 50$ & $580.0 n$ \\
\hline 1.195 & 585.119 \\
\hline 1.561 & $580 . \mathrm{WH}$ \\
\hline 1.484 & $580.5 A$ \\
\hline $1 .=16$ & $587.4 b$ \\
\hline 1.954 & 587.52 \\
\hline
\end{tabular}

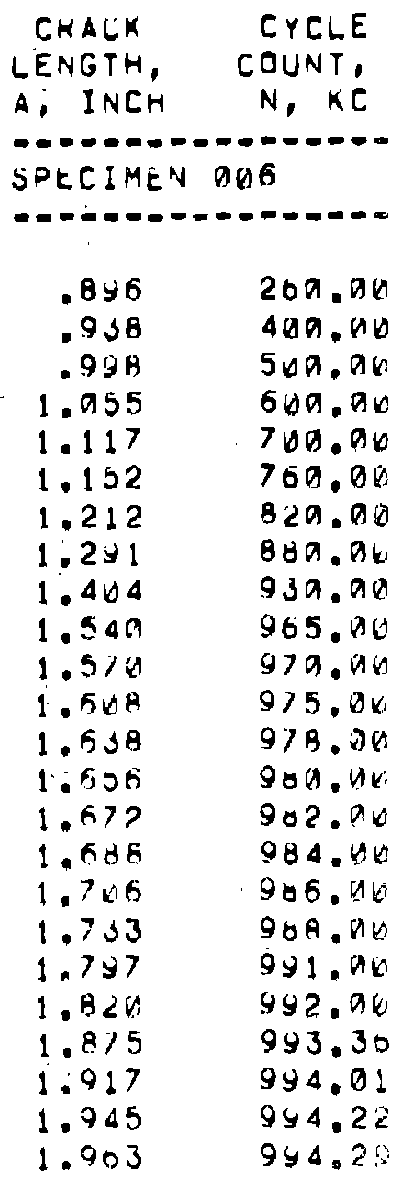




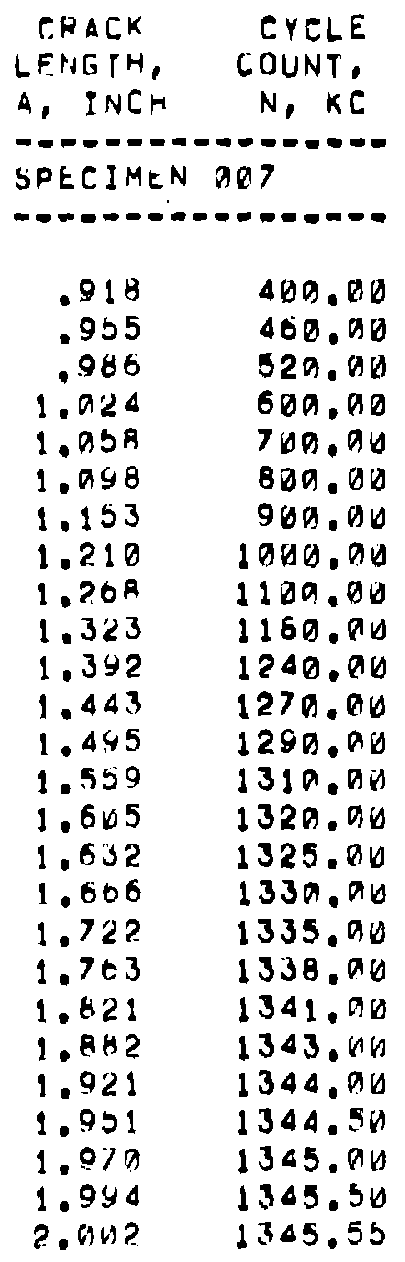
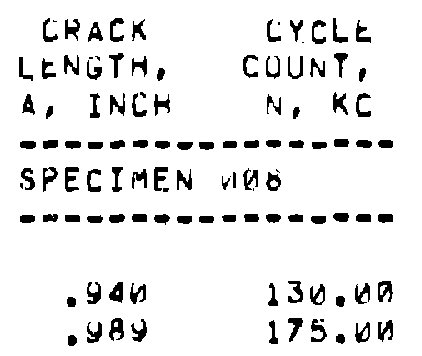

1. 435

1.060

1.164

1.134

1.178

1.228

1.267

$1.31 \mathrm{~b}$

1.366

1.425

1.456

1. $20 \mathrm{~s}$

$1.56 \mathrm{w}$

1.060

1.734

1.171

1.610

1. 044

1.040

$1.93 n$

c. bus
130.00

$175.6 V$

214.00

235.60

250.40

286.00

$316.4 G$

346.40

$36 v . b a$

386.00

$\triangle 9 \square . B D$

420.00

43 . $B$ H

$44 \mathrm{~V} \cdot \mathrm{VH}$

451.49

465.610

47 . $\triangle 10$

472.00

474.00

475.00

470.49

$477.6 \mathrm{n}$

477.78

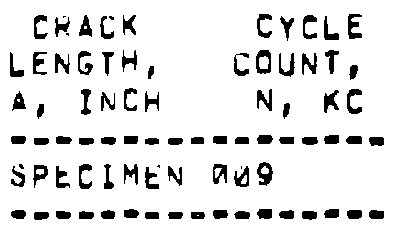

.913

1. 962

1.069

1.143

1.228

1.369

1.5104

1.566

1.607

1.644

1.667

1.729

1.733

1.836
320.00

460.00

550.06

640.00

700.00

780.00

820.90

830.00

834.00

836.00

837.84

838.00

838.36

838.74 


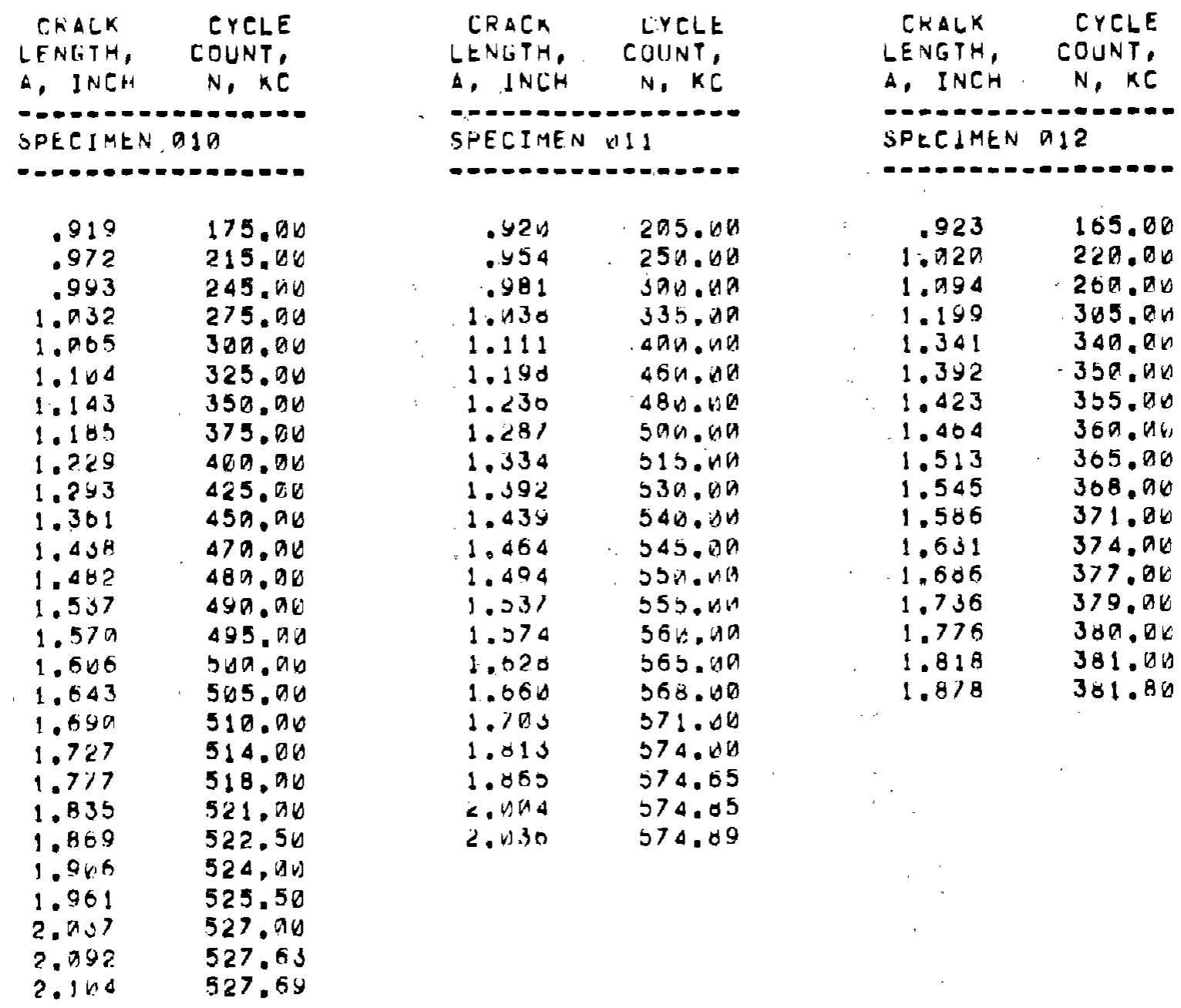




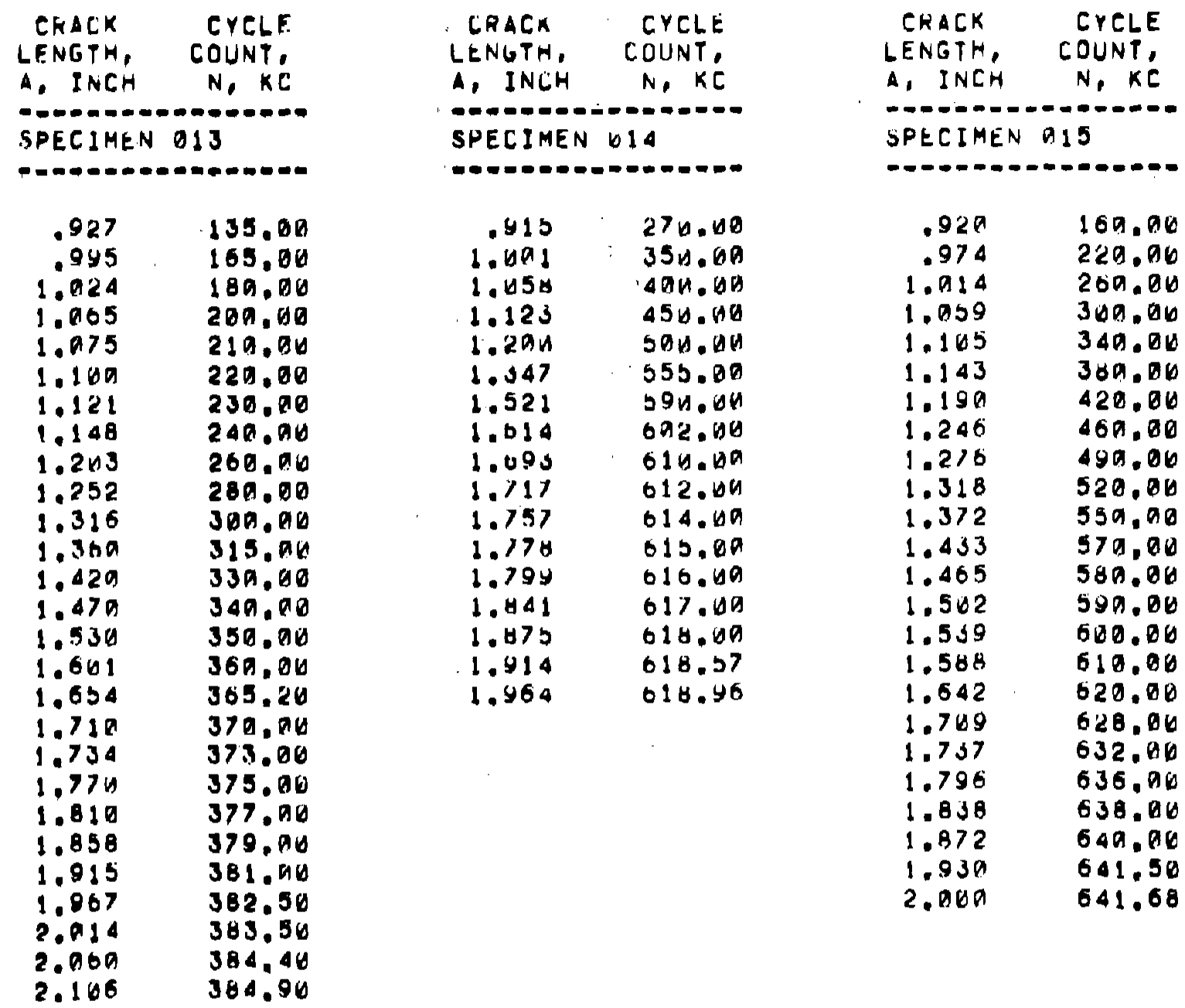




$\begin{array}{ll}\text { CKACK } & \text { CYCLE } \\ \text { LENCTH, COUNT, } \\ \text { A, IICH }\end{array}$

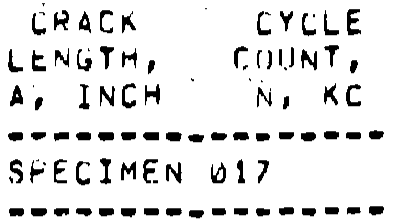

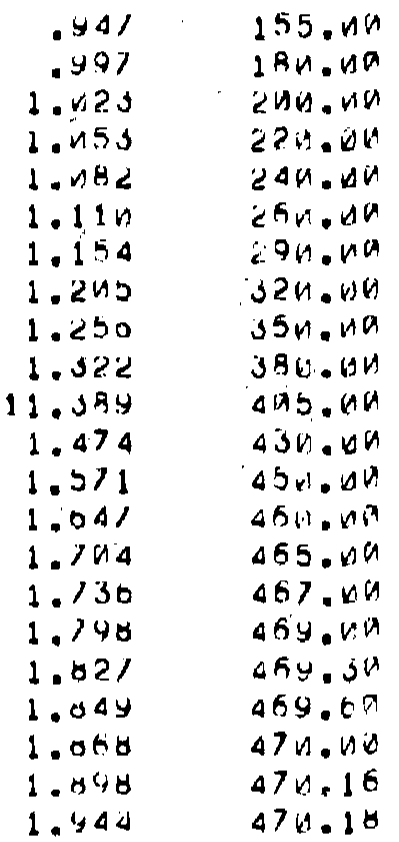

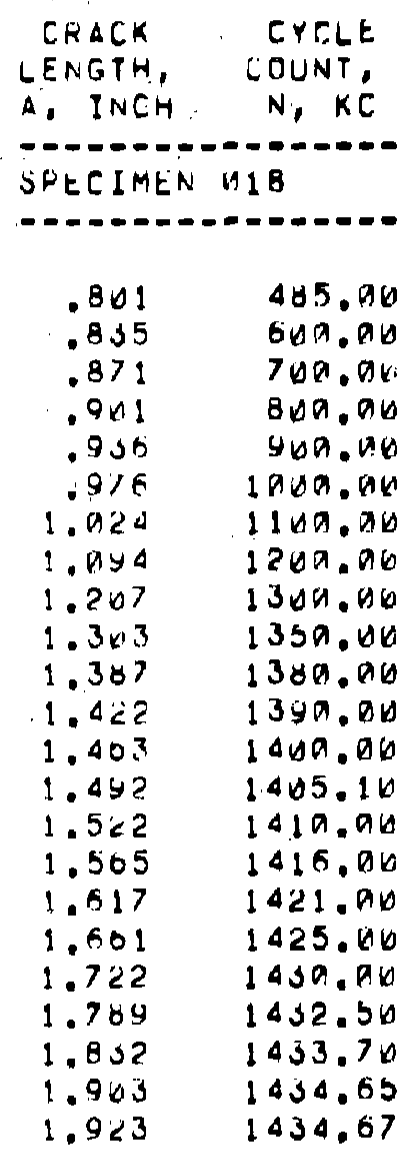




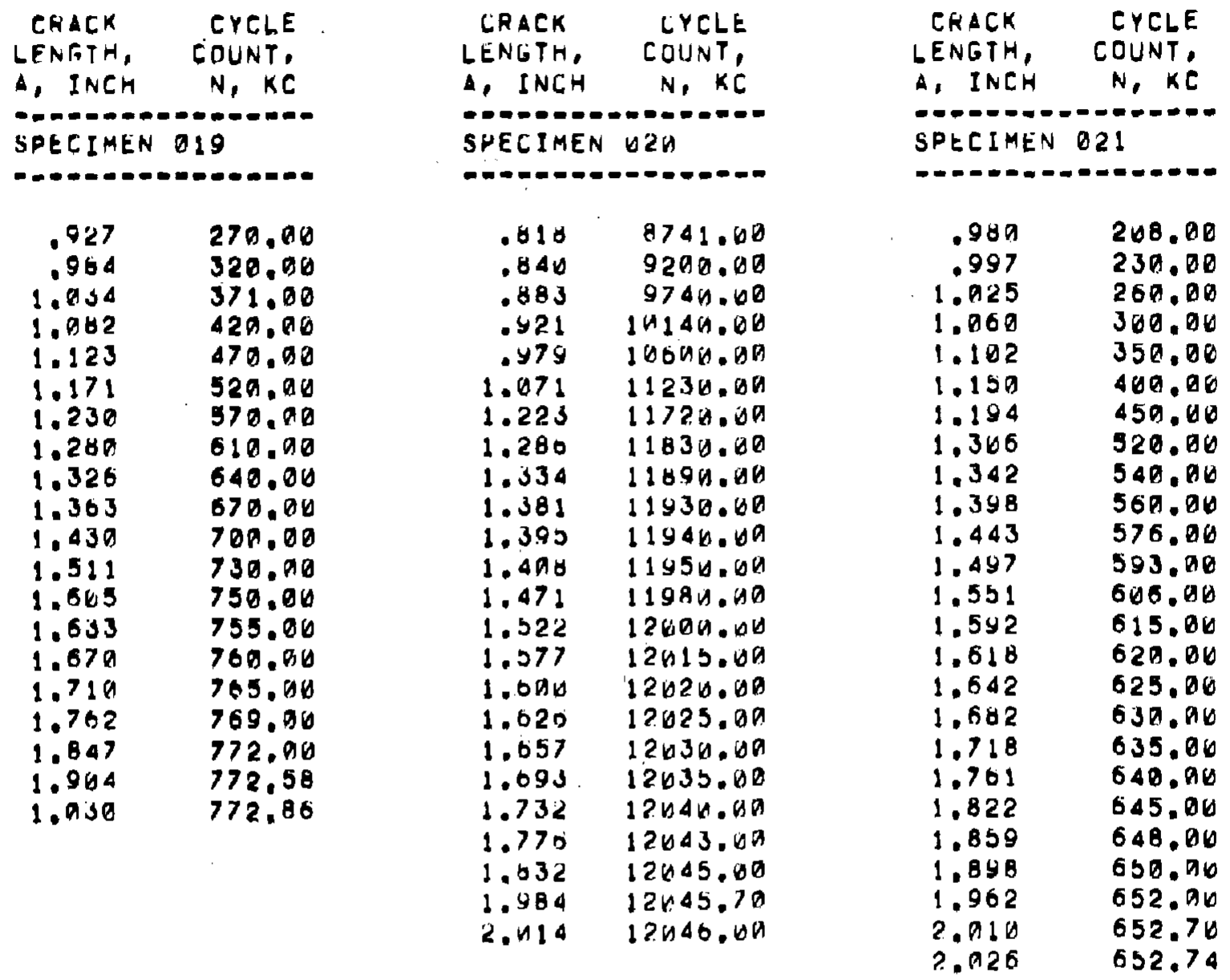




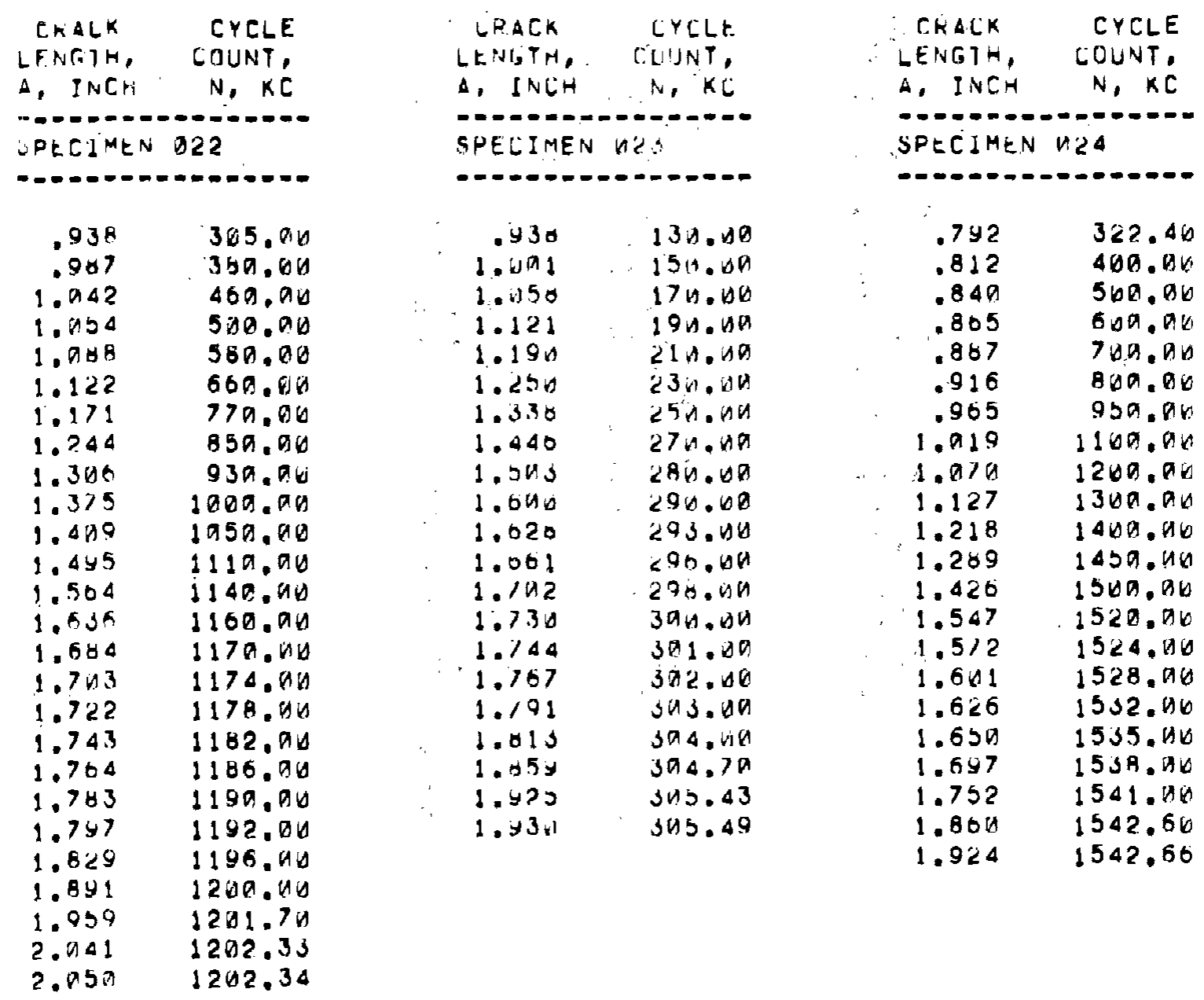




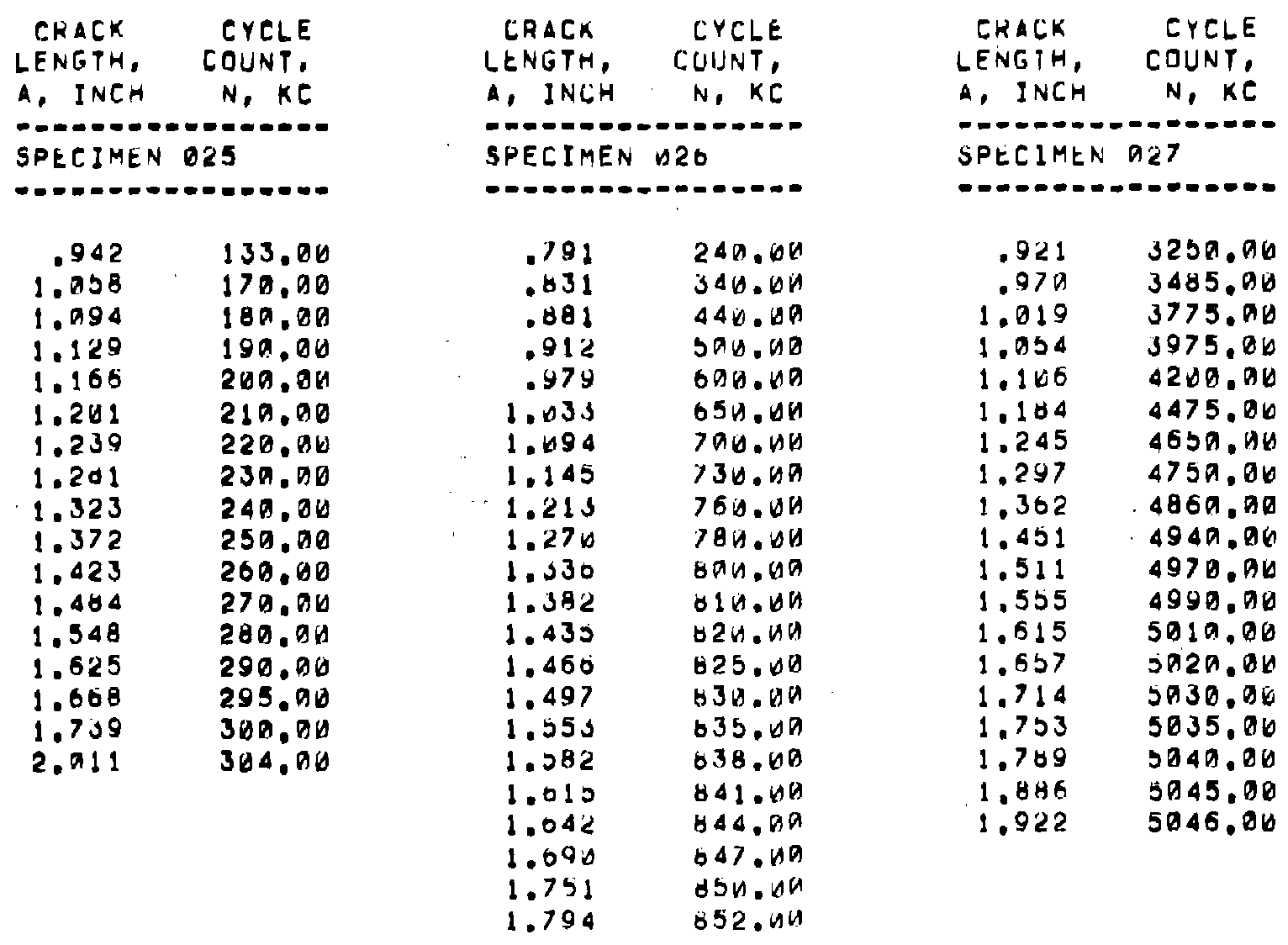




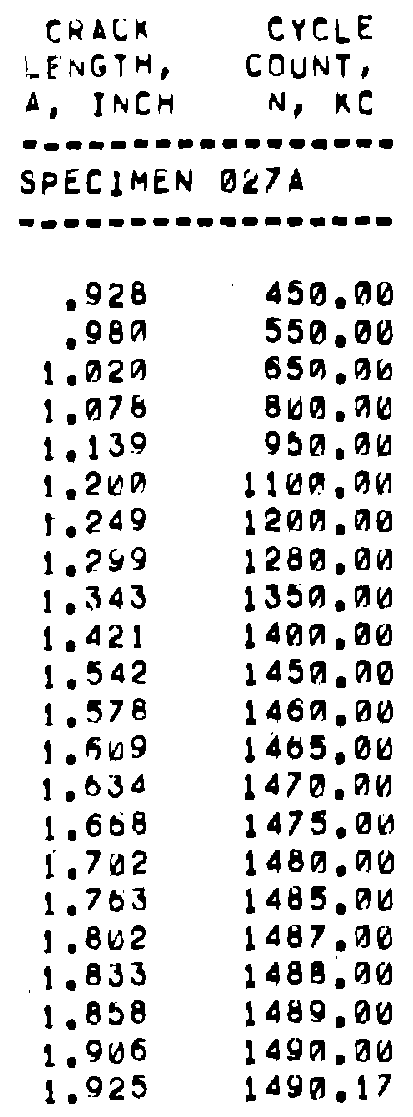

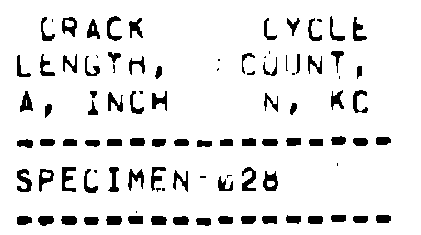

\section{.918 .561 .00}

. $94 a \quad 700.00$

$.989 \quad 790.00$

$1.142 \quad 1470.00$

$1.225 \quad 1160.00$

1.267 1260.49

$1.331 \quad 1235.00$

$1.360 \quad 1250.09$

$1.405 \quad 1265.04$

$1.440 \quad 1286.48$

1.481 .1294 .40

$1.519 \quad 1306.50$

1.541 1345.00

$1.564 \quad 1314.04$

$1.590 \quad 1315.19$

$1.623 \quad 1320.49$

1.06 is $1325.0 a$

1.7as $133 a .4 a$

$1.731 \quad 1332.54$

$1.750 \quad 1335.0$.

$1.790 \quad 1330.54$

$1.021 \quad 1340.09$

$1.877 \quad 1 s 42.00$

$1.94 \Delta \quad 1343.00$

1.934 1344.04

2.130 1340.50

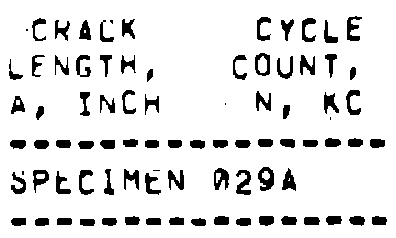

.914

.958

1.008

1. 942

1.980

1.099

1.101

1.214

$1.27 n$

1.359

1.458

1.668

1.744

1.783

1.820

1.835

1.858

1.847

1.920

1.951

1.905

739.00

900.90

1119.00

1270.06

1459.90

1530.06

1730.00

1880.00

2000.00

2150.06

2250.00

2305.00

2325.00

2327.56

2329.96

2339.06

2330.60

2331.10

2331.50

2332.00

2332.97 


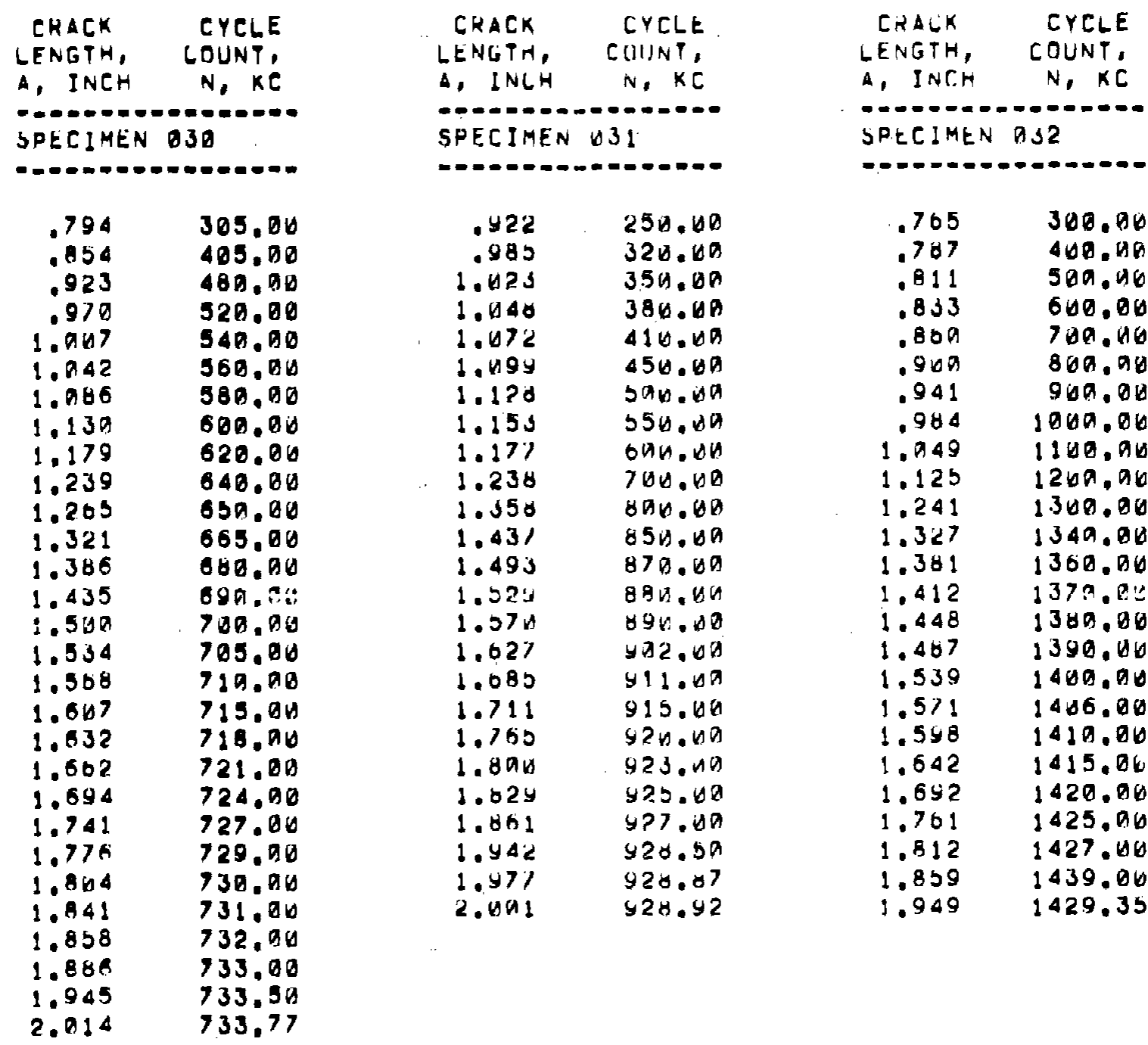




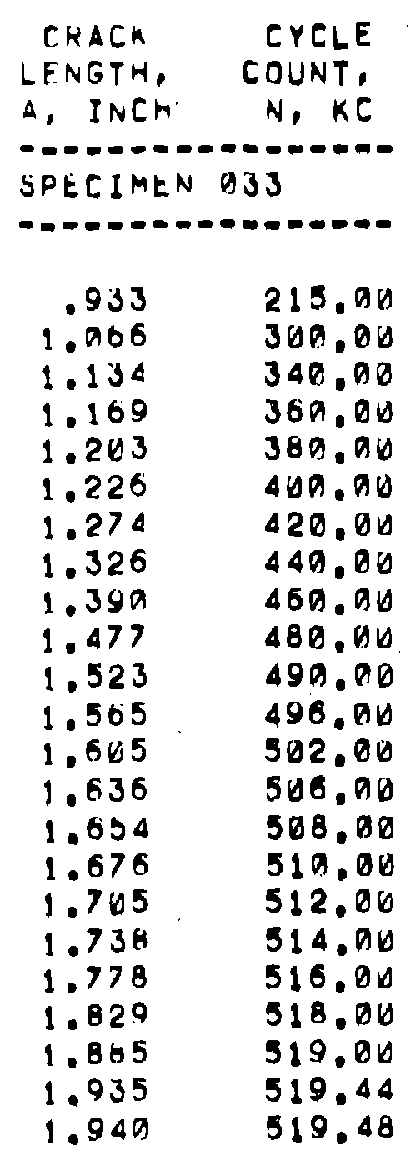

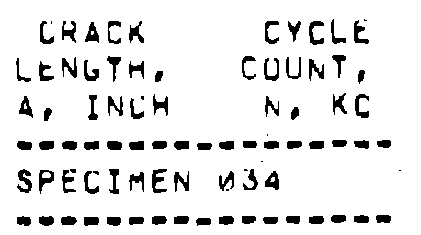

$.995 \quad 185.00$

1. . 76 23n.n日

$1.110 \quad 250.08$

$1.151 \quad 275.119$

1.1.05 295.46

$1.240 \quad 315.40$

$1.286 \quad 335.04$

$1.34 y \quad 355.00$

$1.433 \quad 375.00$

$1.494 \quad 385.06$

$1.545 \quad 391.06$

1.575095 .06

$1.645396 . \Delta 0$

1.020 प9G. 10

$1.051 \quad 402.01$

$1.080 \quad 444.40$

$1.711 \quad 400.09$

$1.741 \quad 447.00$

$1.775 \quad 4 A 8.6 \theta$

$1.63 \mathrm{M}$ any.HB

1.862449 .53

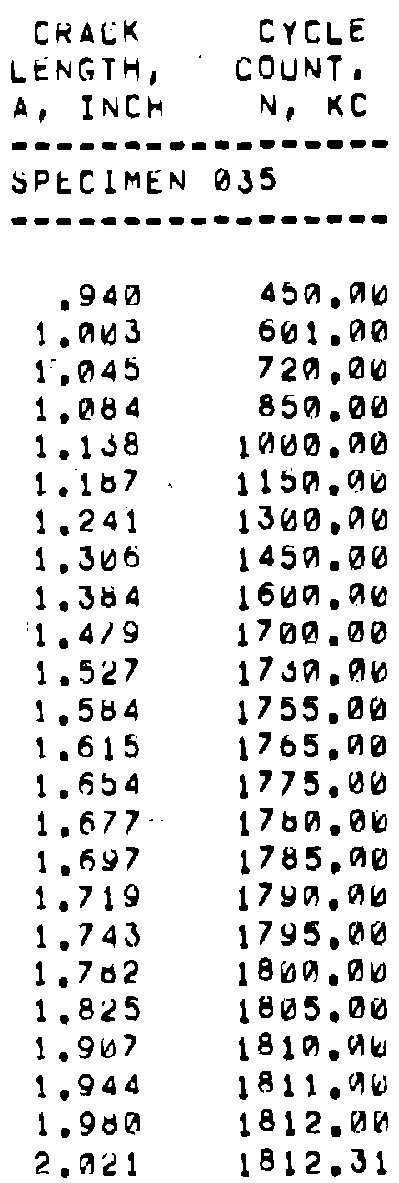




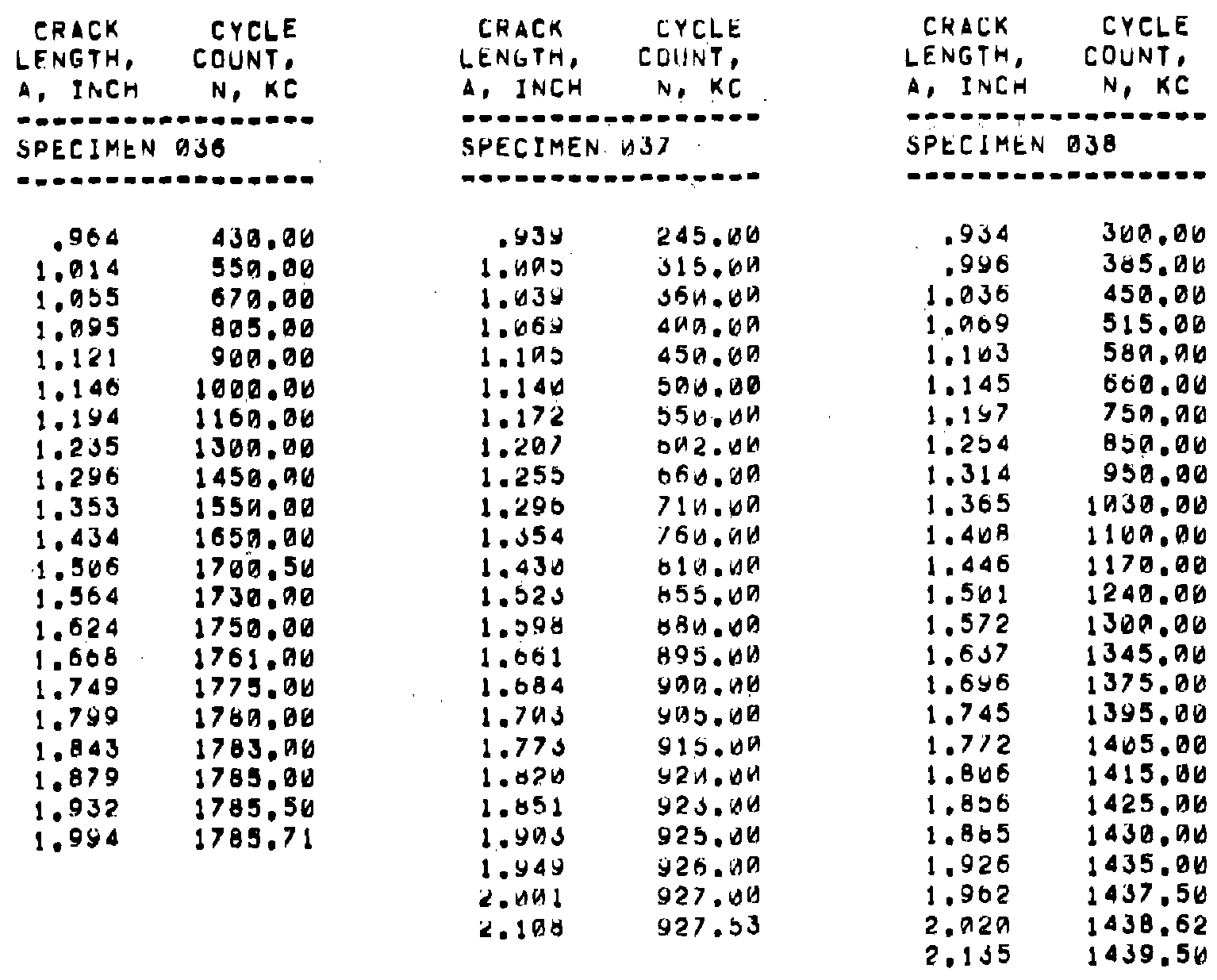




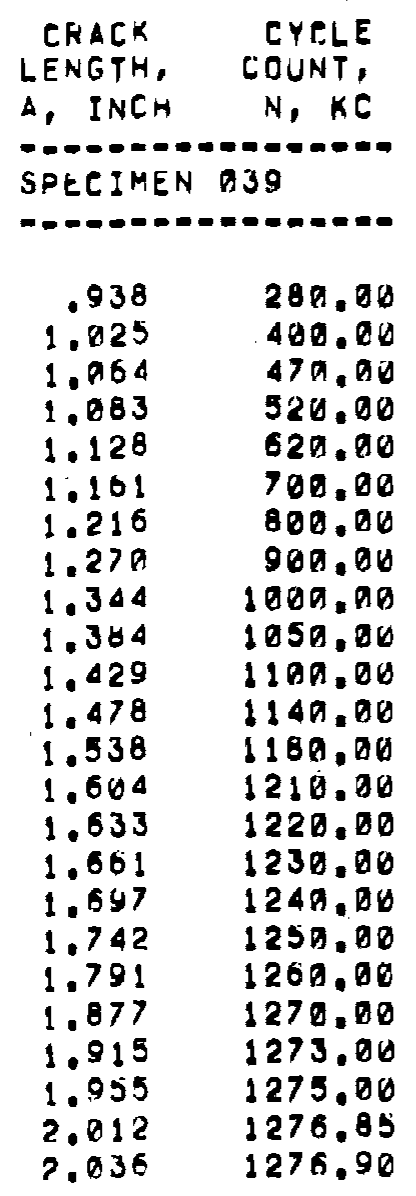

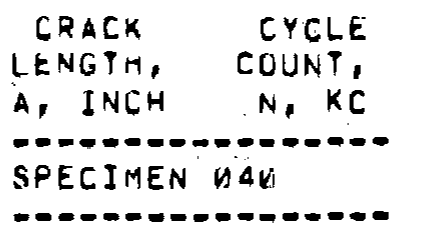

$.985 \quad 174.00$

$1.084 \quad 230.09$

$1.122 \quad 255.00$

$1.152 \quad 275.00$

1.1 AY 300.00

1.221320 .00

$1.253 \quad 346.00$

$1.286 \quad 360.00$

1.322386 .00

$1.398 \quad 413.00$

$1.579 \quad 470.08$

$1.623 \quad 478.69$

$1.656 \quad 484.00$

$1.093 \quad 490.00$

$1.747 \quad 497.00$

1.012512 .89

$1.875 \quad 395.00$

$1.946 \quad 596.50$

1.957

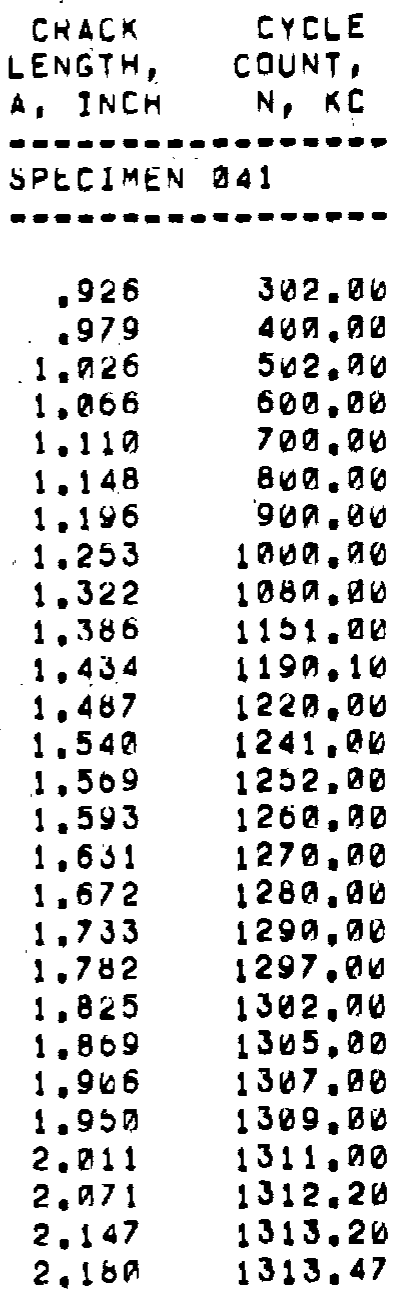




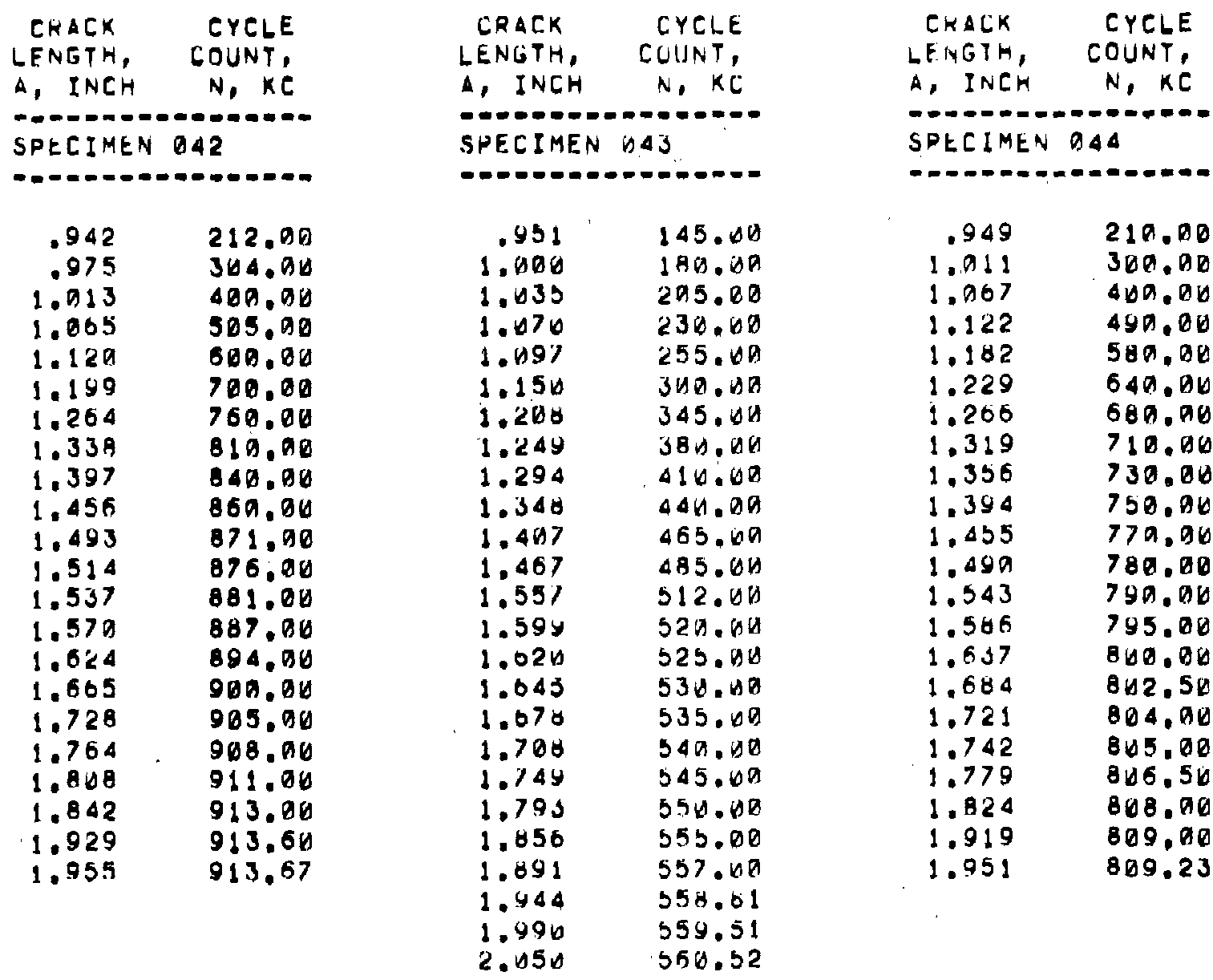




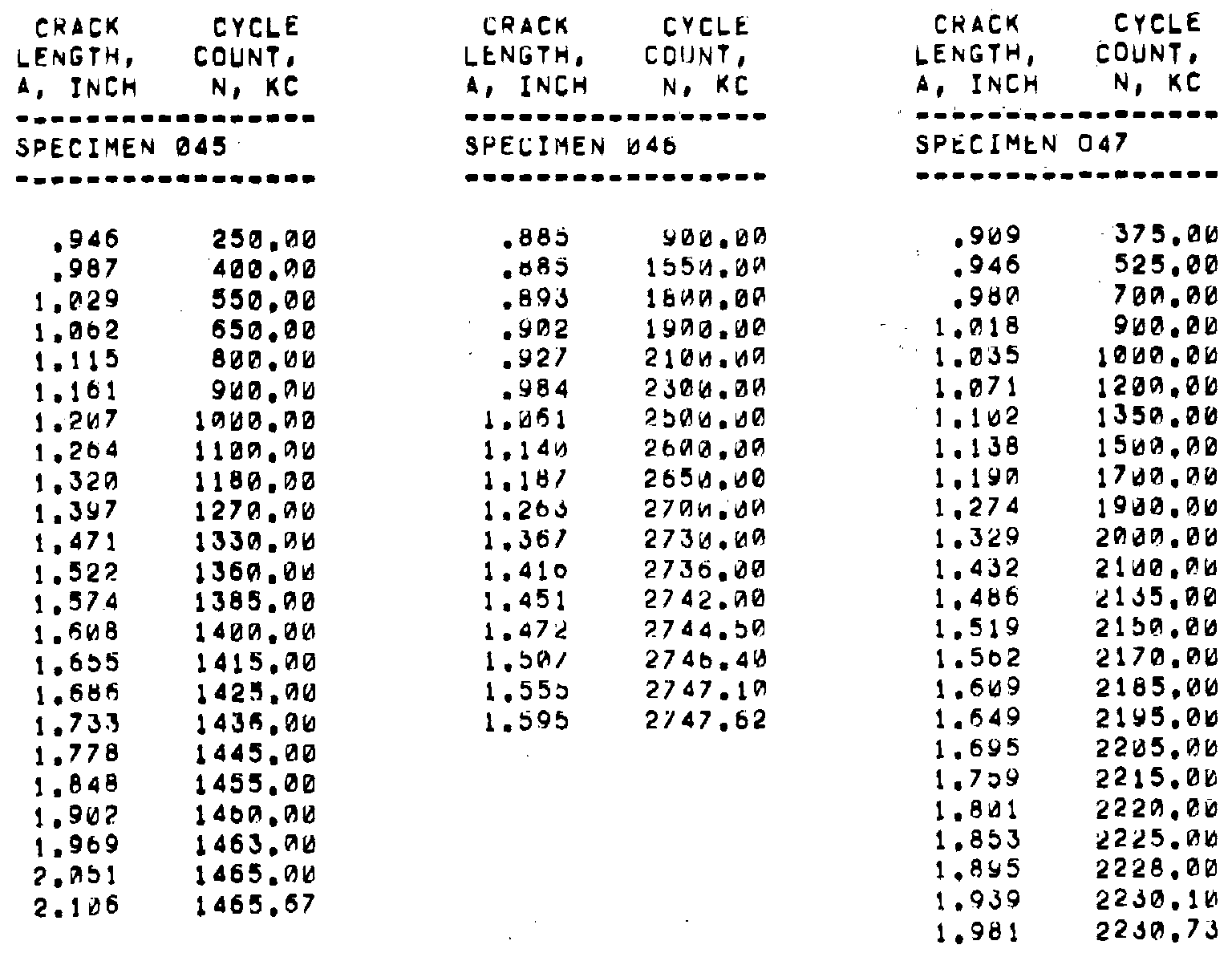




\begin{tabular}{ll} 
CRACK & CYCLE \\
LFNGTH, & COUNT. \\
$A$, INCH & N, KC \\
\hline SPECIMEN O4B \\
\\
\end{tabular}

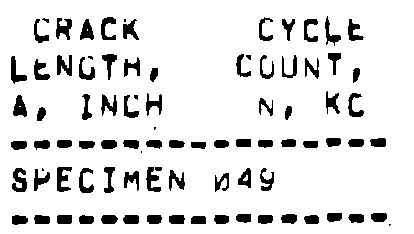

.913

.984

$1.02 y$

l. 050

1. 1192

1.135

1.172

1.231

1.271

1.510

1.382

$1.06 y$

1.010

$1.56 \mathrm{~s}$

1.02 .2

$1.06 \mathrm{~s}$

1. 109

1.770

1.011

1.050

1.541

$1.93 v$

1.964

2. (1) 20
$26 n .40$

336.00

390.00

430.40

$47 n .08$

535.06

370.01

020.00

O5D. 019

$O 8 B .0 A$

$710.0 A$

$7 \Delta H . B S$

$15 \mathrm{H} .0 \mathrm{H}$

164.09

770.04

175.04

$78 n .4 n$

785.04

7 月.

$7 B Y .4 B$

$79 n . \Delta a$

791.48

792.04

792.50

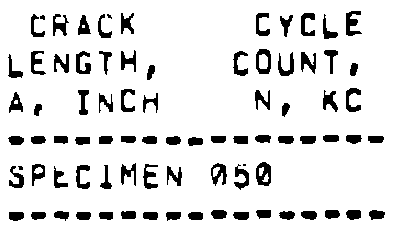

\begin{tabular}{|c|c|}
\hline $\begin{array}{l}.926 \\
.979 \\
1.923 \\
1.944 \\
1.154 \\
1.202 \\
1.257 \\
1.335 \\
1.352 \\
1.453 \\
1.453 \\
1.538 \\
1.576 \\
1.524 \\
1.688 \\
1.731 \\
1.703 \\
1.862 \\
1.859 \\
1.912 \\
1.907\end{array}$ & $\begin{array}{l}285.00 \\
519.00 \\
700.00 \\
910.00 \\
1050.00 \\
1125.00 \\
1209.00 \\
1275.00 \\
1315.00 \\
1345.90 \\
1360.00 \\
1375.00 \\
1345.00 \\
1395.00 \\
1405.00 \\
1419.00 \\
1413.00 \\
1416.00 \\
1419.00 \\
1421.00 \\
1421.70\end{array}$ \\
\hline
\end{tabular}




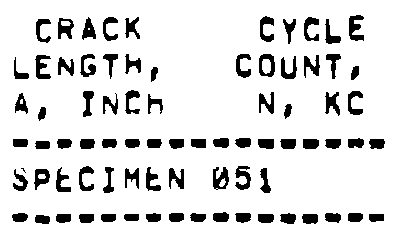

.921365 .00

.945665 .00

.973 .865 .00

.992 1000.00

$1.953 \quad 1272.00$

$1.992 \quad 1509.00$

$1.178 \quad 1739.00$

$1.259 \quad 1880.00$

$1.313 \quad 1949.00$

$1.352 \quad 1970.00$

1.3902000 .01

$1.402 \quad 2049.000$

$1.516 \quad 2469.00$

$1.506 \quad 2076.00$

$1.649 \quad 2985.90$

1.6742090 .94

$1.723 \quad 2095.06$

$1.706 \quad 2098.90$

$1.812 \quad 2109.00$

$1.087 \quad 2109.68$

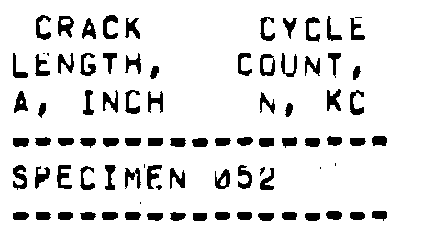

$.082 \quad 275.00$

$.945 \quad 375.60$

$.984 \quad 451.69$

$1.642 \quad 340.00$

1.082 609.60

$1.117 \quad 655.00$

$1.130 \quad 790.09$

$1.170 \quad 760.00$

1.2 .33025 .00

$1.27 y \quad 860.06$

$1.320 \quad 890.60$

$1.384 \quad 926.08$

1.435 g4v.4n

$1.480 \quad 955.60$

$1.337 \quad 970.09$

1.583 984.0日

$1.650 \quad 990.00$

$1.719 \quad 997.04$

1.770 IV92.

1.625 lags.av

1.6901000 .60

1.954 1699.04

$2.034 \quad \ln (x) .53$

2.ubs 1 bia.s.

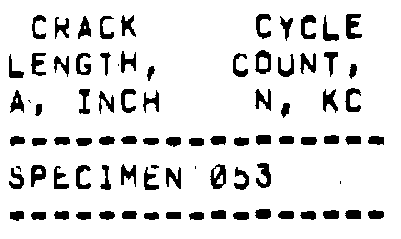

\begin{tabular}{|c|c|}
\hline $\begin{array}{l}.937 \\
.970 \\
.919 \\
.057 \\
.998 \\
.113 \\
.149 \\
.216 \\
.270 \\
.301 \\
.487 \\
.540 \\
.570 \\
.595 \\
.657 \\
.677 \\
.751 \\
.772 \\
.818 \\
.803 \\
.893\end{array}$ & $\begin{array}{l}415.00 \\
505.06 \\
600.00 \\
709.00 \\
800.06 \\
959.00 \\
1059.06 \\
1169.00 \\
1210.00 \\
1262.06 \\
1285.06 \\
1295.06 \\
1309.06 \\
1305.06 \\
1310.06 \\
1315.96 \\
1329.06 \\
1323.06 \\
1325.06 \\
1326.56 \\
1326.56\end{array}$ \\
\hline
\end{tabular}




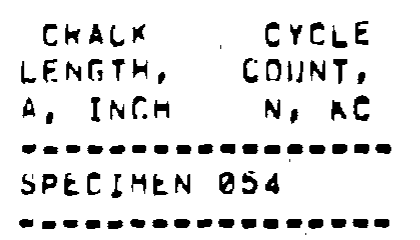

$.904 \quad 175.00$

.951 . 300.01

.961 440.06

$1.011 \quad 537.00$

$1.039 \quad 618.00$

$1.071 \quad 700.80$

$1.125 \quad 325.00$

1.17 s 939.00

$1.263 \quad 1075.00$

$1.321 \quad 1155.00$

$1.305 \quad 1205.40$

$1.451 \quad 1260.00$

$1.564 \quad 1309.00$

$1.587 \quad 1339.66$

$1.629 \quad 1349.00$

$1.654 \quad 1359.04$

$1.701 \quad 1360.96$

$1.730 \quad 1365.90$

1.7012370 .00

1.847 1375.0n

$1.872 \quad 1360.04$

$1.936 \quad 1362.96$

2. 9v0 1382.48

?. 1108

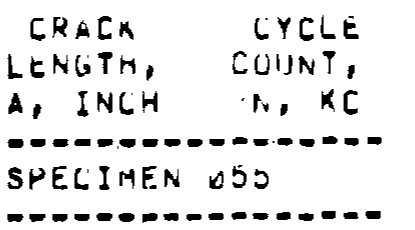

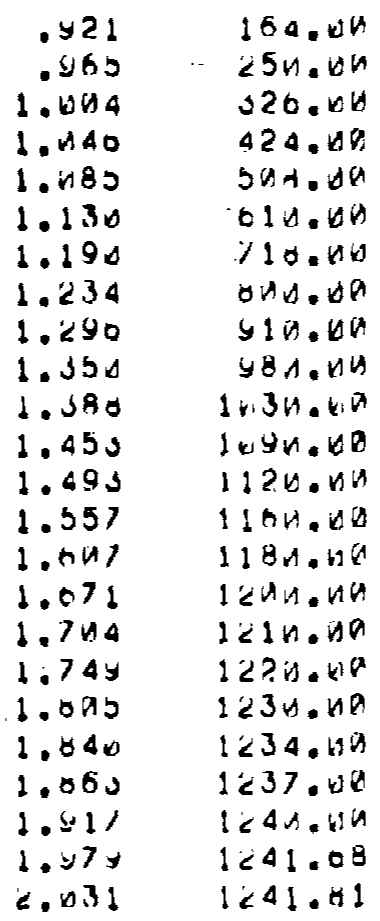

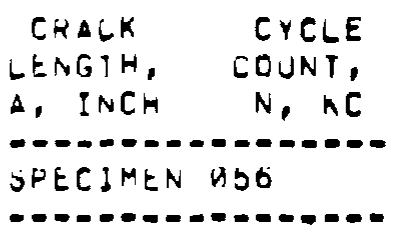

\begin{tabular}{|c|c|}
\hline $\begin{array}{l}.914 \\
.904 \\
.967 \\
.846 \\
.948 \\
.135 \\
.108 \\
.237 \\
.293 \\
.351 \\
.469 \\
.419 \\
.514 \\
.541 \\
.511 \\
.649 \\
.657 \\
.715 \\
.7014 \\
.819 \\
.864 \\
.921 \\
.042\end{array}$ & 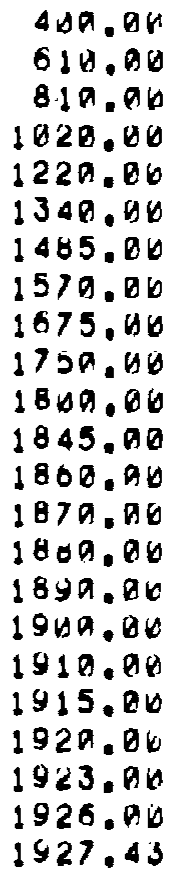 \\
\hline
\end{tabular}




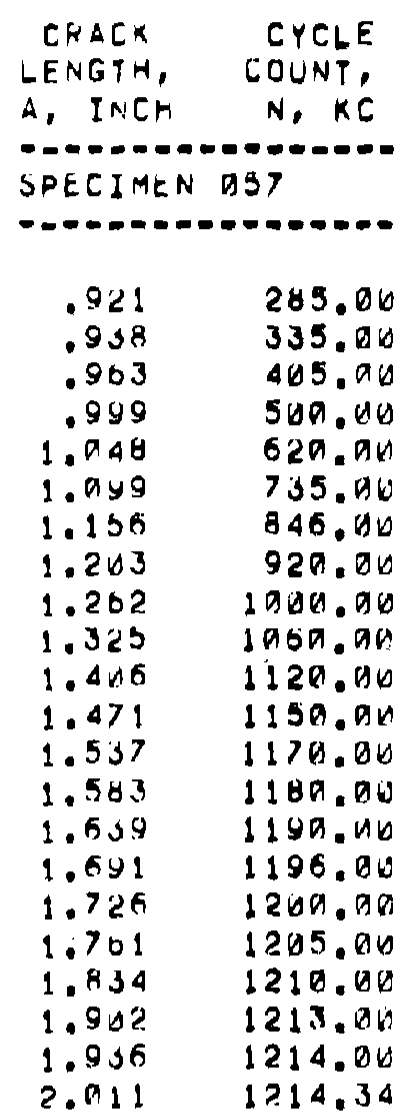

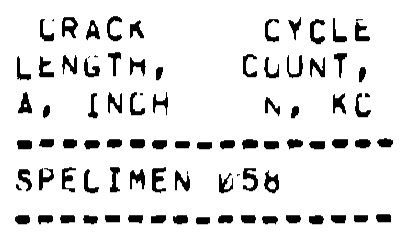

. 9la sua.or $.93 y$ oas.mo .994

1.114

1.179

1.195

1.23n

1.241

1.280

1.317

$1.36 n$

1.420

1.453

1.493

1.572

1.016

790.69

B16.0A

850.09

860.60

Q7 7 . B i

os 8.04

890.09

yub.ua

yI 1.00

920.00

925.018

G 36.0 (1)

934.41

$934.7 n$
CRACK

LENGTH,

: INCH

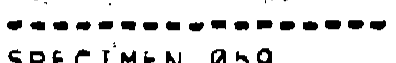

SPECIMEN ODg

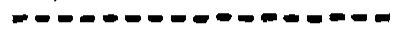

.924

.972

4บด.ดด

500.00

665.26

861.70

1. 989

1.142

1.191

1.243

1.289

1.346

1.341

1.445

1.507

1.569

1.594

1.639

1.689

$1.7 / 0$

1. 797

1.847

1. 898

$1.94 n$

1.991

2. 946
1004.90

1265.40 1966.00 2246.80 2413.06 2527.10 $2619.8 \mathrm{~b}$ 2692.76 2753.94 2778.30 2809.20 2833.86 2863.50 2879.16 2877.64 2882.76 2885.16 2885.86 2486.36 


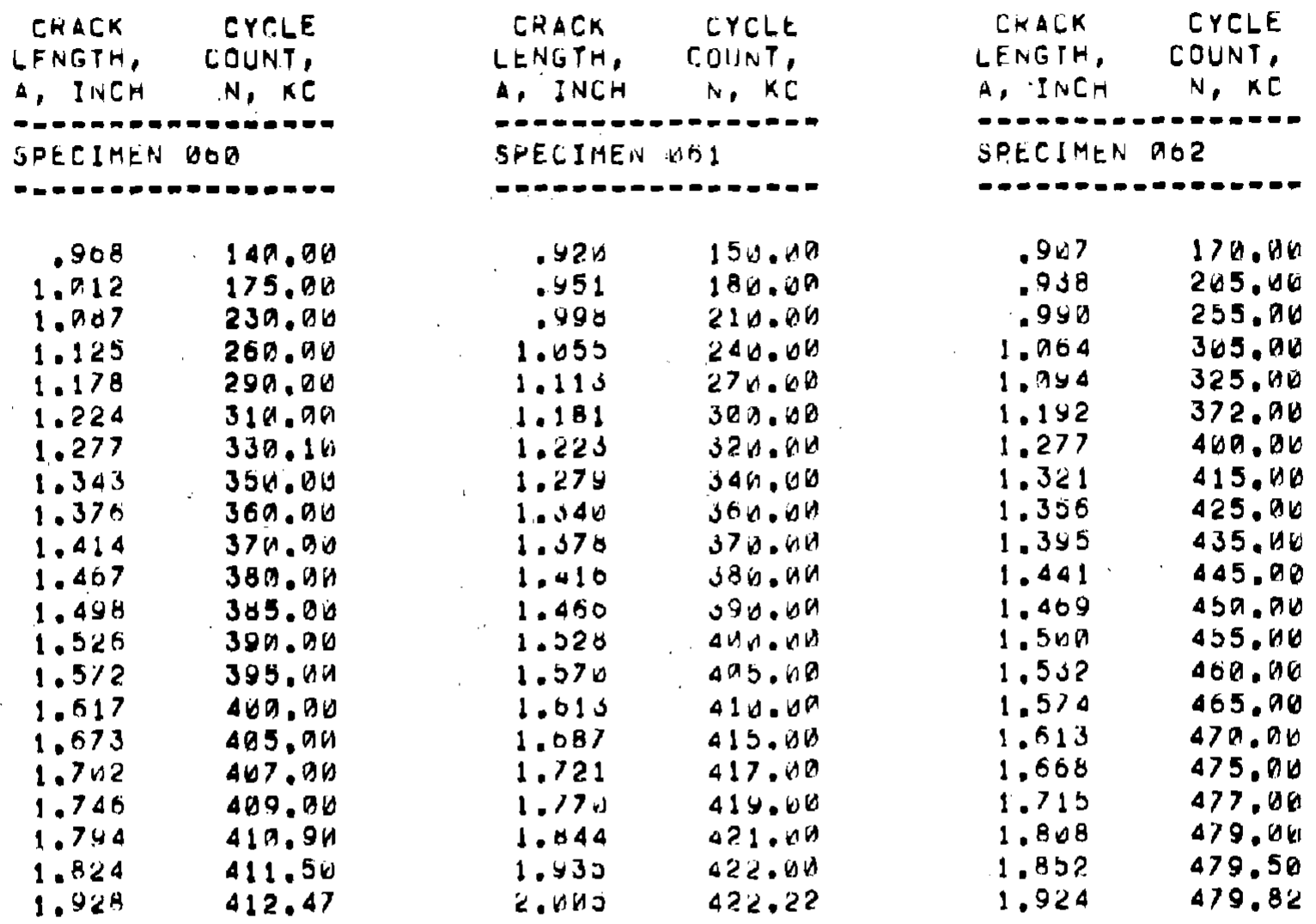




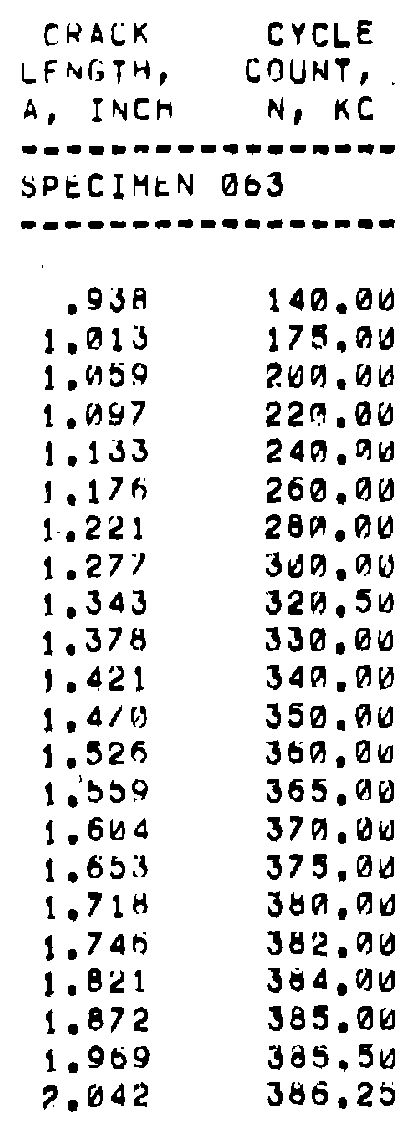

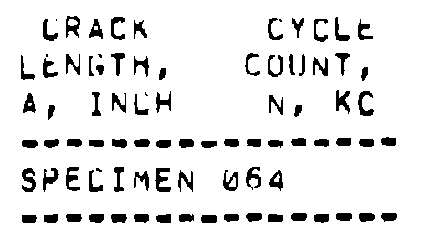

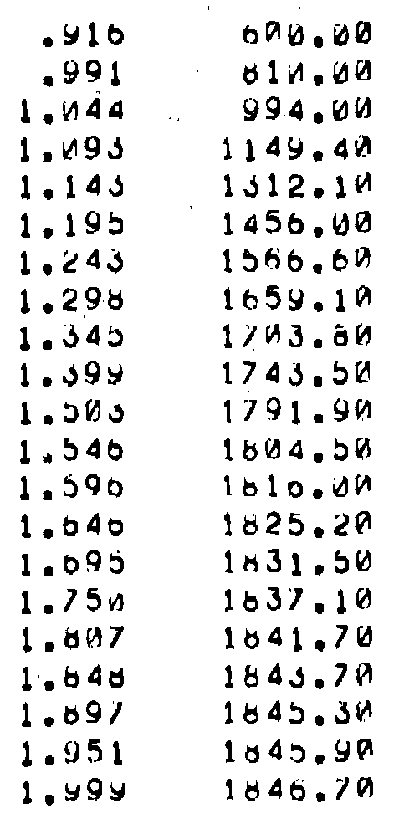

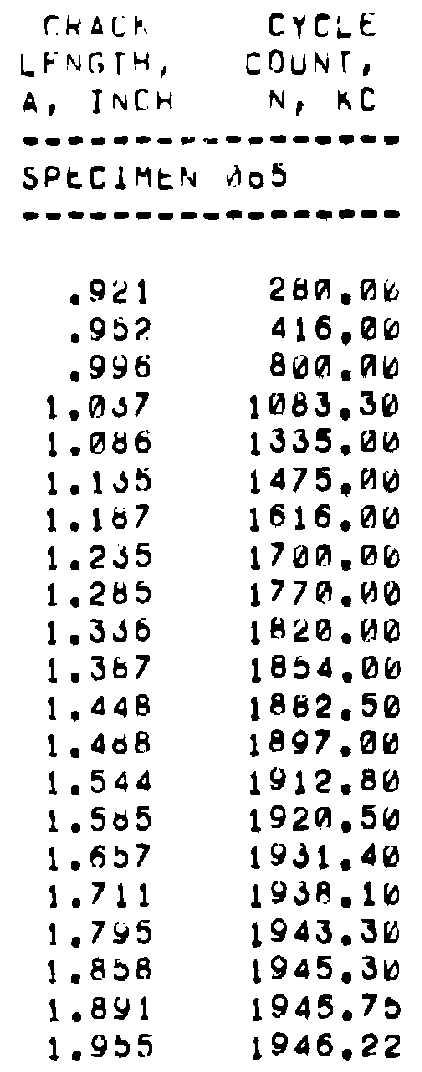




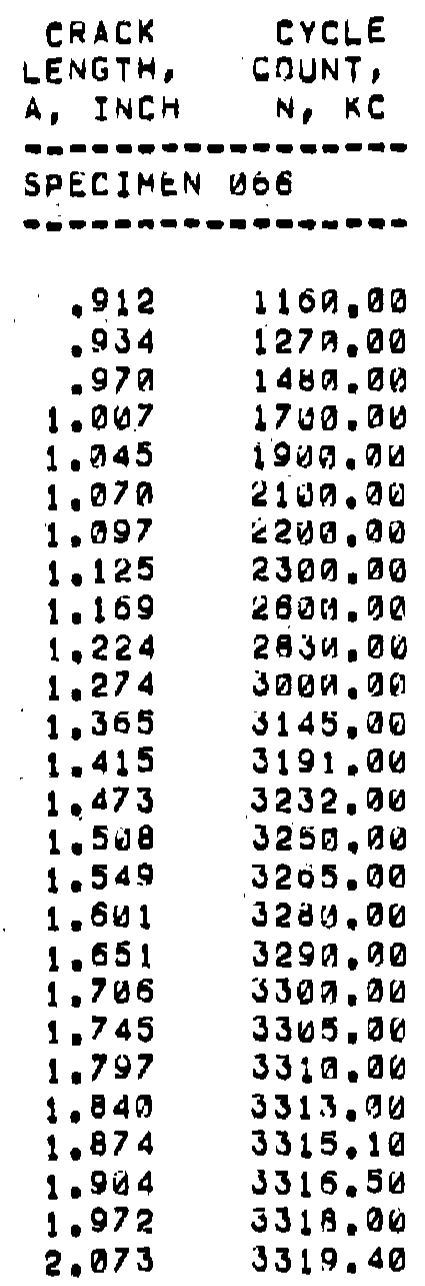


APPENDIX B

\section{REPORT OF INVENTIONS}

After a diligent review of the work performed to generate the aforementioned information, it is believed that no patentable innovation, or invention was made.

However, this report does contain data on static strength and fatigue-crack-propagation properties of rail steels presently in use in the United States - data which is not widely available. Therefore, it is considered that the data base generated here, although still limited, is a unique compilation of importance for the improvement of safety and performance of railroads in the USA.

220 copies

$\mathrm{B}-1 / \mathrm{B}-2$ 
• 